\title{
Asian Pacific association for the study of liver (APASL) guidelines: hepatitis B virus in pregnancy
}

\author{
Manoj Kumar ${ }^{1}$ ( $\cdot$ Zaigham Abbas $^{2} \cdot$ Milad Azami $^{3} \cdot$ Maria Belopolskaya $^{4} \cdot$ A. K. Dokmeci ${ }^{5} \cdot$ Hasmik Ghazinyan $^{6}$. \\ Jidong Jia ${ }^{7}$. Ankur Jindal ${ }^{1} \cdot$ Han Chu Lee ${ }^{8} \cdot$ Wei Lei $^{9} \cdot$ Seng Gee Lim ${ }^{10}$. Chun-Jen Liu ${ }^{11} \cdot$ Qiang Li $^{12}$. \\ Mamun Al Mahtab ${ }^{13}$. David H. Muljono ${ }^{14}$. Madunil Anuk Niriella ${ }^{15}$. Masao Omata ${ }^{16,17}$. Diana A. Payawal ${ }^{18}$. \\ Shiv K. Sarin ${ }^{1}$. Olivier Ségéral ${ }^{19}$. Tawesak Tanwandee ${ }^{20}$. Nirupma Trehanpati ${ }^{21} \cdot$ Kumar Visvanathan $^{22}$. \\ Jin Mo Yang ${ }^{23} \cdot$ Man-Fung Yuen ${ }^{24} \cdot$ Yingjie Zheng ${ }^{25} \cdot$ Y. H. Zhou ${ }^{26}$
}

Received: 11 August 2021 / Accepted: 6 December 2021 / Published online: 3 February 2022

(c) Asian Pacific Association for the Study of the Liver 2022

\begin{abstract}
Hepatitis B virus (HBV) infection still remains a major public health issue in the Asia-Pacific region. Most of the burden of HBV-related disease results from infections acquired in infancy through perinatal or early childhood exposure to HBV in Asia-Pacific. Hepatitis B during pregnancy presents unique management issues for both the mother and fetus. These APASL guidelines provide a comprehensive review and recommendations based on available evidence in the literature, for the management of females with HBV infection through every stage of pregnancy and postpartum. These also address the concerns, management challenges, and required follow-up of children born to hepatitis B-positive mothers.
\end{abstract}

Keywords Hepatitis B · Acute Hepatitis B · Chronic Hepatitis B · Pregnancy

\section{Introduction}

Despite the availability of effective preventive measures including vaccination, hepatitis B virus (HBV) infection is still today a major public health issue worldwide, especially in the Asia-Pacific region. Chronic HBV infection may progress to hepatic decompensation, hepatocellular carcinoma, and cirrhosis.

Hepatitis B during pregnancy presents unique management issues for both the mother and the fetus.

Mother-to-child transmission (MTCT) is responsible for a majority of prevalent cases of chronic HBV infection in the Asia-Pacific region. Because HBV infection in infancy or early childhood often leads to chronic infection, it is important to take appropriate measures to prevent MTCT.

These guidelines are intended to be used by health-care providers, and suggest the preferred approaches to the management of females with HBV infection throughout the

Manoj Kumar

manojkumardm@gmail.com; mksharma@ilbs.in

Shiv K. Sarin

shivsarin@gmail.com; sksarin@ilbs.in

Extended author information available on the last page of the article pregnancy and the postpartum period, and of children born to infected mothers. This document provides general guidelines only and will be applicable to the management of most of the patients, but should not replace clinical judgment for unique patients. In addition, despite increasing knowledge and research, some areas of uncertainty still exist and, therefore, appropriate choices should be made based on the evolving evidence, and the current literature as it evolves.

The experts from the members of the APASL guidelines' development sub-committee were given specific areas for reviewing and writing consensus statements according to the level of evidence and strength of recommendation as per the current literature (Table 1) [1]. Then, the manuscript was circulated to all the members of the group for suggestions and endorsement.

\section{Epidemiology of hepatitis B virus infection in pregnant females in Asia-Pacific}

\section{Review of literature}

The burden of HBV infection in the general population including pregnant females is particularly high in 
the Asia-Pacific region, although it varies widely among countries. The common routes of transmission of HBV are perinatal transmission; and horizontal transmission (during childhood through close contacts, unsafe injection practices, and transfusion of blood products) [2].

In the Asia-Pacific, most of the burden of HBV-related diseases results from infections acquired in infancy through perinatal or early childhood exposure to HBV. Infection acquired at an early age commonly becomes chronic: the rates of development of chronicity for infants infected in the first year of life, for children infected between 1 and 5 years of age, and peoples infected as adults are $80-90 \%, 30-50 \%$, and $<5 \%$, respectively [3].

The World Health Organization (WHO) Global Health Sector Strategy on Viral Hepatitis 2016-2021 had defined targets for elimination of viral hepatitis as a major global public health threat by 2030 [4]. All WHO regions are working toward the 2030 global hepatitis B elimination target of a $90 \%$ reduction in new cases of chronic HBV infection (equivalent to $<0.1 \% \mathrm{HBsAg}$ prevalence among children aged 5 years). Other global targets for 2030 include $90 \%$ coverage of hepatitis B vaccine birth dose (within $24 \mathrm{~h}$ ) (HepB birth dose vaccination) and other interventions to prevent MTCT of HBV, and 90\% coverage of all doses of HBV vaccine (HepB3) [4].

For the purpose of reviewing the epidemiology in the Asia-Pacific region, the countries of the region were grouped as follows (according to geography): North Asia (Russia); Central Asia (Afghanistan, Kazakhstan, Kyrgyzstan, Tajikistan, Turkmenistan, and Uzbekistan); Western Asia (Armenia, Azerbaijan, Bahrain, Cyprus, Georgia, Iran, Iraq, Israel, Palestine, Jordan, Kuwait, Lebanon, Oman, Qatar, Saudi Arabia, Syria, Turkey, United Arab Emirates, Yemen);East Asia (China Mainland, Mongolia, North Korea, South Korea, Japan, Taiwan); Southeast Asia (Brunei Darussalam, Cambodia, Indonesia, Lao PDR, Malaysia, Myanmar, Philippines, Singapore, Thailand, Timor-Leste, Vietnam); South Asia (Bangladesh, Bhutan, India, Maldives, Nepal, Pakistan, Sri Lanka); and Pacific Countries (Australia, New Zealand, and Pacific Island Countries and Territories). Pacific Island Countries and Territories include Samoa, Bougainville, Cook Islands, Federated States of Micronesia, Fiji, French Polynesia, Guam, Kiribati, Nauru, New Caledonia, Papua New Guinea, Samoa, Solomon Islands, Tokelau Islands, Tonga, Tuvalu, Vanuatu, and Wallis and Futuna Islands.

\section{North Asia (Russia)}

In Russia, all pregnant females are tested for HBsAg in the first and in the third trimesters of pregnancy. Nevertheless, the data on the prevalence of chronic HBV infection in this population group are accessible only in some regions, since there is no general registration of this data. The modeled HBsAg national and children under-5-year-old prevalence in 2019 were estimated to be $0.6 \%$ (95\% CI $0.54-0.67 \%$ ) and $0.03 \%$ (0.03-0.04\%), respectively [5] (Table 2). In 2019, Russia achieved HepB3 coverage of 97\% [6] (Table 2).

The available studies show that the prevalence of chronic HBV infection in pregnant females varies significantly depending on the region of Russia and the year the study was conducted. For example, HBsAg prevalence among pregnant female in Russia was reported as $0.7 \%$ in 2014 and $0.5 \%$ in 2015 [7]. Note that these data include all forms of hepatitis B, i.e., acute hepatitis B, as well as chronic HBV infection. The HBsAg detection rate in pregnant females also varies significantly across regions of Russia. In northern and central regions, the prevalence of HBsAg in pregnant females varies between 0.3 and $0.5 \%$, while in south-eastern and eastern parts of the country, it reaches $1.4-1.5 \%$ [8-10].

\section{Central Asia (Afghanistan, Kazakhstan, Kyrgyzstan, Tajikistan, Turkmenistan, and Uzbekistan)}

There are little data on HBV infection in pregnant females from Central Asian countries. The modeled HBsAg national and children under-5-year-old prevalence in 2019 were estimated to be $5.9 \%$ (95\% CI $4.63-7.17 \%$ ) and $1.66 \%$ (1.16-2.2\%) in Afghanistan, 2.26\% (1.85-2.57\%) and 0.22\% $(0.17-0.28 \%)$ in Kazakhstan, $2.55 \%$ (2.13-2.99\%) and 0.64\% $(0.50-0.81 \%)$ in Kyrgyzstan, $2.52 \%(2.11-2.89 \%)$ and $0.29 \%$ $(0.22-0.37 \%)$ in Tajikistan, $2.65 \%(2.23-3.02 \%)$ and $0.38 \%$ $(0.28-0.46 \%)$ in Turkmenistan, and $4.34 \%$ (3.85-4.9\%) and $0.42 \%(0.29-0.52 \%)$ in Uzbekistan, respectively [5]. In 2019, HepB3/HepB-birth dose coverage was $66 \% / 37 \%$ in Afghanistan, 97\%/93\% in Kazakhstan, 95\%/ 96\% in Kyrgyzstan, 97\%/99\% in Tajikistan, 99\%/99\% in Turkmenistan, and $96 \% / 99 \%$ in Uzbekistan, respectively [6].

While a low HBsAg prevalence in pregnant females has been reported from Afghanistan (1.14\% in 2010) [11] and Kazakhstan (1.2\% in 2016) [12], a much higher prevalence of $10.1 \%$ (in 2015) is reported from Tajikistan (however, the reliability of these data is questionable due to a small size of the considered group) [13]. There are no data regarding HBsAg positivity among pregnant females in Uzbekistan, Kyrgyzstan, and Turkmenistan.

\section{Western Asia (Armenia, Azerbaijan, Bahrain, Cyprus, Georgia, Iran, Iraq, Israel, Jordan, Kuwait, Lebanon, Oman, Qatar, Saudi Arabia, Syria, Turkey, United Arab Emirates, and Yemen)}

There are little data on HBV infection in pregnant females from Western Asian countries. The modeled HBsAg national and children under-5-year-old prevalence in 2019 were estimated to be $2.09 \%$ (95\% CI $1.72-2.37 \%$ ) and 
Table 1 Evidence grade used for the APASL Guidelines on Hepatitis B in pregnancy ( adapted from the GRADE system [1]

\begin{tabular}{|c|c|c|}
\hline Grading of evidence & Notes & Symbol \\
\hline High quality & $\begin{array}{l}\text { Further research is very unlikely to change our confidence in the estimate } \\
\text { Effect }\end{array}$ & A \\
\hline Moderate quality & $\begin{array}{l}\text { Further research is likely to have an important impact on our confidence in the } \\
\text { estimate of effect and may change the estimate effect }\end{array}$ & $\mathrm{B}$ \\
\hline Low or very low quality & $\begin{array}{l}\text { Further research is very likely to have an important impact on our confidence in the esti- } \\
\text { mate of effect and may change the estimate effect. Any estimate of effect is uncertain }\end{array}$ & $\mathrm{C}$ \\
\hline Grading of recommendations & Notes & Symbol \\
\hline Strong recommendation warranted & $\begin{array}{l}\text { Factors influencing the strength of the recommendation included the quality of the evi- } \\
\text { dence, presumed patient-important outcomes, and cost }\end{array}$ & 1 \\
\hline Weaker recommendation & $\begin{array}{l}\text { Variability in preferences and values, or more uncertainty: more likely a weak recom- } \\
\text { mendation is warranted. Recommendation is made with less certainty; higher cost or } \\
\text { resource consumption }\end{array}$ & 2 \\
\hline
\end{tabular}

$0.16 \%(0.11-0.21 \%)$ in Armenia, 3.22\% (2.79-3.63\%) and $0.56 \%(0.41-0.72 \%)$ in Azerbaijan, 2.64\% (2.25-3.03\%) and $0.12 \%(0.09-0.16 \%)$ in Bahrain, $0.7 \%(0.67-0.72 \%)$ and $0.02 \%(0.01-0.02 \%)$ in Cyprus, $1.48 \%(1.46-1.5 \%)$ and $0.24 \%(0.21-0.28 \%)$ in Georgia, $1.53 \%(1.34-1.71 \%)$ and $0.09 \%(0.07-0.11 \%)$ in Iran, $1.98 \%(1.62-2.31 \%)$ and $0.43 \%(0.31-0.56 \%)$ in Iraq, $0.53 \%(0.43-0.62 \%)$ and $0.04 \%(0.02-0.05 \%)$ in Israel, $3.37 \%(3.26-3.48 \%)$ and $0.53 \%(0.50-0.56 \%)$ in Jordan, $1.17 \%(0.97-1.41 \%)$ and $0.07 \%(0.05-0.09 \%)$ in Kuwait, $2.82 \%(2.43-3.24 \%)$ and $0.58 \%(0.43-0.76 \%)$ in Lebanon, $2.5 \%(2.11-2.9 \%)$ and $0.09 \%(0.07-0.11 \%)$ in Oman, $1.4 \%(1.25-1.55 \%)$ and $0.10 \%(0.07-0.13 \%)$ in Qatar, $2.72 \%(2.31-3.14 \%)$ and $0.15 \%(0.12-0.19 \%)$ in Saudi Arabia, 3.08\% (2.99-3.17\%) and $0.82 \%(0.67-0.96 \%)$ in Syria, $2.43 \%(2.31-2.56 \%)$ and $0.17 \%(0.14-0.20 \%)$ in Turkey, $1.82 \%(1.51-2.11 \%)$ and $0.12 \%(0.09-0.17 \%)$ in United Arab Emirates, and $5.46 \%$ (4.93-6.0\%) and $1.63 \%$ (1.28-2.01\%) in Yemen respectively [5].

In 2019, HepB3/HepB-birth dose coverage was 92\%/96\% in Armenia, 94\%/98\% in Azerbaijan, 99\%/98\% in Bahrain, 94\%/94\% in Georgia, 99\%/95\% in Iran, $84 \% / 41 \%$ in Iraq, $96 \% / 95 \%$ in Israel, $91 \% / 93 \%$ in Kuwait, $80 \% / 80 \%$ in Lebanon, 99\%/99\% in Oman, 98\%/ 97\% in Qatar, 97\%/96\% in Saudi Arabia, 99\%/99\% in Turkey, and 98\%/91\% in United Arab Emirates, respectively [6]. The HepB3 coverage in 2019 was $94 \%$ in Cyprus, $89 \%$ in Jordan, 54\% in Syria, and $73 \%$ in Yemen, respectively [6].

An old report found HBsAg prevalence of $0.2 \%$ in 1998 and $0.5 \%$ in 1999, in pregnant females in Armenia [14]. In Armenia, coverage of infant vaccination and three doses of Hepatitis B universal vaccination is increasing gradually. As a result, incidence of Hepatitis B has been dramatically decreased among the children under 14 years old since introduction year in 1999 [15].
In Azerbaijan, 1.5\% HBsAg positivity was found in 2010 in pregnant females [16].

In Iran, HBsAg prevalence in pregnant females range from $1.3 \%$ in 2014 to $0.18 \%$ in 2016 [16-26] (Table 2). In a recent meta-analysis published in 2018 , the pooled prevalence of $\mathrm{HBsAg}$ among pregnant females was $1.35 \%(95 \%$ CI $1.22-1.48 \%$ ) in Iran [27].

In Iraq, a case-control study done in Baghdad on 40 pregnant females visiting private-sector hospital in 2010-2011 showed HBsAg to be 5\% [28]. However, another study done in primary health centers on 6975 pregnant females in 2016-2017 found HBsAg prevalence to be $0.13 \%$ [29].

Reported HBsAg prevalence in pregnant females in Israel, in a review in 1999, was ranging from 0.6 to $4 \%$ with rates varying among ethnic groups [30]. In a study published in 2010, on 186619 deliveries from 1988 to 2007, at a University medical center, found $\mathrm{HBs}$ Ag prevalence of $0.3 \%$ [31]. Another study on all singleton deliveries between the years 1991-2014 at a University Medical Center in Israel found $0.2 \% \mathrm{HBsAg}$ prevalence in pregnant females [32].

Reported prevalence among pregnant females in Jordan ranges from 4.3 in 2002 to $5 \%$ in 2020 [33, 34].

A study done in 2012-2013 in 4062 pregnant females in the Hawalli Province in Kuwait found $0.3 \% \mathrm{HBsAg}$ positivity [35].

In 2006, the prevalence of HBsAg among pregnant was 7.1\% in Oman, 1\% Qatar [36].

In Saudi Arabia, HBsAg prevalence in pregnant females ranged from $2.44 \%$ in 2005 to $4.1 \%$ in 2012 [37-39]. In a recent meta-analysis in 2018 , the pooled prevalence of HBsAg in Saudi Arabia was 2.63\% (95\% CI 2.17-3.18\%) [27].

In a recent study in Turkey on 11,015 refugee Syrian pregnant patients, HBsAg prevalence was found to be $1.1 \%$ between 2012 and 2018 [40]. 


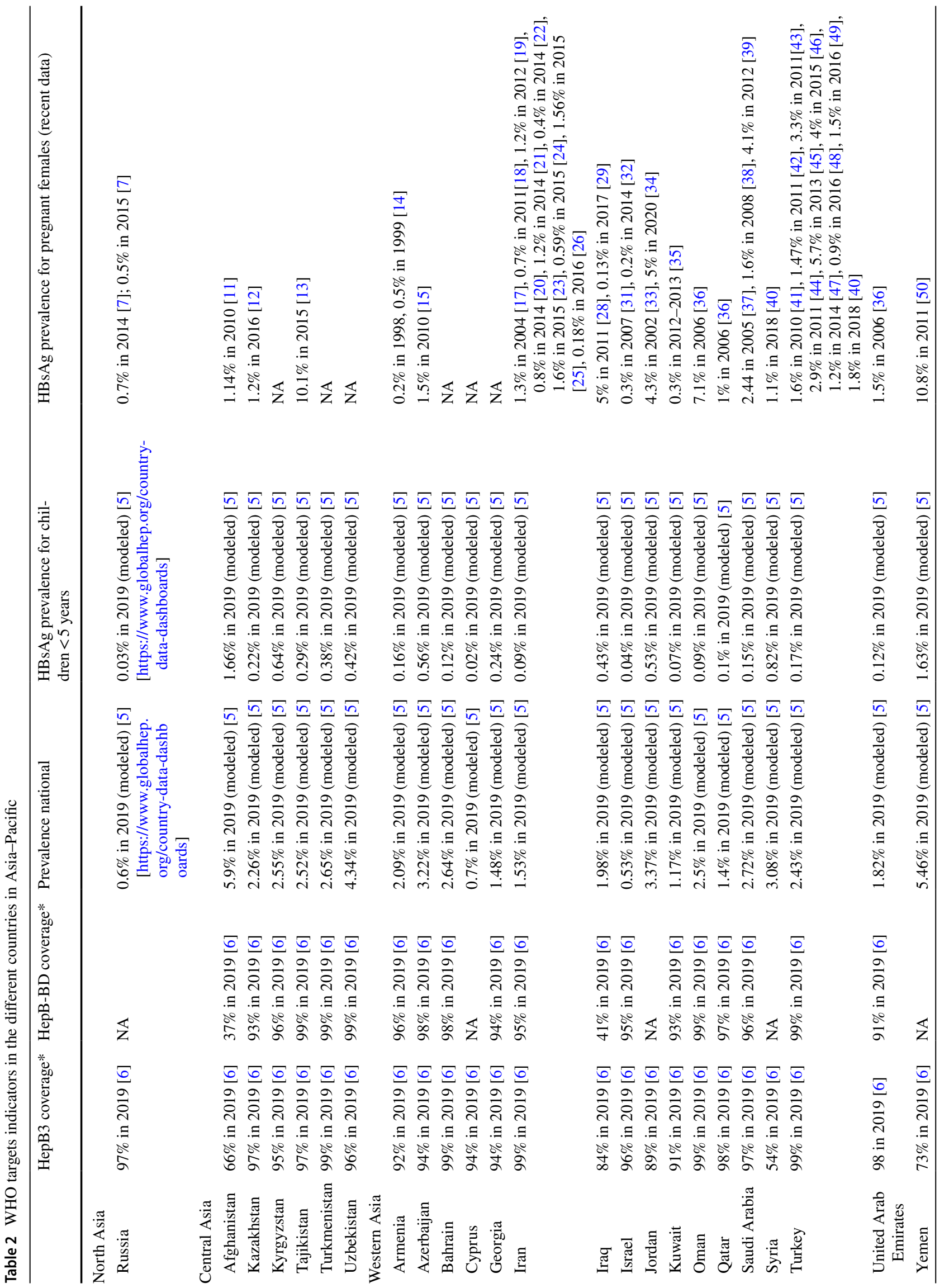




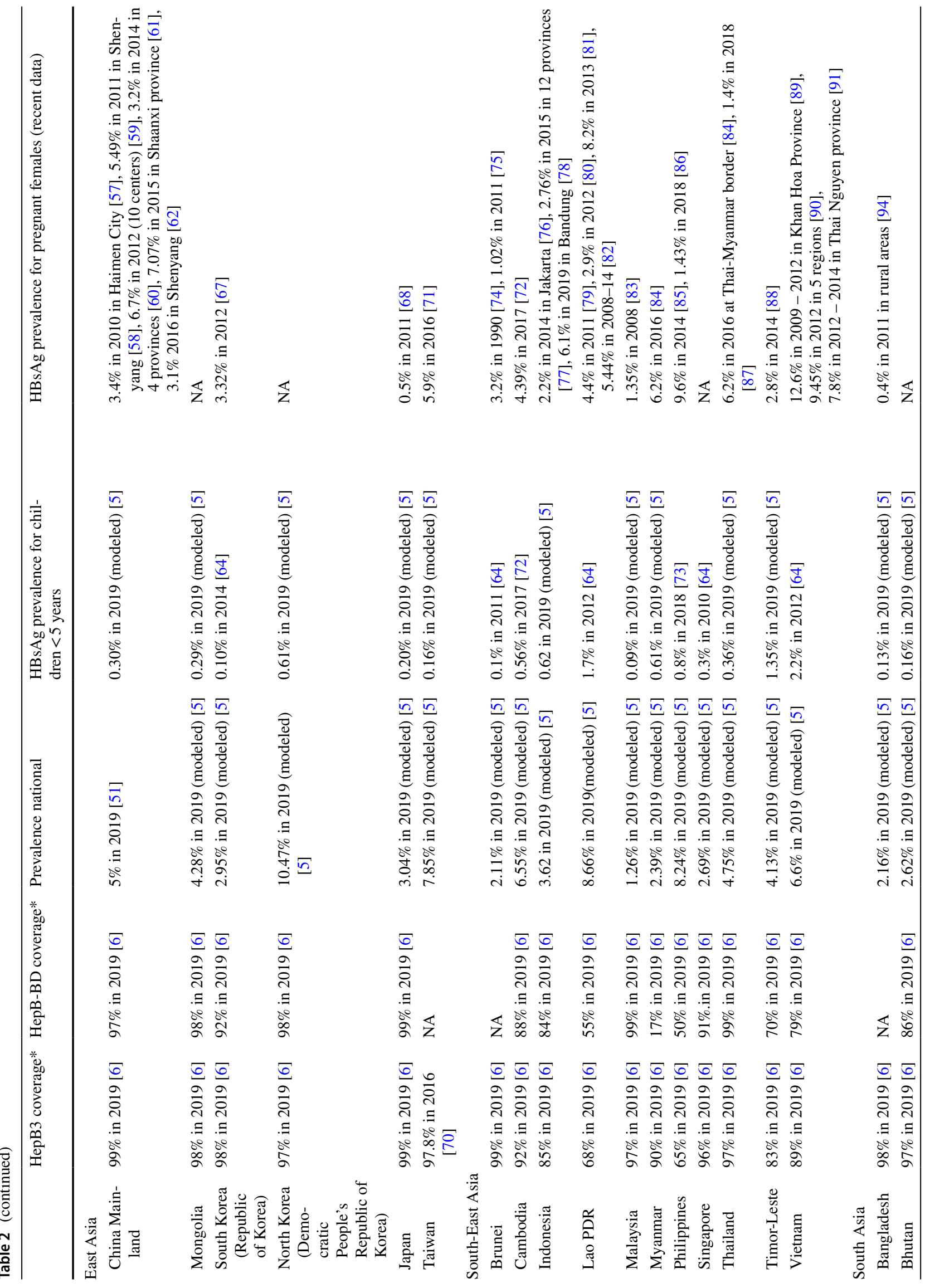




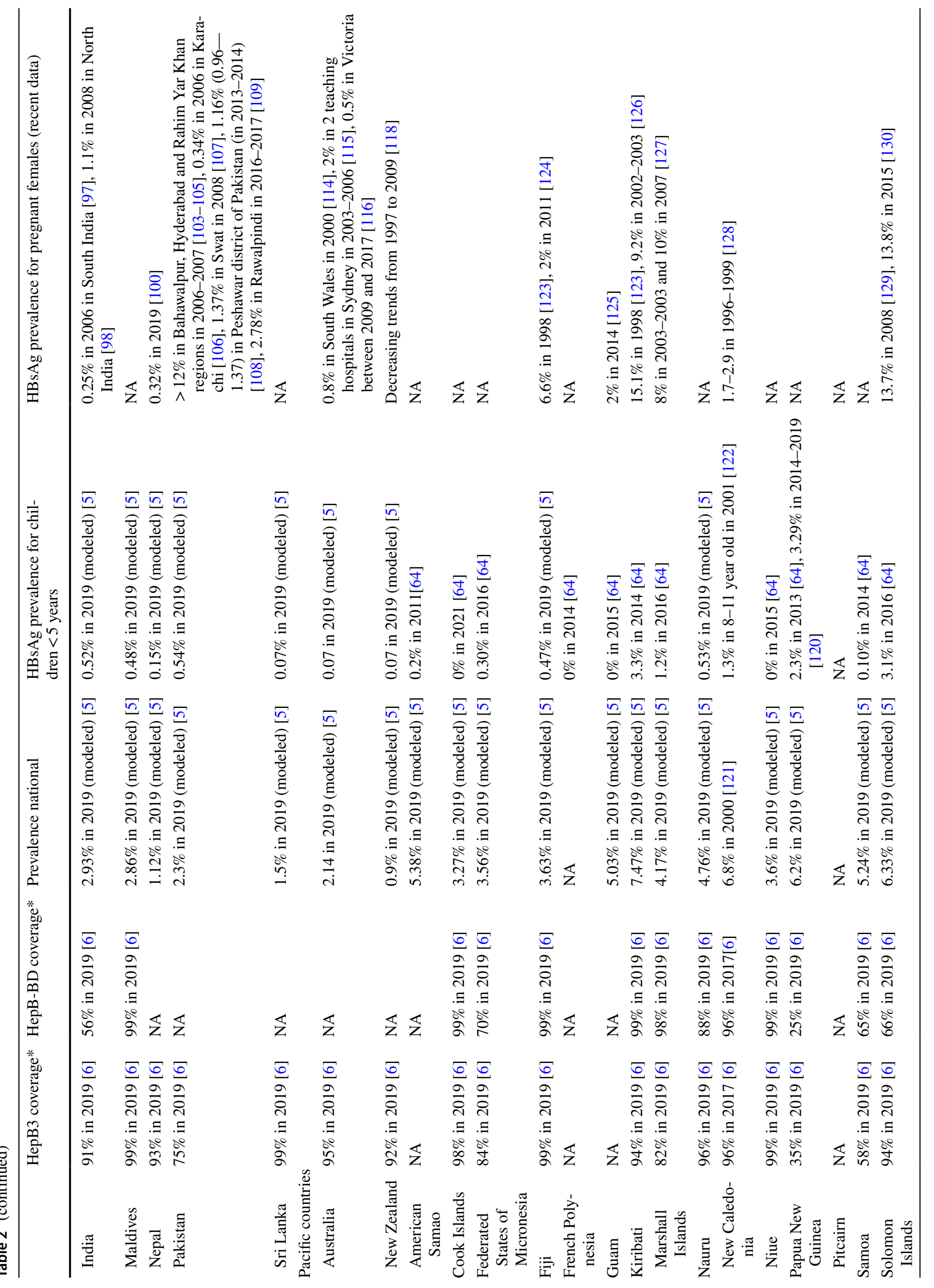


In Turkey, HBsAg prevalence in pregnant females ranges from $1.6 \%$ in 2010 to $1.8 \%$ in 2018 [40-49] (Table 2). In a recent meta-analysis in 2018 , the pooled prevalence of HBsAg in Turkey was 2.84\% (95\% CI 2.68-3.01\%) [27].

In 2011, the prevalence of HBsAg among pregnant in Yemen was 10.8\% [50].

\section{East Asia (China Mainland, Mongolia, North Korea, South Korea, Japan, and Taiwan)}

The HBsAg national prevalence and children under 5-yearold prevalence were estimated to be $5 \%$ (in 2018) [51], and $0.30 \%(0.20-0.50 \%)$ (in 2019) in China Mainland, respectively [5]. In 2019, China Mainland achieved HepB3 coverage of $99 \%$, and HepB-birth dose coverage of $97 \%$ [6]. In China Mainland, the prevalence of HBsAg in child-bearingaged females has been extensively investigated in several large cross-sectional studies including several millions of females as part of the Triple Elimination of MTCT of HIV, HBV, and Syphilis [51]. Currently, in this age group (20-49 years old), the overall prevalence of HBsAg is around 5.5\% (4.9-11.8\%) [52-56].

Specifically, the HBsAg prevalence in pregnant females (mostly aged 26-28 years, varying from 16 to 47 years) has also been widely reported as 4.5\%(3.0-7.0\%), with around $37 \%$ (26-67\%) of them being also positive for $\mathrm{HBeAg}$ [57-62].

The modeled HBsAg national and children under 5-yearold prevalence in 2019 were estimated to be $4.28 \%$ (95\% CI $3.88-4.7 \%)$ and $0.29 \%(0.20-0.36 \%)$ in Mongolia, respectively [5]. In 2019, Mongolia achieved HepB3 coverage of 98\%, and HepB-birth dose coverage of 98\% [6]. In Mongolia, the prevalence of $\mathrm{HBsAg}$ is $9.4 \%$ in child-bearing-aged females [63].

The modeled HBsAg national prevalence and children under 5-year-old prevalence were estimated to be $2.95 \%$ (95\% CI 2.81-3.1\%) in 2019 [5], and $0.10 \%$ in 2014 [64] in South Korea (Republic of Korea), respectively. In 2019, South Korea (Republic of Korea) achieved HepB3 coverage of $98 \%$, and HepB-birth dose coverage of $92 \%$ [6]. In South Korea (Republic of Korea), the prevalence of HBsAg in child-bearing-aged females ( $20-49$ years) is $1.7-3.7 \%$ in recent years $[65,66]$. In pregnant females, the HBsAg prevalence is $3.32 \%$ in 2012 [67].

The modeled HBsAg national and children under-5-yearold prevalence in 2019 were estimated to be $10.47 \%$ (95\% CI 9.11-12.29\%) and $0.61 \%(0.47-0.78 \%)$ in North Korea (Democratic People's Republic of Korea) [5]. In 2019, North Korea (Democratic People's Republic of Korea) achieved HepB3 coverage of 97\%, and HepB-birth dose coverage of 98\% [6]. There are no recent data on HBsAg prevalence in pregnant females in North Korea. 
In 2019, the modeled HBsAg national prevalence and children under 5-year-old prevalence were estimated to be $3.04 \%$ (95\% CI 2.67-3.37\%) [5] and $0.20 \%(0.0-0.40 \%)$ in Japan, respectively [64]. In Japan, mother-to-child transmission is the major route of establishing chronicity of $\mathrm{HBV}$, but it is less common than in other Asian countries. In 2019, Japan achieved HepB3 coverage of 99\%, and HepB-birth dose coverage of $99 \%$ [6]. From June, 1985, all pregnant females were screened for the presence of serum HBsAg, and from January, 1986, the Government started financing programs for prevention of vertical transmission of $\mathrm{HBV}$ infection. This program involves HBsAg testing of all pregnant female and inoculation of anti-HBsAg human immunoglobulin (HBIG) and HBV vaccines to all infants born to HBsAg-positive mothers, which has led to extremely low prevalence of HBsAg in general population as well as pregnant female in Japan. In a recent study on pregnant female who gave birth at all delivery hospitals/clinics in Hiroshima prefecture between April 2010 and March 2011, it was found that overall $\mathrm{HBsAg}$-positive rate was $0.51 \%(95 \% \mathrm{CI}$ $0.40-0.63 \%)$, and an extremely low prevalence $(0.10 \% ; 95 \%$ CI $0.00-0.25 \%$ ) was observed among pregnant female born after 1986. Perinatal HBV transmission is estimated to be almost completely inhibited in the next generation [68].

Taiwan is a success story of tackling hepatitis B virus infection. The modeled HBsAg national and children under5-year-old prevalence in 2019 were estimated to be $7.85 \%$ (95\% CI $7.5-9.19 \%)$ and $0.16 \%(0.13-0.18 \%)$ in Taiwan, respectively [5]. From epidemiology studies in Taiwan, the rate of HBsAg carriage was high in the general population (15-20\%) before 1970; and more than $70 \%$ of hepatocellular carcinoma (HCC) was associated with chronic HBV infection [69]. To tackle this serious health problem, the Taiwan government launched a mass vaccination program against hepatitis B in July 1984, and the program was very successful in the prevention of new HBV infection in the young generations [69]. Statistics from the Ministry of Health and Welfare, Taiwan, revealed that the 2016 newborn HBV vaccination rate was as high as $97.8 \%$ [70]. To investigate the evolution of HBV infection status in pregnant mothers, Su et al. conducted a 32-year cross-sectional study using the data from the National Immunization Information System in Taiwan [71]. Maternal HBsAg and HBeAg data was collected from a screening program. The authors then used an age-periodcohort model to analyze 940180 pregnant females collected in years 1996, 2001, 2006, 2011, and 2016, respectively. They found that the annual rate of HBsAg seropositivity decreased from 13.4\% during 1984-1985 (before the era of nationwide vaccination) to $5.9 \%$ in 2016 (3 decades after vaccination program). The annual rate of $\mathrm{HBeAg}$ seropositivity decreased from $6.4 \%$ during $1984-1985$ to $1.0 \%$ in 2016. Pregnant females born after July 1986 (the HBV vaccination cohort) had the lowest risk (relative risk $=0.27$ ) of $\mathrm{HBsAg}$ positivity compared with those born before June 1984. After controlling the birth cohort effect, the rate of HBsAg carriage in pregnant female has been significantly decreased through the universal infant HBV immunization program. These findings suggested that the majority of perinatal HBV infection on the next generation will be prevented in Taiwan [71]. To further lower the risk of vertical transmission, new strategies in combination with the vaccination program have already been implemented in the post-immunization era in Taiwan, including the administration of birth dose HBIG and HBV vaccine to all newborns of chronic $\mathrm{HBV}$-infected mothers and the administration of oral nucleos(t)ide analogue during the third trimester of pregnant females with high serum viral load.

\section{Southeast Asia (Brunei Darussalam, Cambodia, Indonesia, Lao PDR, Malaysia, Myanmar, Philippines, Singapore, Thailand, Timor-Leste, and Vietnam)}

The HBsAg national prevalence and children under-5-yearold prevalence were $2.11 \%$ (95\% CI 1.82-2.41\%) in 2019 (modeled) [5] and $0.10 \%$ in 2011[64] in Brunei Darussalam, $6.55 \%(5.5-7.56 \%)$ in 2019 (modeled) and $0.56 \%$ in 2017 [72] in Cambodia, 3.62\% (3.17-4.05\%) in 2019 (modeled) and $0.62 \%(0.49-0.76 \%)$ [5] in Indonesia, $8.66 \%$ (7.32-10\%) in 2019 (modeled) [5] and 1.7\% (0.8-2.6\%) in 2012 [64] in Lao PDR, 1.26\%(1.14-1.38\%) and $0.09 \%$ (0.07-0.12\%) in 2019 (modeled) [5] in Malaysia, $2.39 \%$ (1.99-2.71\%) and $0.61 \%(0.46-0.82 \%)$ in 2019 (modeled) [5] in Myanmar, 8.24\% (7.2-9.36\%) in 2019 (modeled) [5] and $0.70 \%$ in 2018 [73] in Philippines, $2.69 \%$ (2.52-2.86\%) in 2019 (modeled) [5] and $0.30 \%$ in 2010 [64] in Singapore, $4.75 \%(4.43-5.09 \%)$ and $0.36 \%(0.28-0.45 \%)$ in 2019 (modeled) [5] in Thailand, $4.13 \%$ (3.34-4.93\%) and $1.35 \%$ (1.01-1.80\%) in 2019 (modeled) [5] in Leste, and 6.6\% (6.3-6.92\%) in 2019 (modeled) [5] and 2.20\% (1.5-3.10\%) in 2011 [64] in Vietnam, respectively (Table 2).

In 2019, HepB3/HepB-birth dose coverage was 92\%/88\% in Cambodia, 85\%/84\% in Indonesia, 68\%/55\% in Lao PDR, 97\%/99\% in Malaysia, 90\%/17\% in Myanmar, 65\%/50\% in Philippines, 96\%/91\% in Singapore, $97 \% / 99 \%$ in Thailand, $83 \% / 70 \%$ in Timor-Leste, and $89 \% / 79 \%$ Vietnam, respectively [6]. In 2019, HepB3 coverage was 99\% in Brunei Darussalam [6].

As reported in Table 2, HBsAg prevalence among pregnant females is $>2 \%$ for all the countries in Southeast Asia (intermediate level) with data available and $>7-8 \%$ for some of them (high level). However, many of these data were reported 10 years ago and recent national seroprevalence surveys are missing.

One old study in 1990 found 3.2\% HBsAg positivity in pregnant females of Brunei Darussalam [74]. Another study done in a tertiary care hospital (in 2011) in Brunei found 
HBsAg positivity to be $1.02 \%$, significantly higher among the Chinese $(2.4 \%)$, indigenous $(4.0 \%)$, and expatriates (1.5\%) than among the Malays (0.8\%) [75].

One survey conducted among children (5-7 years old) born during 2010-2012 and their mothers in Cambodia found overall $\mathrm{HBsAg}$ positivity of $4.39 \%$ (95\% CI 3.53-5.45\%) among mothers and $0.56 \%$ (95\% CI $0.32-0.98 \%$ ) among children. HBsAg positivity was higher among children without hepatitis B vaccination $[4.62 \%$ (95\% CI 1.31-14.97\%)], and among children with an HBsAgpositive mother [10.11\% (95\%CI 5.41-18.11\%)]. Although hepatitis B vaccination birth dose (HepB-BD) was received by $78.4 \%$ of the children, only $54.4 \%$ received the birth dose timely [72].

In Indonesia, HBsAg prevalence of $2.2 \%$ was found among pregnant females in Jakarta (in 2014) [76]. HBsAg prevalence among 69,891 pregnant females across 12 provinces in Indonesia was $2.76 \%$ in 2015, with the lowest found in West Sumatra Province (1.6\%) and the highest in West Papua Province (8.0\%) [77]. A study conducted from July 2018 to April 2019 in 27 midwifery clinics and one private obstetric clinic in Bandung (Indonesia) found HBsAg positivity of $6.1 \%$ among the pregnant females [78].

In Loa PDR, in studies on children and mother pairs, HBsAg prevalence was found to be $4.4 \%$ (95\% CI $3.0-5.7 \%$ ) in 2011 [79] and $2.9 \%$ (95\% CI $1.7-4.2 \%$ ) in mothers in 2012 [80]. Another study has found HBsAg prevalence of $8.2 \%$ in 2013 [81]. In a recent retrospective study from Lao PDR, performed in a Hospital Laboratory on pregnant females from 2008 to 2014, showed overall HBsAg positivity of 5.44\% (95 CI 5.1-5.8\%), with the annual prevalence ranging from 4.6 to $6.2 \%$. A slight but steady and significant decrease in prevalence over the 7 years of the study could be documented [82].

In a cross-sectional study of antenatal mothers who attended government health clinics in Ipoh (Malaysia) between July 2008 and October 2008 found HBsAg prevalence of $1.35 \%$ [83].

Among females tested (2012-2016) in antenatal clinics on the Thai-Myanmar border (immigrants and refugees from Myanmar), overall confirmed HBsAg prevalence was $6.2 \%$ [84].

In a study among pregnant subjects attending prenatal clinic at the Philippine General Hospital from January to July 2014, HBsAg positivity was found to be $9.6 \%$ [85], whereas another study found $\mathrm{HBsAg}$ prevalence of $1.43 \%$ in pregnant females admitted to a tertiary hospital in Philippines (from 2014 to 2018) [86].

In a recent hospital-based study from Thailand, on pregnant females attending antenatal clinics (2015-2018), HBsAg prevalence was $1.4 \%$ [87].
In a study on females delivering at private clinic (2013-2014) in Timor-Leste HBsAg prevalence was 2.8\% [88].

In studies from Vietnam, HBsAg prevalence was $12.6 \%$ (95\% CI 11.1-14.0\%) in Khan Hoa Province, central Vietnam in 2009-2012 [89], 9.45\% in 2012 in 5 regions [90], and $7.8 \%$ in 2012-2014 in Thai Nguyen province [91].

In these countries with high-prevalence populations, infant vaccination against HBV is crucial. Most of the countries in South-East Asia have achieved $>90 \%$ HepB3 coverage (excepting a few countries like Indonesia, Lao PDR, Philippines, Timor-Leste, and Vietnam) and $>50 \%$ of HepB-birth dose coverage (except Myanmar) as recommended by WHO for 2020. Currently $>90 \%$ HepB-birth dose coverage has been achieved by some of the countries (Malaysia, Singapore, and Thailand) (Table 2). However, as reported in Table 2, HBsAg prevalence for children 5 years old remains $>1 \%$ in a few countries (Lao PDR, Timor-Leste, and Vietnam) (WHO 2020 target) and $>0.1 \%$ in most of the countries (WHO 2030 target).

\section{South Asia (Bangladesh, Bhutan, India, Maldives, Nepal, Pakistan, and Sri Lanka)}

In 2019, the modeled HBsAg national prevalence and children under-5-year-old prevalence were $2.16 \%(95 \%$ CI $1.97-2.35 \%)$ and $0.13 \%(0.10-0.16 \%)$ in Bangladesh, respectively [5]. In 2019, HepB3 dose coverage was $98 \%$ in Bangladesh [6]. In one old study (1992), HBsAg was positive in $3.6 \%$ in 500 pregnant mothers [92]. In another study on 1800 pregnant females who delivered from October 1995 to January 1996 at Dhaka Medical College Hospital, 63 of 1800 or $3.5 \%$ of the mothers were found to be HBsAg positive. Of the $63 \mathrm{HBsAg}$-positive mothers, 19 (30.2\%) were found to be HBeAg positive. Only two of the HBsAgpositive mothers had established acute infection [93]. More recent studies have found decreasing trend. In a study (2011), HBsAg was positive in $0.4 \%$ of pregnant females in rural Bangladesh. This study was done years after incorporating hepatitis B vaccination schedule in the Expanded Program on Immunization (EPI) to vaccinate the children in rural Bangladesh; the prevalence is gradually declining [94].

In 2019, the modeled HBsAg national prevalence and children under-5-year-old prevalence were $2.62 \%$ (95\% CI $2.53-2.73 \%)$ and $0.16 \%(0.13-0.17 \%)$ in Bhutan, respectively [5]. In 2019, HepB3/HepB-birth dose coverage was 97\%/86\% in Bhutan [6]. Data on HBsAg prevalence in pregnant females are lacking from Bhutan.

In 2019, the modeled HBsAg national prevalence and children under-5-year-old prevalence were $2.93 \%$ (95\% CI $2.57-3.29 \%)$ and $0.52 \%(0.42-0.63 \%)$ in India, respectively [5]. In 2019, HepB3/HepB-birth dose coverage was 91\%/56\% in India [6]. Many studies from the Indian subcontinent have 
looked specifically at the prevalence of HBsAg positivity in pregnant females. However, only very few studies were sufficiently large, with adequate number of females screened, to reach a meaningful conclusion. In one old study, $\mathrm{HBsAg}$ positivity in pregnant female was $3.7 \%$ in 1987[95] and $1 \%$ in 1999 in North India [96]. More recent studies have found lower HBsAg prevalence in pregnant females: $0.25 \%$ in 2006 in South India [97] and 1.1\% (2004-2008) in North India [98]. In 2019, the modeled HBsAg national prevalence and children under-5-year-old prevalence were $2.86 \%$ (95\% CI $2.37-3.39 \%)$ and $0.48 \%(0.34-0.64 \%)$ in Maldives, respectively [5]. In 2019, HepB3/HepB-birth dose coverage was 99\%/99\% in Maldives, respectively [6].

Nepal belongs to low endemic zone according to Hepatitis B surface antigen (HBsAg) seroprevalence, as the overall prevalence of hepatitis B in Nepal is estimated at $0.9 \%$ [99]. In 2019, the modeled HBsAg national prevalence and children under-5-year-old prevalence were $1.12 \%$ (95\% CI $1.02-1.23 \%)$ and $0.15 \%(0.11-0.18 \%)$ in Nepal, respectively [5]. In 2019, HepB3 coverage was $93 \%$ in Nepal [6]. In a nested prospective case study (2019), Shedain et al. found prevalence values of HBV $0.32 \%$ in 16,400 of pregnant females who attended a tertiary-level hospital over a period of 1 year. The infection was clustered in the indigenous ethnicities, nearly threefold higher infection compared to other than indigenous ethnicities. According to some authors, increased alcohol consuming pattern; seen in those indigenous communities, which can lead to increase the sexual risk behavior and unsafe sexual relationship that may be responsible for this high prevalence in those communities [100].

The overall prevalence of HBsAg was $2.5 \%$ in a prevalence survey carried out in 2010 to obtain national estimates on hepatitis B and C infections in Pakistan [101]. In 2019, the modeled HBsAg national prevalence and children under5-year-old prevalence were $2.3 \%$ (95\% CI 2.04-2.61\%) and $0.54 \%(0.43-0.68 \%)$ in Pakistan, respectively [5]. In 2019, HepB3 coverage was 75\% in Pakistan [6]. Most of the studies from Pakistan on the prevalence of hepatitis B in pregnancy are hospital-based. One meta-analysis (2011) of nine studies showed the HBV prevalence of $5.872 \% \pm 4.984 \%$ in pregnant females in Pakistan [102]. This extensive heterogeneity is due to the difference in the prevalence of hepatitis B in different regions of Pakistan and different periods. A very high frequency of $\geq 12 \% \mathrm{HBV}$ infection in pregnant females has been reported in Bahawalpur, Hyderabad, and Rahim Yar Khan regions in 2006-2007 [103-105]. Other studies have found lower prevalence. Among pregnant females prevalence of HBsAg was found to be $0.34 \%$ in 2006 in Karachi [106], 1.37\% in Swat in 2008 [107], 1.16\% (95\% CI 0.96-1.37\%) in Peshawar district of Pakistan (in 2013-2014) [108], and 2.78\% in Rawalpindi in 2016-2017 [109]. Moreover, HBsAg was generally reported with low frequency in private-sector patients and high in public-sector patients.
In Sri Lanka, the prevalence of HBsAg is generally low. In 2019, the modeled HBsAg national prevalence and under5-year-old prevalence were 1.5\% (95\% CI 1.34-1.66\%) and $0.07 \%$ (0.06-0.10\%) in Sri Lanka, respectively [5]. In 2019, HepB3 coverage was 99\% in Sri Lanka [6]. In Sri Lanka, although no specific studies on prevalence of HBV infections among pregnant mothers are available, it is reasonable to presume the prevalence is likely to be much lower than in the neighboring countries.

\section{Pacific Countries (Australia, New Zealand, and Pacific Island Countries and Territories)}

Australia, New Zealand (NZ), and Pacific Island Countries and Territories (PICT) fall within the World Health Organization (WHO) Western Pacific Region which has a high prevalence of HBV and related morbidity [110]. The PICT consist of three regions incorporating many countries: Melanesia (comprising Fiji, New Caledonia, Papua New Guinea, the Solomon Islands, and Vanuatu); Micronesia (comprising the Federal States of Micronesia, Guam, Kiribati, Marshall Islands, Nauru, Palau); and Polynesia (comprising Samoa, American Samoa, Tonga, Cook Islands, Tuvalu, Tokelau, Niue, Wallis and Futuna, French Polynesia and the Pitcairn Islands).

New Zealand and Australia introduced universal HBV vaccination of infants in 1988 and 2000, respectively. By the year 2000, both NZ and Australia had introduced catch-up vaccination programs for adolescents and other high-risk groups [111]. In both the countries, birth dose HBV vaccination within $24 \mathrm{~h}$ of birth, along with hepatitis $\mathrm{B}$ immune globulin (HBIG), is given to infants born to HBsAg-positive mothers. Overall health outcomes are poorer and burden of communicable and noncommunicable diseases greater among indigenous peoples (Aboriginal and Torres Strait Islander people in Australia and Māori in New Zealand) as compared with non-Indigenous peoples. Immigration from other Asia-Pacific countries with high HBV prevalence is also common in Australia and NZ [110].

In 2019, the modeled HBsAg national prevalence and children under-5-year-old prevalence were $2.14 \%$ (95\% CI $1.94-2.34 \%)$ and $0.07 \%(0.06-0.09 \%)$ in Australia, respectively [5]. In 2019, HepB3 dose coverage was 95\% in Australia [6]. In Australia, the majority of chronic HBV infections occur in migrants from endemic areas and their children, and also HBV prevalence is higher in Indigenous peoples (Aboriginal and Torres Strait Islander people) [112]. In Australia, $0.4-1.3 \%$ of pregnant females are chronically infected with HBV keeping with the low prevalence in general population [113]. HBsAg prevalence in pregnant females was $0.8 \%$ in South Wales in 2000 [114], $2 \%$ in 2 teaching hospitals in Sydney (2003-2006) [115], and 0.5\% in Victoria among mothers of all singleton births between 2009 and 2017 [116]. 
In 2019, the modeled HBsAg national prevalence and children under-5-year-old prevalence were $0.9 \%(95 \% \mathrm{CI}$ $0.78-1.01 \%)$ and $0.07 \%(0.05-0.08 \%)$ in New Zealand, respectively [5]. In NZ, Māori, Pacific, and Asian New Zealanders have higher HBV prevalence than European New Zealanders [117]. In 2019, HepB3 dose coverage was $92 \%$ in New Zealand [6]. A clear downwards trend was found in antenatal hepatitis B prevalence rates from 1997 to 2009 in one study, and is likely to be as a result of the introduction of the hepatitis B vaccine onto the universal schedule throughout New Zealand in 1988 [118].

The Pacific Islands and Territories (PICT) are very diverse socio-culturally, economically, geographically, and demographically [119].

The majority of PICTs are low-income and middleincome countries. Pacific Island Countries and Territories have moderate-high HBsAg prevalence (Table 2). The HBsAg national prevalence and children under-5-year-old prevalence were 5.38\% (95\%CI 4.45-6.28\%) in 2019 (modeled) [5] and 0.20\% in 2011 [64] in American Samoa, 3.27\% (2.69-3.74\%) in 2019 (modeled) [5] and 0\% in 2012 [64] in Cook Islands, 3.56\% (3.11-4.03\%) in 2019 (modeled) [5] and $0.30 \%(0.10-0.50 \%)$ in 2016 [64] in Federated States of Micronesia, 3.63\% (3.15-4.1\%) in 2019 (modeled) [5] and $0.47 \%(0.34-0.58 \%)$ in 2019 (modeled) [5] in Fiji, 5.03\% (4.31-5.86\%) in 2019 (modeled) [5] and 0\% in 2015 [64] in Guam, $7.47 \%$ (6.13-8.88\%) in 2019 (modeled) [5] and 3.30\% (2.4-4.6\%) in 2014 [64] in Kiribati, 4.17\% (3.52-4.86\%) in 2019 (modeled) [5] and 1.20\% (0.60-1.90\%) in 2016 [64] in Marshall Islands, $4.76 \%$ (3.87-5.7\%) in 2019 (modeled) [5] and $0.53 \%(0.36-0.69 \%)$ in 2019 (modeled) [5] in Nauru, 3.61\% (2.92-4.23\%) in 2019 (modeled) [5] and $0 \%$ in 2015 [64] in Niue, 6.2\% (5.82-6.47\%) in 2019 (modeled) [5] and 3.29\% in 2014-2019 [120] in Papua New Guinea, 5.24\% (4.25-6.3\%) (modeled in 2019) [5] and $0.10 \%$ in 2014 [64] in Samoa, 6.33\% (4.87-7.42\%) (modeled in 2019) [5] and 3.1\%(2.0-4.9\%) in 2016 [64] in Solomon Islands, $6.37 \%$ (5.21-7.67\%) in 2019 (modeled) [5] and $2.97 \%$ (1.99-4.12\%) in 2019 (modeled) [5] in Tokelau Islands, 3.95\% (3.23-4.59\%) in 2019 (modeled) [5] and $0.41 \%(0.24-0.55 \%)$ in 2019 (modeled) [5] in Tonga, 5.76\% (4.79-6.68\%) in 2019 (modeled) [5] and 1.48\% (1.03-2.0\%) in 2019, (modeled) [5] in Tuvalu, and 5.16\% (4.21-6.18\%) in 2019 (modeled) [5] and 1.45\% (0.96-1.95\%) in 2019 (modeled) [5] in Vanuatu respectively. One study found HBsAg prevalence of $6.6 \%$ in young military recruits in 2000 in New Caledonia [121]. HBsAg prevalence was $1.3 \%$ in children 8-11 years in 2001 in New Caledonia [122].

$\mathrm{HBV}$ vaccination for infants and children started between 1995 and 1997 in all PICT, including birth dose delivery in most countries. Younger age at first pregnancy in PICT increases risk of mother-to-child transmission, as a greater proportion of young mothers are HBV envelope antigen
(HBeAg) positive with high viral load. In 2019, HepB3/ HepB-birth dose coverage was $98 \% / 99 \%$ in Cook Islands, $84 \% / 70 \%$ in Federated States of Micronesia, 99\%/99\% in Fiji, 94\%/99\% in Kiribati, 82\%/98\% in Marshall Islands $96 \% / 99 \%$ in Nauru, $99 \% / 99 \%$ in Niue $35 \% / 25 \%$ in Papua New Guinea, 58\%/65\% in Samoa, 94\%/66\% in Solomon Islands, 99\%/99\% in Tonga, 92\%/98\% in Tuvalu, and $90 \% / 82 \%$ in Vanuatu, respectively.[6].

One of the largest and most complete HBsAg prevalence studies in PICT was by Wilson et al. who reported HBsAg prevalence based on serological surveys conducted in 1998 (across Fiji, Vanuatu, Tonga, and Kiribati as part of a vaccination efficacy study (published 2000, after HBV vaccination introduction). The survey found HBsAg prevalence among pregnant females of $6.6 \%$ in Fiji, $15.1 \%$ in Kiribati, $18.6 \%$ in Tonga, and $12.3 \%$ in Vanuatu [123].

HBsAg prevalence of $2 \%$ was found in antenatal females in 2011 in Nausori, Fiji [124].

HBsAg prevalence was $2 \%$ in 2014 in Guam among pregnant females [125].

A study conducted in 2002 and 2003 found $\mathrm{HBsAg}$ prevalence of $9.2 \%$ (CI 4-15\%) in 269 pregnant females in Tarawa, Kiribati [126].

HBsAg prevalence in Marshallese pregnant females was $8 \%$ in 2003-2003 and 10\% in 2007 [127].

Studies conducted in the East-Coast provincial hospital (New Caledonia) (from 1996 to 1999) found HBsAg prevalence ranging from 1.7 to $4.9 \%$ in pregnant females [128].

In Solomon Islands, among pregnant females, studies have found HBsAg prevalence of $13.7 \%$ in 2008 (antenatal cohort in Honiara, Gizo, and Munda) [129], and $13.8 \%$ in 2015 among pregnant females attending antenatal clinic in Honiara [130].

\section{Areas of future research}

Countries need to generate accurate and large-scale data on prevalence of HBsAg in pregnant females, and their virological characteristics.

\section{Immunopathogenesis of hepatitis B virus infection (acute and chronic) in pregnancy}

\section{Review of literature}

\section{Immunopathogenesis of acute HBV infection in pregnancy}

There is scarcity of reports on acute hepatitis B infection in pregnancy; however, it seems that the clinical course does not differ from pregnant females to non-pregnant females [131]. The usual disease course would likely be uneventful. Under a very rare circumstance, fulminating hepatitis occurs. 
Natural history of HBV infection is determined by complex interactions between virus and the host immune response [132]. In pregnancy, maternal immunity is totally altered to tolerate semi-foreign body of fetus, and also pregnancy is associated with increased adrenal corticosteroids and other hormones that play a significant role in altering host immunity and viral replication.

There are greater chances of acute liver failure in pregnancy due to acute HBV infection, but at the same time, others have reported none of the detrimental effect of pregnancy on clinical recovery in acute HBV infection [133].

Due to weak T-cell response, HBsAg loss and seroconversion may be delayed in the pregnant females with acute hepatitis B than non-pregnant [131]. T cells are markedly reduced during early pregnancy up to the 20th week of gestation to reduce the level of immunity. Increased hormone levels during pregnancy, including progesterone, estrogen, and human chorionic gonadotropin, have been shown to have a clear suppressive effect on cell-mediated immunity. HBV-specific CD8 T cells play a pivotal role in clearing the acute HBV infection; however, it is observed that HBV-specific T-cell responses are weaker or absent in pregnant females than non-pregnant females or adult males [134].

\section{Immunopathogenesis of chronic HBV infection in mothers during pregnancy and postpartum period}

The immunological changes during pregnancy and the postpartum period affect the natural history of chronic HBV infection. Biochemical hepatic flares and higher rates of $\mathrm{HBeAg}$ loss (and HBsAg clearance) have been reported in the early postpartum period due to immune reconstitution [135]. Most flares are self-limited and do not require therapy, but some can be severe, resulting in liver failure [136]. HBeAg-positive mothers have higher incidence of ALT flares as compared to the $\mathrm{HBeAg}$-negative mothers. $\mathrm{HBe} A g$ titers $<1: 650$ among $\mathrm{HBe} A g$-positive mothers have been shown to be associated with $\mathrm{HBeAg}$ clearance in the postpartum period [137]. Immunological changes (like regulatory T-cell expansion and an increase in Th1 cytokines, IFN- $\gamma$, and IL-12) occurring during pregnancy to prevent fetus rejection are reversed after delivery [138].

There are also some differences in immune responses among $\mathrm{HBeAg}$-positive mothers (higher frequency of $\mathrm{CD} 19+\mathrm{B}$ cells, lower frequency of CD $3+\mathrm{CD} 4+\mathrm{T}$ cells, and peripheral NK-cell inhibition) as compared to $\mathrm{HBeAg}$ negative mothers [139].

Reactivation of chronic HBV infection has also been reported during pregnancy [140]. Cortisol levels peak at around delivery, and a sudden decrease in levels during postpartum period has effects similar to steroid withdrawal, causing HBV reactivation. Defective HBV-specific T-cell responses also occur in the peripartum period [141].

\section{Immunopathogenetic mechanisms involved in MTCT}

HBV MTCT can potentially occur prenatal or intra-uterine, natal or at the time of birth, and postpartum. Most HBV infections occur perinatally (at birth or soon after) in unvaccinated infants, but historically reports have suggested that approximately $3 \%$ to $8 \%$ of infections may occur through the intra-uterine route [142]. However, the findings that, after administration of HBIG and hepatitis B vaccine in newborn infants, MTCT of HBV occurs only in 2-3\% of infants born to $\mathrm{HBsAg}$-positive mothers $(<0.1 \%$ of infants of $\mathrm{HBeAg}$ negative mothers and 5-10\% of infants of $\mathrm{HBeAg}$-positive mothers) clearly indicate that historically estimated intrauterine transmission appears to be overstated. It is believed that intra-uterine transmission of $\mathrm{HBV}$ is the most significant contributor to MTCT and immunoprophylaxis failure [see below].

The presence of $\mathrm{HBeAg}$ and other viral proteins (like $\mathrm{HBx}$ ) can affect the risk of MTCT. Maternal HBeAg seropositivity is a significant risk factor for MTCT. In chronic $\mathrm{HBV}$ infection, $\mathrm{HBeAg}$ has an immunomodulatory role, and early in utero exposure to $\mathrm{HBeAg}$ may promote chronicity instead of viral clearance [143].

Studies in mouse models have shown that conditioning of hepatic macrophages by maternal $\mathrm{HBeAg}$ generates antiinflammatory macrophages, which lead to HBV persistence. However, in the absence of HBeAg preconditioning, macrophages acquire a proinflammatory phenotype, leading to HBV clearance by activated CD8 + T cells [144].

In pregnant females with viral loads of $>3 \log 10$ copies/mL, functional hepatitis $\mathrm{B} X$ protein $(\mathrm{HBx})$ produced in HBV-infected placenta cells could activate phosphoinositide 3-kinase in placenta, which signals inhibition of apoptosis in placental cells, allowing for HBV persistence in trophoblasts [145].

High viral load is a known significant risk factor for MTCT [see below]. Placental infection occurs progressively through different cellular layers from maternal to the fetal side, with the depth of placental tissue infection in direct proportion to maternal viral load [146].

Occult HBV infection (OBI) is characterized by serum HBsAg negativity with or without serum antibodies (anticore and/or anti-HBs), and HBV DNA in serum or liver or extra-hepatic reservoirs (peripheral blood mononuclear cells or lymphoid system). OBI may occur in infants born to HBsAg-positive mothers despite the receipt of immunoprophylaxis. Most studies show very low or no OBI in vaccinated children born to HBsAg-positive mothers [147]. Further studies are needed to assess the vertical transmission of OBI and its clinical implications. 
In one Japanese study, genotype $\mathrm{C}$ was associated with increased perinatal transmission rates as compared to genotype B. However, the increased MTCT risk may be due to higher viral loads and $\mathrm{HBeAg}$ positivity in mothers with HBV genotype C infection [148]. Other studies did not find an association between MTCT risk and the HBV genotype [149].

Naturally occurring HBV variants are selected under host pressure. One study found that in $\mathrm{HBeAg}$-negative pregnant females having precore mutant G1896A and HBV DNA levels of 4-5 $\log 10$ copies/mL, HBV transplacental transmission did not occur (no HBV DNA was found in the analyzed placenta), and no passive-active immunoprophylaxis failure was seen in the infants at 1 year of age [150]. Another retrospective study from China Mainland suggested that dual basal core promoter mutants have a protective role in MTCT, as these were found in mothers who did not transmit HBV to their neonates; but this association may also be related to lower maternal viral loads in pregnant females with dual basal core promoter mutants [151].

Impaired dendritic cell function and decreased levels of follicular T cells (CD4 + C-X-C chemokine receptor type $5+)$, plasma B cells (CD19+CD38+) within PBMCs, and low serum IL-21 were found in mothers in association with MTCT, versus mothers who did not transmit HBV to their infants. Also, newborns showed transcriptomic imprints of their mothers, suggesting that mothers' immune signatures could be a potential marker for MTCT $[152,153]$.

\section{Hepatitis B vaccine-specific responses in infants born to mothers who were $\mathrm{HBsAg}$ positive and role in immune response to $\mathrm{HBV}$ vaccine}

One Taiwanese study found that only $16 \%$ of the peoples who had received the HBV vaccine as infants had anti-HBs at 15 years of age [154]. The factors associated with blunted immune response in infants born to $\mathrm{HBsAg}$-positive and $\mathrm{HBeAg}$-positive mothers include transplacental passage of $\mathrm{HBsAg}$ and transient HBsAg positivity in the infants [155].

Increasing the vaccine dose from 10 to $20 \mu \mathrm{g}$ improved the immunogenicity among the infants born to HBeAg-positive mothers [156]. Also, HBV vaccine alone is as effective as the combination of HBIG plus vaccine, in preventing $\mathrm{HBV}$ infection in infants born to HBeAg-negative mothers [157].

Lower amounts of the T helper 1 cytokine IL- 2 secretion in an in vitro stimulation assay has been found to be associated with vaccine failure among infants receiving the complete immunoprophylaxis [158]. In utero encounter to HBV antigens is suggested by the HBV-specific T-cell responses in uninfected vaccinated infants born to $\mathrm{HBeAg-negative}$ chronic $\mathrm{HBV}$-infected mothers; although this exposure does not impair the neonatal $\mathrm{B}$-cell and $\mathrm{T}$-cell responses to the
HBV vaccine [159]. HBV-specific T-cell responses can be seen in children for up to 10 years after their primary infant vaccination, despite having negative or low anti-HBs levels [160].

\section{Trained immunity in infants born to mothers who were $\mathrm{HBsAg}$ positive and role in immunoprophylaxis failure}

Exhaustion of $\mathrm{HBV}$-specific $\mathrm{CD} 8+\mathrm{T}$-cell responses is one of the mechanisms for HBV persistence. Diminished expression of $\mathrm{CD} 3+\mathrm{T}$-cell receptor zeta chain is associated with functionally defective CD $8+\mathrm{T}$ cells (producing less interferon- $\gamma$ ) and reduced expression of the cytotoxicity marker CD107a in HBsAg-positive newborns versus HBsAg-negative and healthy newborns [161]. HBsAgpositive pregnant females have also shown immature transitional B cells and decreased plasma B cells continuously from third trimester till delivery. Also, higher pre-vaccination levels of immature transitional B cells were found in HBsAg-positive newborns compared with HBsAg-negative infants born to HBsAg-positive mothers. The frequency of immature transitional B cells declined at 12 months after vaccination in $\mathrm{HBs} \mathrm{Ag}$-positive newborns, whereas no changes were observed in HBsAg-negative and uninfected healthy newborns [162]. Although, these novel observations added a new perspective in understanding the key mechanisms of HBV chronicity in newborns, yet it is unknown when this phenomenon starts during pregnancy; therefore, it may be worthwhile to analyze the kinetics of TCR zeta expression and regulatory $\mathrm{T}$ cells throughout pregnancy.

Serum cytokine profiling from neonates born to $\mathrm{HBsAg}$ positive mothers revealed a cytokine signature compatible with a Th1-like response (high levels of IL-12 p40 and low levels of Th2 cytokines IL-4, IL-5, IL-13, and IL-10) and a decrease in proinflammatory cytokine profile (IL-1 $\beta$ and IL-6). Also, cord blood mononuclear cells from neonates who were HBsAg positive showed a stronger response compared to healthy controls to an unrelated bacterial challenge. Despite increased levels of IL-12p40 and IFN- $\alpha 2$ in HBVinduced trained immunity, $\mathrm{HBV}$-specific T-cell response was lacking which indicates that trained immunity may induce monocytes in cord blood to fight against other pathogens, but does not help in HBV clearance [163]. It is presumed that placental DCs and neutrophils secrete IL-12p40, and thus play a direct role in the modulation of maternal or neonatal infections. Maternal HBeAg "trains" Kupffer cells in utero, thus playing a role in HBV persistence [144].

\section{Areas of future research}

Further studies are necessary in serially collected samples from mothers and infants to clearly understand the dynamics 
of the host immune response in association with HBV flares and MTCT.

Although combined maternal $\mathrm{HBeAg}$ positivity and high viral loads is an established risk factor for MTCT, HBV genotype, PC/BCP mutations, and risk of immunoprophylaxis failure is not well understood and may be an area of future studies.

Further studies are needed to assess the vertical transmission of OBI despite appropriate immunoprophylaxis and its clinical implications.

\section{How hepatitis B virus infection (acute and chronic) impacts the health of pregnant females and outcome of pregnancy}

\section{Review of literature}

Many epidemiologic studies have reported possible impact of maternal HBV infection on the perinatal and pregnancyrelated outcomes. However, results from studies have been contradictory and the possible role of maternal HBV infection in the pathogenesis of pregnancy-related outcomes remained unresolved. A study suggested that higher HBV viral load may be associated with poorer pregnancy-related outcomes [164].

A prospective cohort study from China Mainland suggested that maternal chronic HBV infection was associated with an increased risk of miscarriage [165].

A few studies from China also demonstrated significant associations between maternal chronic HBV infection and low birth weight or small-for-gestational age [166, 167]. However, studies from the U.S. reported no significant association between maternal chronic HBV infection and smallfor-gestational age [168, 169].

For gestational diabetes mellitus, a meta-analysis revealed that maternal chronic HBV infection had a $47 \%$ increased risk of gestational diabetes mellitus (adjusted odds ratio: 1.47) compared with those without HBV infection [170]. This association might stem from low-grade systemic inflammatory response from HBV infection [171].

For pregnancy-induced hypertension, previous case-control and cohort studies have demonstrated inconclusive results $[172,173]$. A recent meta-analysis suggested that maternal chronic HBV infection was associated with $23 \%$ decreased risk of pre-eclampsia [174]. However, most of included studies were case-control studies and possible mechanism has not been postulated for this association.

Impact of maternal chronic $\mathrm{HBV}$ infection on preterm birth is also inconclusive. A meta-analysis demonstrated no association between maternal chronic HBV infection and preterm labor [175]. However, another recent meta-analysis suggested a significant association between maternal chronic
HBV infection and premature birth [176]. Of note, abnormal liver function test and concomitant fatty liver were stronger risk factors for preterm birth than maternal chronic HBV infection in previous study [177]. It is possible that liver inflammation per se plays an important role of preterm birth regardless of maternal chronic $\mathrm{HBV}$ infection.

Cohort studies from China Mainland demonstrated that maternal chronic HBV infection was associated with an increased risk of intrahepatic cholestasis of pregnancy [178, 179].

A study from U.S. found that patients with chronic HBV infection were less likely to perform cesarean delivery. However, studies from Asia showed that patients with HBV infection had an increased rate of cesarean delivery. This result might stem from on maternal request or obstetrician's recommendation based on the belief that cesarean delivery reduces mother-to-child transmission [180].

No associations were found between chronic HBV infection and adverse perinatal outcomes, including gestational diabetes mellitus, pre-eclampsia, placenta previa, premature separation of placenta, premature rupture of membranes, preterm birth, and low birth weight in females undergoing assisted reproductive technology [181].

\section{Recommendations}

Hepatitis B viral infection in the mother does impact the perinatal and pregnancy-related outcomes both in the mother and the newborn. The maternal effects include miscarriage, gestational diabetes mellitus, pregnancy-induced hypertension, preterm birth, intrahepatic cholestasis of pregnancy, and cesarean delivery. However, the data from available studies are not strong enough to associate these complications to mere HBV infection (B2).

\section{Areas of future research}

Whether serum HBV viral load is associated with increased risk of perinatal outcomes in maternal HBV infection should be further investigated.

\section{Impact of pregnancy on hepatitis B virus infection severity and outcomes (acute and chronic) and management of liver disease (general management and use of antivirals) in pregnant females with hepatitis B virus infection}

\section{Review of literature}

Although the management for patients with acute and chronic HBV infection during pregnancy is similar to that 
of non-pregnant patients, several issues may be considered because of the presence of the fetus in pregnant patients. These will be addressed under different scenarios described below.

There is scarcity of reports on acute hepatitis B infection in pregnancy; however, it seems that the clinical course is not differ from non-pregnant state [131], and hence, the management would mainly be supportive. The usual disease course would likely be uneventful. Under a very rare circumstance, when fulminating hepatitis occurs, the management decision would be made with the considerations of the chance of spontaneous liver function recovery in the mother and the degree of fetus maturity. As such, liver transplantation and early fetal delivery may be contemplated accordingly.

Obstetricians sometimes would manage chronic HBVinfected patients with pregnancy for pregnancy-related liver problems and hepatitis B virus-related problems, both of which, in particular, the latter would involve the management by hepatologists. The most common liver problem in pregnancy is HBV flares. Incidence of HBV flare and hepatic decompensation has been studied in a large retrospective study recruiting 310 chronic HBV-infected patients with pregnancy (19 received nucleos(t)ide analogs (NA) before pregnancy; 16 received NA during the first or second trimesters; 5 during the third trimester) [182]. ALT flares [defined by $\geq 2 \times$ upper limit of normal (ULN)] occurred in $14 \%$ during pregnancy and $16 \%$ within 6 months of delivery. ALT flares $\geq 5 \times$ ULN or $\geq 10 \times$ ULN occur in $\leq 5 \%$ during pregnancy or postpartum period. Overall, $12 \%$ of patients with ALT flares developed jaundice and 2\% [2 patients (1 with pre-existing cirrhosis)] developed hepatic decompensation. According to another study with 158 pregnant females, ALT flares developed in $3.4 \%$ during pregnancy and $4.3 \%$ after delivery [136]. No flares were severe and no liver decompensation was observed. As mentioned above, ALT flares can also occur during the postpartum period. According to one study $(n=317)$, postpartum ALT flares $>2 \times$ ULN and $>5$ X ULN occurred in $9.8 \%$ and $1.9 \%$ in CHB mothers [183]. Another study with 126 patients reported $25 \%$ chance of postpartum ALT flares which usually resolved spontaneously [184]. Acute-on-Chronic liver failure (ACLF) due to HBV reactivation had been reported in a case series of 5 patients (all were non-cirrhotic) and all recovered with antiviral treatment [185]. Rarely happened condition is patients requiring liver transplantation for fulminating hepatic failure due to HBV reactivation $[140,186]$. In summary, mild ALT flares during and shortly after delivery are not uncommon, whereas hepatic decompensation is rare.

Although NA treatment would theoretically reduce the chance of ALT flares due to HBV reactivation, whether it should be given routinely would depend on the different scenarios.
Patients who are already on long-term NA therapy before conception

In the patients who are already on long-term NA therapy before conception, the question would be whether the treatment should be stopped once pregnancy is planned or confirmed. There are two major considerations in this context: (1) whether NA would increase the risk of fetus anomalies if it is continued throughout the pregnancy and (2) whether discontinuation of NA therapy would jeopardize the liver condition of the mothers and if in case becoming severe, adversely affects the fetus. To date, on one hand, there are no prospective control studies to compare the mother and fetus outcome between those continue and those discontinue NA therapy. On the other hand, there is absence of evidence on the hypothetical chance of teratogenic effects of the HBV treatment continuation that we could learn from the experience from HIV pregnancy registry. According to the Antiretroviral Pregnancy Registry, of the 11867 females on anti-retroviral therapies for HIV and/ or HBV infection, the rate of birth defects was $2.7 \%$ which is very similar to the rate $(2.72 \%)$ in the general population [187]. Among the NAs, tenofovir disoproxil fumarate (TDF), lamivudine (LAM), and telbivudine (LdT) have been assessed as providing good maternal and infant safety [188, 189].

Among the currently available NAs, LdT and TDF are classified as category B drugs (no risk in animal studies, but unknown in humans), whereas LAM, adefovir (ADV), and entecavir (ETV) are classified as category C drugs (teratogenic in animals, but unknown in humans) by the US FDA. Category B NAs (LdT and TDF) may be considered for mothers needing antiviral treatment during the first through third trimester of pregnancy.

As LAM and LdT have low genetic barriers that may lead to the emergence of drug-resistant strains of HBV [190], TDF should be the first choice for pregnant females. If the pregnant female has impaired renal functions or osteoporosis, LdT or LAM can be used [191, 192]. ETV and ADV should be avoided in females with pregnancy intention, because these drugs have potential serious adverse effects or teratogenesis [191]. If these drugs have been taken before pregnancy, it should be changed to TDF [192].

The newly approved tenofovir alafenamide (TAF) has been recommended for CHB treatment in many parts of the world owing to its better renal and bone safety profile compared to TDF. However, there are limited data on the use of TAF in pregnancy, while it is not recommended during breastfeeding [193].

Concerning the effect on the liver if treatment is stopped, it is well known that around $40-50 \%$ of non-pregnant chronic HBV-infected individuals would have ALT flares after NA cessation [194], with majority of the events happening within the first-year treatment cessation. In the context of 
chronic $\mathrm{HBV}$-infected patients with pregnancy, according to a study, 8 (6 of those had fivefold increase in ALT levels) out of 12 patients would experience ALT flares after stopping NA treatment during pregnancy [195]. According to another study, ALT flares occurred in $31 \%$ of patients who stopped NA during the first trimester (16\% of patients who stopped NA before pregnancy) [196]. Cases of acute exacerbation of HBV with liver failure that eventually required urgent liver transplantation have been reported [140, 186].

There are two factors in pregnancy which would enhance the chance of ALT flares postpartum after treatment cessation. First, pregnant females are relatively younger and, therefore, more immune active. They are expected to have a higher chance of HBV reactivation upon treatment cessation. Second, it is known that pregnancy induces immune suppressive state in the mothers to reduce fetal rejection. Together with the increased cortisol, estrogen, and progesterone levels, it creates a potential favorable condition for the $\mathrm{HBV}$ to replicate. One study had demonstrated an increase in HBV DNA levels and a decrease in ALT levels during pregnancy, while these profiles reversed after pregnancy [197]. However, another study found that HBV DNA levels during pregnancy were highly variable with some patients having a rise in third trimester or postpartum period, while majority of patients having static HBV DNA levels throughout the pregnancy [198]. Further to these findings, a recent study had shown that pregnant CHB patients had a shift toward Th1 response over Th2 during peripartum period with the host immunologically attempting to clear the virus [199], although it usually fails. At the same time, cortisol levels would decrease immediately after delivery enhancing a steroid withdrawal effect [137].

These combined factors would increase the chance of HBV reactivation, especially during the later course of pregnancy and early course after delivery. Taken all the above findings and considerations together, it is recommended that NA would better to be continued throughout the pregnancy and early postpartum to avoid uncontrolled HBV reactivation. This recommendation would be much stronger in patients with advanced fibrosis/cirrhosis. It is because severe flares, maternal mortality, and fetal death occur in $15 \%, 1.8 \%$, and $5.2 \%$, respectively, after treatment cessation according to a retrospective study of 400 pregnant females with HBV-related cirrhosis [200].

If a woman was planning pregnancy or a pregnant chronic HBV-infected mother was taking the NA of FDA-defined pregnancy category $\mathrm{C}$ drugs, it is recommended to switch to a FDA-defined pregnancy category B drugs.
Treatment naïve chronic HBV-infected patients who become pregnant

The second scenario applies in treatment naïve chronic HBV-infected patients who become pregnant. As mentioned above, HBV reactivation can occur as a result of alteration of immune regulation during and after pregnancy (postpartum). Immune reconstitution during early postpartum period is associated with ALT flares and hence increased $\mathrm{HBeAg}$ and HBsAg loss. According to one study, HBV DNA flares (defined by $>2 \log \mathrm{IU} / \mathrm{mL}$ ) and ALT flares (defined by 5 X ULN or 3 X the baseline values) occur in $9 \%$ and $6 \%$ of patients during pregnancy and $4 \%$ and $10 \%$ within 3 months of delivery, respectively [201]. Fifty percent of these ALT flares were observed during the second trimester or earlier. According to another study examining 146 pregnant chronic HBV-infected patients not receiving antiviral treatment, the median ALT levels significantly increase from $17 \mathrm{U} / \mathrm{L}$ at baseline to $29 \mathrm{U} / \mathrm{L}$ at postpartum period [202]. In addition, 7 "immunotolerant" patients developed postpartum ALT flares with the median ALT level of 75 U/L [202]. ACLF due to HBV reactivation has been reported in chronic HBV-infected patients with pregnancy [140]. This is likely due to the natural decline of cortisol levels (usually peaked at term and delivery) during postpartum period mimicking the steroid withdrawal effect. Close monitoring of the HBV DNA and ALT flare profiles during pregnancy and postpartum period for those who are not on NA throughout the pregnancy is recommended. This monitoring should be extended till 6 months post-delivery. If the severe ALT flares are evidenced, prompt initiation of NA treatment should be implemented.

\section{Portal hypertension in chronic HBV-infected females with established cirrhosis}

Another issue is management of portal hypertension in chronic HBV-infected females with established cirrhosis. These patients usually have a relatively lower chance of conception because of two reasons. First, they are relatively older. Second, patients with liver cirrhosis would have hypothalamic-pituitary dysfunction and disturbed sex hormone metabolism [203], both of which would adversely affect fertility. Because of this, the incidence of cirrhosis in pregnant females is found to be very low with approximately 1 in 5950 pregnancies [204]. Nonetheless, in chronic HBVinfected pregnant patients with cirrhosis, portal hypertension may be exaggerated during pregnancy due to the normal physiological changes associated with pregnancy. These include increase in blood volume, increase in heart rate, and decrease in systemic vascular resistance. It has been shown that MELD score is predictive for significant liverrelated complications during pregnancy [205] In particular, 
MELD $>10$ is highly sensitive and specific for predicting liver decompensation during pregnancy [205].

For patients with compensated cirrhosis and with a plan for pregnancy, screening for varices is required before pregnancy and preventive measure for acute variceal bleeding, e.g., endoscopic ligation is required. Acute variceal bleeding with catastrophic outcomes can occur during pregnancy in $18-32 \%$ of these patients [206] with the mortality rate of up to $50 \%$ [207]. It usually occurs during the second trimester or during delivery. It is more related to the gravid uterus and to repeated Valsalva maneuvers [208]. It is recommended to perform endoscopy surveillance with endoscopic ligation for medium- and large-sized varices during the second trimester in patients even with the absence of varix in the first screening before pregnancy. This procedure is safe and effective in preventing acute variceal bleeding. If bleeding risk is assessed to be high (in patients with large varices), non-selective beta blocker may be considered [209]. Close fetal monitoring is necessary for the possibility of fetal bradycardia and intra-uterine growth retardation. Nevertheless, overall, propranolol therapy appears to be quite safe for pregnancy. The use of vasopressin (may also be applicable to octreotide) is, however, contraindicated because of the decrease in placental perfusion and increased risk of placental abruption [210]. Several successful cases with the use of transjugular intrahepatic portosystemic shunt (TIPS) have been reported [211]. Worsening of ascites with compromised respiratory function has also been reported in these patients [212].

\section{Patients with stable chronic HBV disease undergoing prophylactic treatment to prevent mother-to-child transmission}

The final scenario is patients with stable chronic HBV disease undergoing prophylactic treatment to prevent motherto-child transmission based on the high HBV DNA levels (>200,000 IU/mL) [see below].

\section{Recommendations}

Acute hepatitis B infection in patients with pregnancy usually requires specialized supportive treatment (weak recommendation, moderate-quality evidence); and if severe and progressive, urgent liver transplantation may be needed. Early termination of pregnancy and early fetal delivery are rarely required (B2).

For females already on NA treatment before pregnancy with established advanced fibrosis/cirrhosis, continuation of the NA treatment throughout the pregnancy is highly recommended (B1).
For females already on NA treatment before pregnancy with less-advanced fibrosis, continuation of NA treatment during pregnancy should be considered $(\mathrm{C} 1)$.

During pregnancy, switching from FDA classified pregnancy category class $\mathrm{C}$ to class $\mathrm{B}$ should be considered. TDF is recommended as the first choice antiviral for pregnant females (B1).

For chronic HBV-infected females who were not eligible for antiviral treatment, and are thus treatment-naïve at the time of pregnancy, HBV DNA and ALT levels monitoring are mandatory throughout the pregnancy, and up to 6 months after pregnancy, treatment is indicated with significant flares (B1).

Pregnant females with chronic HBV infection and established cirrhosis and with a plan for pregnancy should undergo a surveillance endoscopy to screen to varices; prophylactic variceal management is recommended before pregnancy $(\mathrm{C} 1)$.

For pregnant females with cirrhosis, it is recommended to perform endoscopy surveillance with endoscopic ligation for medium- and large-sized varices during the second trimester in patients even with the absence of varix in the screening before pregnancy $(\mathrm{C} 1)$.

\section{Areas of future research}

Whether or not to continue NAs in females already on NA treatment before pregnancy and with less-advanced fibrosis requires further studies.

Whether to start NA in pregnant females who before getting pregnant were not eligible for anti-HBV therapy needs further studies.

More data on TAF safety in pregnancy are needed.

\section{Mother-to-child transmission (MTCT) of hepatitis B virus [mechanisms and associated factors]}

\section{Review of literature}

Mother-to-Child Transmission (MTCT) of HBV refers to the entry and replication of maternally derived HBV in offspring to produce novel virions. MTCT of HBV is a major cause of chronic HBV infection. Before the availability of hepatitis B immunoglobulin (HBIG) and hepatitis B vaccine, MTCT of HBV occurred in 70-90\% of the children born to $\mathrm{HBsAg}$ - and $\mathrm{HBeAg}$-positive mothers and $10-40 \%$ of those born to HBeAg-negative mothers. With the administration of HBIG and hepatitis B vaccine, MTCT rates in children of $\mathrm{HBeAg}$-positive and $\mathrm{HBeAg}$-negative chronic $\mathrm{HBV}$-infected mothers have been reduced to $4-10 \%$ and $<0.1 \%$, respectively [213, 214]. MTCT of HBV is considered to occur 
during ante-partum (in utero), intra-partum (during labor and delivery), or postpartum (after birth) period.

\section{$\mathrm{HBV}$ in utero transmission}

In utero transmission of $\mathrm{HBV}$ refers to the replication of HBV in fetal hepatocytes before birth. Although it is considered that HBV DNA may integrate in ova and granular cells and HBV may infect embryos [215], the findings that the neonatal immunoprophylaxis protected against MTCT of $\mathrm{HBV}$ in almost all infants born to HBeAg-negative mothers [213, 214], or born to HBeAg-positive mothers who received oral antivirals during the third trimester of pregnancy [216, 217] indicate the unlikelihood of HBV in utero transmission through infection of embryos.

The presence of HBsAg and/or HBV DNA in umbilical or peripheral blood samples collected shortly after birth was presumably considered to be a consequence of in utero transmission [218, 219]; this was also assumed to be the main reason for MTCT of HBV after passive-active immunoprophylaxis (i.e., immunoprophylaxis failure) [220]. However, longitudinal observations showed that most of infants with positive HBsAg and/or HBV DNA at birth were not HBsAg positive in the follow-up [221, 222]. Thus, the presence of HBsAg or HBV DNA at birth just indicates exposure to, but not infection with HBV [222].

As a general rule, the prerequisite for in utero transmission of a microbial pathogen is that it can cross placentas. However, HBV is not cytopathogenic and there is no evidence for placental damage caused by HBV. Theoretically, placental barrier may prevent the entry of HBV into fetus. The findings that acute hepatitis B occurring in the first or second trimester of pregnancy rarely caused HBV infection in infants indicate that the virus does not easily cross the placenta [223]. The lack of anti-HBc IgM in newborn infants of HBV-infected mothers also suggests little in utero transmission [224].

To date, there are no practicably available ways to define HBV in utero transmission. As aforementioned, the presence of HBsAg and/or HBV DNA in umbilical cord blood or infants shortly after birth cannot be used to define in utero transmission [221, 222]. It is generally accepted that persistence of positive HBsAg from birth to several months of age can define in utero transmission [225]; however, the measurement of HBV markers was performed at intervals of one or more months and the dynamic changes of $\mathrm{HBsAg}$ or HBV DNA levels during these intervals were unknown. Because the maternal HBsAg in infants may remain for more than 1 month [226] and seroconversion of HBsAg may be detected 4-5 weeks after inoculation of HBV in experimentally infected chimpanzees [227], it is possible that, if newborn infants are infected during intra-partum period, they may actively produce viral markers before the disappearance of maternally derived $\mathrm{HBsAg}$ and/or $\mathrm{HBV}$, leading to the persistence of HBsAg in circulation. Thus, the reported persistence of HBsAg and/or HBV DNA at intervals of 1 month or more does not necessarily mean true in utero transmission, and the possibility of transmission occurred during intra-partum period cannot be excluded.

In summary, MTCT of HBV by in utero transmission, if really occurs, should be very rare. More convincing evidence is required to demonstrate $\mathrm{HBV}$ in utero transmission.

\section{HBV intra-partum transmission}

HBV intra-partum transmission refers to the entry of maternal HBV in newborn infants during labor and/or delivery and, subsequently, the replication of HBV in infants. The vast majority of MTCT of HBV occurs during the intrapartum period. Maternal blood can cross placenta during labor [228]. After starting the first stage of labor, the repetitive and strong contractions of the uterus may cause maternal-fetal microtransfusion or transplacental leakage, leading to the entry of maternal HBsAg and HBV into expectant infants, which may explain the presence of HBsAg and/or HBV DNA in $>30 \%$ of infants at birth [221, 222]. During the second stage of labor, an infant directly comes in contact with maternal HBV-containing body fluids, during which maternal HBV may enter into newborn infants through obvious or imperceptible lesions of skin and/or mucosa. Thus, all infants born to HBsAg-positive mothers, regardless of HBeAg state or HBV DNA level, inevitably undergo exposure to maternal HBV.

In addition, before the availability of immunoprophylaxis, MTCT of HBV occurred in 70-100\% of infants born to mothers who had acute hepatitis B near delivery [229], but rarely occurred in infants born to mothers with acute hepatitis B occurred during the first or second trimester of pregnancy [223]. The reason is likely that the mothers with acute hepatitis B around delivery might have high viral load at delivery, which is a main risk factor for MTCT of HBV, whereas the mothers with acute hepatitis B at the first or second trimester might have resolved the infection or might have low viral level at delivery.

\section{HBV postpartum transmission}

In the era of no immunoprophylaxis against hepatitis B, postnatal transmission of HBV from HBsAg-positive mothers to their offsprings occasionally occurred because of the close contacts. With the universal vaccination against hepatitis B in all infants and administration of HBIG in infants of HBsAg-positive mothers as well, postnatal transmission of HBV rarely occurs. Theoretically, HBV may be transmitted through breastfeeding, because HBV can be detected in breast milk and nipple cracks may occur during 
breastfeeding. However, studies showed that breastfeeding does not have additional risk for infection in infants [see below].

\section{Risk factors for MTCT of HBV}

Maternal HBV DNA level and HBeAg state: Maternal high HBV DNA level (viral load) is a main risk factor for MTCT and immunoprophylaxis failure. Studies showed that maternal HBV DNA levels that may cause immunoprophylaxis failure are somewhat varied, ranging from $>2 \times 10^{5} \mathrm{IU} /$ $\mathrm{ml}$ or $>2 \times 10^{6} \mathrm{IU} / \mathrm{ml}$ measured with commercial reagents made in China Mainland [221, 222], > $10^{7} \mathrm{IU} / \mathrm{ml}$ tested with Abbott Real-Time HBV DNA assay [230], to $>2 \times 10^{7}$ IU/ $\mathrm{ml}\left(10^{8}\right.$ copies $\left./ \mathrm{ml}\right)$ detected with Roche reagents [214]. A meta-analysis was done by WHO to assess the risk of perinatal infection according to the maternal HBV viral load (measured by $\log 10 \mathrm{IU} / \mathrm{mL}$ ) among infants who received a timely birth dose and HBIG. Studies with a small sample size ( $<10$ subjects) were excluded. When timely birth dose and HBIG were used, there was no breakthrough infection reported when the maternal HBV DNA viral load was below $5.3 \log _{10} \mathrm{IU} / \mathrm{mL}(200,000 \mathrm{IU} / \mathrm{mL})$ [231]. Therefore, it is generally accepted to use HBV DNA $\geq 2 \times 10^{5} \mathrm{IU} / \mathrm{ml}$ as a threshold for risk of MTCT after the immunoprophylaxis [192, 231, 232].

$\mathrm{HBe} A g$-positive individuals have higher HBV DNA levels.

In Asia, the median HBV DNA levels in HBeAg-negative chronic HBV-infected pregnant females are approx $3-4 \log _{10}$ $\mathrm{IU} / \mathrm{ml}$, and the proportion of $>10^{6} \mathrm{IU} / \mathrm{ml}$ is only $0.5-1.8 \%$, while the HBV DNA levels in $\mathrm{HBeAg}$-positive pregnant females are $>7 \log _{10} \mathrm{IU} / \mathrm{ml}$ and the proportion of $>10^{6} \mathrm{IU} /$ $\mathrm{ml}$ or $>10^{6}$ copies $/ \mathrm{ml}$ is over $80 \%[98,233]$. Immunoprophylaxis failure occurs in $<0.1 \%$ of children born to HBeAgnegative mothers, but in $4-10 \%$ of children born to $\mathrm{HBeAg}$ positive mothers [213, 214]. Thus, the presence of HBeAg in pregnant females indicates the risk of MTCT even after immunoprophylaxis. Meta-analysis by WHO to assess the performance (sensitivity and specificity) of HBeAg tests in pregnant female with HBV infection in identifying female with high HBV DNA levels ( $\left.\geq 5.3-6.2 \log _{10} \mathrm{IU} / \mathrm{mL}\right)$, found good sensitivity [88.2\% (95\% CI 83.9-91.5)] and specificity [92.6\% (95\% CI 90-94.5)] of HBeAg for diagnosis of HBV viremia $\geq 5.3-6.2 \log _{10} \mathrm{IU} / \mathrm{mL}$ [231]. For predicting the risk of mother-to-child transmission, $\mathrm{HBeAg}$ had high sensitivity [99.1\% (95\% CI 61.8-100)], but low specificity [55.7\% (95\% CI 34.0-75.5)]. When restricted to children receiving birth dose vaccine plus HBIG, $\mathrm{HBeAg}$ had a sensitivity of 98.8\% (95\% CI 52.0-100) and specificity of $49.2 \%$ (95\% CI 25.1-73.7). Thus, compared to HBV DNA, HBeAg has high sensitivity but lower specificity for predicting the risk of mother-to-child transmission. HBV DNA quantification is the best method to determine eligibility for tenofovir prophylaxis in pregnant females to prevent MTCT. However, $\mathrm{HBeAg}$ can be used as an alternative test in settings with limited access to HBV DNA quantification [231].

Time of immunoprophylaxis in newborn infants: Newborn infants of HBsAg-positive mothers are exposed to maternal HBV during labor and delivery; those who are born to mothers with high viral loads are exposed to more amounts of maternal viruses. Theoretically, if the maternal viruses can be completely neutralized by the immunoprophylaxis as well as the neonatal innate immunity before they enter into hepatocytes, MTCT will not occur at all. Studies showed that delayed or missed use of HBIG and/or hepatitis B vaccine may increase the likelihood of MTCT [234, 235].

Recent studies showed that, after early (within $1 \mathrm{~h}$ after birth) administration of HBIG and hepatitis B vaccine, MTCT of HBV in infants born to HBeAg-positive mothers was reduced to $1.2-2.4 \%$ [236], much lower than reported rate of $4-10 \%$ in infants who received recommended immunoprophylaxis within 12 or $24 \mathrm{~h}$ after birth[213, 214]. Thus, timely administration of the immunoprophylaxis in newborns is critical for preventing MTCT of HBV.

Other risk factors for MTCT of HBV: Recently, it has been proposed that quantification of HBsAg may predict MTCT of HBV [237, 238]; however, this is controversial [239].

Investigations on the association between HBV genotypes or mutations in the ' $a$ ' determinant of S gene and MTCT remain inconclusive [240].

In addition, studies on the issue of whether cesarean section may reduce MTCT of HBV showed conflicting results [see below].

\section{Recommendations}

MTCT of HBV mainly occurs during labor and delivery. The rate and timing of intra-uterine transmission is not well known and requires further studies (B2).

Known risk factors for MTCT are high maternal HBV DNA level or positive HBeAg status, and suboptimal use of HBIG and/or hepatitis B vaccine after birth. (A1).

\section{Areas of future research}

More studies on searching convincing evidence of in utero transmission are needed.

Whether quantification of HBsAg may predict MTCT of HBV needs to be studied.

The effect of cesarean section in preventing MTCT in females with high viral load or positive $\mathrm{HBeAg}$ if they do not receive antivirals during the trimester of pregnancy. 


\section{Prevention of mother-to-child transmission}

\section{Review of literature}

Mother-to-child transmission (MTCT) of HBV is the leading mode of transmission in endemic populations [231]. The infected children of HBV-infected mothers become a reservoir of infection for subsequent horizontal infection in the community, and the HBV infected females in turn continue maternal-to-infant transmission to their descendants. The prevention of MTCT is the most effective mean of interrupting this vicious cycle, reducing the prevalence of HBV infection in successive generations [241].

\section{Immunoprophylaxis and prevention of MTCT}

Without any intervention, MTCT of HBV is $70-90 \%$ if mother is $\mathrm{HBsAg}$-positive and $\mathrm{HBeAg}$-positive; and 10-30\% if mother is HBsAg-positive only [241]. Timely hepatitis B vaccination birth dose (HepB birth dose) alone is 70-95\% effective in preventing MTCT [241-243]. Timely HepB birth dose plus the completion of hepatitis $\mathrm{B}$ vaccine series is $>95 \%$ effective in preventing MTCT [242].

Thus, all infants should receive the first dose of hepatitis B vaccine as soon as possible (preferably within $24 \mathrm{~h}$ ) after birth, followed by completion of the vaccination series. In the case of preterm babies, the birth dose should be given even if the baby weight is $<2 \mathrm{~kg}$, but should be followed by a further three vaccine doses starting at 6 weeks of age [244]. This is because the hepatitis B vaccine has reduced immunogenicity in preterms with $<2 \mathrm{~kg}$ weight [245].

Many studies including Cochrane systematic reviews indicate that combination of Hepatitis B vaccine with HBIG is more efficient in reducing MTCT prevalence than vaccine or HBIG alone [246, 247].

One systematic review found that 200 IU HBIG had equivalent effectiveness to $100 \mathrm{IU}$ HBIG in infants born to $\mathrm{HBsAg}$-positive mothers for preventing HBV infection [rela-

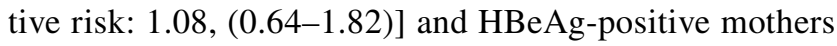
[relative risk: $0.84(0.39-1.77)$ ] [248].

Although a combination of $\mathrm{HBV}$ vaccine plus HBIG is the optimum strategy to prevent HBV infection in babies of HBsAg-positive mothers, utility of addition of HBIG to vaccine in babies of $\mathrm{HBeAg}$-negative mothers is unclear. One recent meta-analysis concluded that $\mathrm{HBV}$ vaccine alone is equally effective to vaccine plus HBIG for neonates of $\mathrm{HBeAg}$-negative chronic HBV-infected mothers in preventing MTCT of HBV infection [249]. In full-term neonates born to $\mathrm{HBeAg}$-negative chronic HBV infected mothers, protection against MTCT of HBV infection achieved by timely HBV vaccination may not be significantly improved by additional HBIG use [231]. Moreover, due to cost, supply, and safety issues, HBIG use may not be feasible in many regions. It has been shown that HBV vaccine without HBIG has a protective efficacy of $70-95 \%$ in HBeAg-positive chronic HBV-infected mothers also [250]. These findings support the use of hepatitis $B$ vaccine alone in settings where use of HBIG is not feasible. Very recently, it was reported that a free-immunoglobulin alternative strategy using $\mathrm{HBeAg}$ RDT/ALT algorithm to assess eligibility for TDF prophylaxis associated with an early vaccination in delivery room could reduce HBV MTCT to $1.48 \%$ [95\% CI 0.40-3.74] for TDF-eligible pregnant female, $0 \%$ [95\% CI 0-1.41] for those treated more than 1 month, and to $1.06 \%$ [95\% CI 0.39-2.30] for not TDF-eligible female [251].

\section{Antiviral therapy for the prevention of MTCT}

Antivirals can be useful in HBsAg-positive pregnant female as an additional measure to prevent MTCT of HBV. A WHO-commissioned systematic review and meta-analysis (included 129 studies) found that antivirals had protective effect in preventing MTCT [TDF $300 \mathrm{mg}$ : odds ratio (OR) $0.16,95 \%$ CI $0.10-0.26$; lamivudine $100 \mathrm{mg}$ : OR $0.17,95 \%$ CI $0.13-0.22$; and telbivudine $600 \mathrm{mg}$ : OR $0.10,95 \%$ CI 0.08-0.13]. TDF has a high barrier to drug resistance, and should be the first choice.. All studies in the meta-analysis included HBIG in both trial arms (except six studies, in which the use of HBIG was not reported) [231]. Another systematic review and meta-analysis on 7463 studies also concluded that peripartum antiviral prophylaxis is highly effective, specifically TDF, for the prevention of HBV MTCT [252].

Also there was no adverse effects of maternal TDF prophylaxis on infant bone mineral density at 1 year of age [231].

The maternal HBV DNA levels above which maternal NAs treatment should be started for preventing MTCT is $\geq 200,000 \mathrm{IU} / \mathrm{mL}$ or $\geq 5.3 \log _{10} \mathrm{IU} / \mathrm{mL}$. HBV DNA quantification is the best method to determine eligibility for TDF prophylaxis in HBsAg-positive mothers for prevention of MTCT. However, $\mathrm{HBeAg}$ can be used as an alternative test in settings with limited access to HBV DNA quantification [231].

HBeAg RDTs could also represent an option to identify females at risk of transmission [253]. The overall sensitivity of identifying high viremia with RDTs is lower as compared to the laboratory enzyme immunoassay techniques [254]. Nevertheless, their possible use in decentralized areas is a major advantage for many countries in the region where it is not possible to have access to enzymatic techniques or viral load quantification outside the capital city.

In many countries, $\mathrm{HBeAg-negative} \mathrm{chronic} \mathrm{HBV}$ infections are common. $\mathrm{HBeAg}$-negative chronic $\mathrm{HBV}$ infection is characterized by the lack of serum $\mathrm{HBeAg}$, persistent or fluctuating moderate to high levels of serum HBV DNA 
and fluctuating or persistently elevated ALT values, mainly because of mutations in the basal core promoter (BCP) and precore (PC) genes responsible for down-regulation of $\mathrm{HBeAg}$ production. Adding ALT measurement for HBeAgnegative pregnant females could represent an option to identify pregnant female with $\mathrm{HBe} \mathrm{Ag}$-negative chronic hepatitis $B$ at risk of high HBV DNA as reported in Cambodia [255].

Recently, it has been proposed that quantification of HBsAg may predict MTCT of HBV [237, 238]; however, others reported different results [239]. HBsAg level $>4.0$ $\log _{10} \mathrm{IU} / \mathrm{mL}$ has been suggested as a cut-off to start antiviral prophylaxis to prevent MTCT of HBV [237], as high maternal HBsAg level has been associated with higher risk of HBV immunoprophylaxis failure in some studies [238]. However, the correlation of HBsAg level with maternal HBV DNA level was not found in many studies [239]. Further prospective studies are needed before introduction of HBsAg quantification as a reliable test in pregnant females for eligibility of maternal NAs prophylaxis to prevent MTCT of HBV [215].

Varying schedules have been suggested to start and stop peripartum antiviral prophylaxis, ranging from starting at 24-28 to 28-32 weeks of gestation, and from stopping at delivery to 12 weeks postpartum [192, 231]. The WHO meta-analysis found that effectiveness of TDF prophylaxis for preventing MTCT was similar irrespective of the timing of start of TDF: TDF prophylaxis starting at $<28$ weeks (OR 0.10, 95\% CI 0.04-0.25), 28 weeks (OR 0.24, 95\% CI $0.13-0.44$ ), or $>28$ weeks (OR $0.09,95 \%$ CI $0.02-0.32$ ) [231]. Some studies suggest that earlier start of NAs, i.e., in the second trimester, might be more efficacious than in the third trimester as this might lead to greater viral load reduction in females treated earlier [252]. A Bayesian network meta-analysis and system review showed that the risk of MTCT decreased significantly in pregnant females accepting intervention before 28 weeks of gestation, as compared to those initiating after 28 weeks [relative risk: 0.019, (0.00034-0.19)] [256]. In the recent PROHM study, HBV transmission rate was $6.52 \%$ [1.37-17.9] for those treated less than 1 month as compared to $0 \%$ [95\% CI 0-1.41] for those treated more than 1 month [251].

There has been some concern that NA (used for MTCT prevention only) withdrawal at or after delivery might increase the risk of postpartum flares [197]. The WHO meta-analysis found that $8 \%$ of the mothers receiving TDF during pregnancy experienced a flare after discontinuation, compared with $6 \%$ of mothers who did not receive TDF at a matched time-point. This suggests that discontinuation of TDF prophylaxis might not increase the risk of flare [risk difference: 0.00 (95\%CI 0.04-0.04)] [231]. Most flares are mild and self-limiting; only a few require antiviral therapy $[184,257]$. Another meta-analysis found similar rate of hepatitis flare among mothers discontinuing antiviral treatment immediately after delivery, 4 weeks postpartum, and 12 weeks postpartum [258]. Thus, HBsAg-positive pregnant females receiving antivirals for MTCT prevention can discontinue antiviral treatment immediately after delivery or continue up to 12 weeks postpartum. HBV DNA could rebound after antiviral discontinuation; close monitoring should be done and antiviral treatment can be considered if meeting treatment indications for therapy [259].

One study found that 6 weeks postpartum is the peak period of hepatitis flares, and $96.0 \%$ of the hepatitis flares occurred within 24 weeks postpartum. Therefore, followup to at least 24 weeks postpartum after discontinuation of antivirals (used for MTCT only) should be done [260]. One study on chronic hepatitis B virus-infected females who received telbivudine beginning at week 24 or 28 of gestation and followed up to 52 weeks postpartum found that, compared with female having a normal ALT level throughout pregnancy, those with elevated ALT had a significantly higher rate of ALT flare after telbivudine withdrawal (25.0\% vs $11.9 \% ; p=0.039$ ). And females with elevated ALT during pregnancy who continued antiviral treatment to 52 weeks postpartum had a significantly higher HBeAg seroconversion and decline in HBsAg levels [261]. Thus, pregnant females with ALT flares during pregnancy should undergo monitoring and continue long-term antiviral treatment after delivery, and stopping rules as per guidelines for other chronic HBV-infected patients should be followed. Females with evidence of advanced liver fibrosis/cirrhosis should also continue long-term antiviral treatment after delivery, and stopping rules as per guidelines for other chronic HBVinfected patients should be followed [259].

Recent studies have found that children with and without fetal exposure to TDF during late pregnancy to prevent maternal transmission of HBV had comparable long-term growth, renal function, and bone development, assessed by serum bone metabolism markers and DXA scans, up to 6-7 years of age [262].

\section{Recommendations}

All newborns should receive their first dose of hepatitis B vaccine as soon as possible after birth, preferably within $24 \mathrm{~h}$. The birth dose should be followed by three doses to complete the primary series (A1).

HBIG prophylaxis, in conjunction with HBV vaccination, may be of additional benefit for newborn infants whose mothers are HBsAg positive and also $\mathrm{HBeAg}$ positive. In full-term neonates born to mothers who are HBsAg positive but $\mathrm{HBe} A g$ negative, protection against perinatally acquired infection achieved by immediate vaccination against HBV (given within $24 \mathrm{~h}$ ) may not be significantly improved by the addition of HBIG (B1). 
Pregnant females testing $\mathrm{HBsAg}$ positive with an $\mathrm{HBV}$ DNA $\geq 5.3 \log 10 \mathrm{IU} / \mathrm{mL}(\geq 200,000 \mathrm{IU} / \mathrm{mL})$ should receive antiviral prophylaxis for prevention of mother-to-child transmission of HBV. This is in addition to appropriate immunoprophylaxis (B1).

In settings in which antenatal HBV DNA testing is not available, $\mathrm{HBeAg}$ testing can be used as an alternative to HBV DNA testing to determine eligibility for tenofovir prophylaxis to prevent mother-to-child transmission of HBV (B2).

Tenofovir disoproxil fumarate (TDF) is recommended for pregnant females with HBV requiring antiviral prophylaxis for prevention of mother-to-child transmission of HBV (B1).

The antiviral should be initiated at 24-28 weeks of gestation for preventing MTCT. For pregnant females with high viremia who are visiting the hospital after 28 weeks of gestation, antiviral intervention should be initiated immediately. The pregnant mothers should be made aware of the intra-uterine risk of HBV transmission, even with low HBV DNA levels, and can be given a choice of starting antiviral therapy from the first trimester of pregnancy (C2).

Pregnant females taking antivirals for preventing MTCT only can discontinue antiviral treatment immediately after delivery or continue up to 12 weeks postpartum (C2), and should be monitored closely for hepatitis flare and rebound of HBV DNA till at least 24 weeks (C2).

Pregnant females with ALT flares during pregnancy or evidence of advanced liver fibrosis or cirrhosis should continue long-term antiviral treatment after delivery, and stopping rules as per guidelines for $\mathrm{CHB}$ patients should be followed (C1).

Follow-up to at least 24 weeks postpartum after discontinuation of antivirals (used for MTCT only) should be done (C1).

\section{Areas of future research}

Use of HBsAg level and $\mathrm{HBeAg}$ testing as a cost-effective alternative to HBV DNA viral load measurement to determine eligibility for antiviral prophylaxis for MTCT of HBV needs to be studied.

When to stop antivirals after delivery in female and how to follow up such females remain to be studied.

Data regarding the maternal and infant safety of TAF in pregnant females with chronic hepatitis B and the efficacy to prevent MTCT of hepatitis B need to be generated.

Development of RDTs for HBeAg with higher diagnostic accuracy, and evaluation of the performance of HBeAg tests in the presence of co-infection with HIV, HCV, and HDV and in different genotypes are needed.

\section{Safety of invasive obstetric procedures in the pregnant females with hepatitis B virus infection in terms of mother-to-child transmission and optimum mode of delivery in HBsAg-positive mother}

\section{Review of literature}

Invasive procedures during pregnancy such as amniocentesis, chorionic villus sampling, fetal blood sampling, and minimally invasive or open fetal surgery can contribute to MTCT and immunoprophylaxis failure in the newborns. Thus, appropriate management during these invasive procedures is important to minimize the MTCT risk.

Studies have found that amniocentesis is an independent factor for the intra-uterine transmission of HBV [263, 264]. In one case-control study on infants who were born to HBsAg-positive mothers without antiviral exposure and completed appropriate immunization, it was found that there were no significant differences in the vertical transmission rates between the amniocentesis group and the control group if the maternal HBV DNA levels were $<6.99$ $\log 10$ copies/ml. However, among mothers with HBV DNA levels $\geq 7 \log 10$ copies $/ \mathrm{ml}\left(\geq 2 \times 10^{6} \mathrm{IU} / \mathrm{ml}\right)$, a significantly higher vertical transmission rate was seen in the amniocentesis group vs. the control group (50\% vs. $4.5 \%$, respectively, $p=0.006$ ) [263]. In a recent large retrospective study, $143 \mathrm{HBsAg}$-positive females with amniocentesis were compared with 605matched (based on maternal viral loads, antiviral therapy regimens, and delivery dates) nonamniocentesis cases. Pregnant females with serum HBV DNA $\geq 1.0 \times 10^{6}(6.0 \log 10) \mathrm{IU} / \mathrm{ml}$ were offered antiviral therapy. MTCT rate was significantly higher in the females undergoing amniocentesis as compared to those not undergoing amniocentesis (2.80\% vs. $0.50 \%$; RR, $5.64,95 \%$ CI 1.28-24.93). In the amniocentesis group, maternal HBV DNA $\geq 7.0 \log 10 \mathrm{IU} / \mathrm{ml}$ and $\mathrm{HBeAg}$ positivity were associated with higher MTCT rates; and antiviral therapy reduced MTCT rate from 14.3 to $0 \%(p=0.554)$ when maternal HBV DNA was $\geq 7.0 \log 10 \mathrm{IU} / \mathrm{ml}$ [265]. Thus, for HBsAgpositive mothers planned for invasive procedures such as amniocentesis, counseling should include the risk of MTCT of HBV if the serum HBV DNA is $>7.0 \log 10 \mathrm{IU} /$ $\mathrm{mL}$ [266].

The risk and benefit of antiviral prophylaxis in the prevention of MTCT of HBV in highly viremic pregnant mothers, before or immediately after invasive procedures including amniocentesis, remain largely unknown. Available data were very limited in the literature. Besides, the starting and stopping points of maternal treatment for short-term NAs prophylaxis also remain unclarified. 
Non-invasive alternatives should be explored in mothers who require prenatal invasive diagnostic procedures. Among females who need invasive testing, amniocentesis is preferable to chorionic villus sampling. Transplacental amniocentesis should be avoided. The risks and benefits of any invasive procedures should be explained to the patient and informed consent obtained [267].

The major route of perinatal HBV transmission is due to newborn's contact with the HBsAg-positive mother's blood or secretions during delivery. Despite administration of birth dose HBV vaccine plus HBIG, some transmission risk remains for mothers with high HBV DNA levels [See above]. The method of delivery that minimizes the likelihood of MTCT of HBV remains a controversial issue. Recent studies demonstrated a lower risk of HBV transmission with elective cesarean section compared with vaginal delivery. A recent meta-analysis [268] comparing the risk of MTCT of HBV between vaginal delivery versus cesarean section delivery concluded that the risk of HBV infection in cesarean births was significantly lower than that of vaginal delivery in mothers without antiviral prophylaxis during pregnancy. Fortunately at present, for pregnant mothers with high viral load detected during delivery, the risk of MTCT of HBV can be minimized through application of antiviral agent early during third trimester [see above]. Cesarean section should not be performed for the sole indication of reducing risk of vertical HBV transmission.

\section{Recommendations}

The risk of intra-uterine HBV transmission in pregnant mothers with high serum HBV DNA level ( $\geq 7 \log 10 \mathrm{IU} /$ $\mathrm{mL}$ ) and planned for invasive genetic testing procedures such as amniocentesis should be discussed with the pregnant mother and relatives; weighing of the benefits and harms is needed (C2).

Cesarean section should not be performed for the sole indication of reducing risk of vertical HBV transmission (C1).

\section{Areas of future research}

Further prospective studies on risk factors of HBV transmission in pregnant females undergoing invasive procedures like amniocentesis, and the effect of antiviral therapy on the HBV transmission in such mothers are needed.

\section{Assisted conception in chronic hepatitis $B$ virus-infected females in terms of mother-to-child transmission}

\section{Review of literature}

Couples seeking help for assisted conception may be infected with chronic hepatitis B virus. They cannot be denied access to the assisted reproductive technology (ART). For many of them, access to such services may be restricted on ethical, geographical, and financial grounds. They may be avoiding unprotected intercourse using condoms to minimize the risk of infecting their partner. The direct threat to their health can be reduced or eliminated by a modification of practices, guidance, and procedures. Assisted procreation may be required for safe conception if the viral infection cannot be effectively treated or if the couple needs fertility treatments because of an infertility diagnosis (e.g., low sperm counts).

Several assisted reproduction procedures, such as in vitro fertilization (IVF) and intra-cytoplasmic sperm injection (ICSI), are available. Fertility clinics screen patients for blood-borne viral infections, including HBV to prevent vertical transmission and for laboratory safety. From the ethical point of view, there is no reason to advise against assisted reproduction treatment in HBsAg-positive individuals [269]. However, limited access to specialist clinics equipped to cater for these couples and restricted funding may impact negatively couples obtaining risk-reducing assisted reproduction treatment.

\section{Effect of female chronic HBV infection on pregnancy outcomes in assisted reproduction}

It has been shown that HBV exists in ovarian tissues (including oocyte and follicular fluid), and can pass the zona pellucida. Therefore, a potential risk of transmission to the embryo exists, which could explain the finding of MTCT despite immunoprophylaxis [270]. In one study, HBsAg was detected in the nuclei and cytoplasm of oocytes and embryos in 6 of $10 \mathrm{HBsAg}$-negative male/HBsAg-positive female couples (and in 13 of 20 oocytes and embryos) [271]. In another study, the rates of positivity in oocytes and embryos were higher in females with high serum levels of HBV DNA levels; and also in females with HBsAg-positive mothers [272].

Some studies have shown lower rates of fertilization, cleavage, high-quality embryos, and pregnancy in chronic HBV-infected infertile females as compared to non-infected females [273, 274]. Although lower ovarian reserve; and lower rates of fertilization and high-quality embryos have been found in females with HBV DNA levels $\geq 5 \times 10^{2} \mathrm{IU} /$ $\mathrm{mL}$ [275], one systematic review showed that among 
infertile females with chronic HBV infection undergoing assisted reproduction, there was slightly lower rates of fertilization, but similar rates of cleavage, high-quality embryos, implantation, pregnancy, and abortion, as compared to infertile females without chronic HBV infection [276].

Most studies suggest that the risk of maternal vertical HBV transmission during an IVF procedure is similar to that with spontaneous conception and pregnancy [277-279]. One study on 12 babies born to couples with HBV-positive oocytes and/or embryos found that the presence of HBsAg in oocytes and embryos might not result in the vertical transmission of HBV in the offspring of chronic HBV-infected mothers [279]. A study on $251 \mathrm{HBsAg-positive} \mathrm{females}$ (305 children, 176 born with assisted conception, and 129 born with natural conception; $7.5 \%$ of children were $\mathrm{HBsAg}$ positive at birth), found that HBsAg positivity rate among children at birth was similar in the assisted conception group and the natural conception group (6.3\% vs. 9.3\%) [280].

\section{Effect of chronic HBV on male fertility and pregnancy outcome}

Chronic HBV infection can adversely affect male fertility, specifically sperm count, and progressive motility. HBV exposure could lead to reactive oxygen species generation, lipid peroxidation, reduction of total antioxidant capacity, activation of caspases, and DNA fragmentation, resulting in increased apoptosis of sperm cells and loss of sperm membrane integrity and causing sperm dysfunctions [281]. Results of one study suggested that chronic HBV infection in male was associated with poor sperm quality. There were increased rates of asthenozoospermia and oligozoospermia/azoospermia. The embryo transfer outcomes and clinical pregnancy rates in ICSI cycles were decreased, but do not affect the outcome of IVF [282]. One study reported that the percentage of normal sperm morphology in HBVseropositive husbands was significantly lower than that of seronegative counterparts (5.0\% versus $10.0 \%, p=0.009$ ). However, there was no adverse effect of chronic HBV infection on the assisted reproduction outcomes [278]. Another study addressing the effect of male chronic HBV infection on outcomes of IVF and embryo transfer treatment included the 215 couples undergoing their first oocyte donation cycles, 19 couples with seropositive husbands/seronegative wives had lower implantation rate, and lower clinical pregnancy rate, but the difference was not statistically significant [283].

HBV can integrate into sperm chromosomes, causing mutagenic effects, and there is the possibility of vertical transmission of HBV via the germ cells [284]. This finding supports the assumption that human sperm cells may act as vectors for the vertical transmission of HBV genes via the germline to progeny [285]. These findings make the sperm washing procedures to remove seminal plasma for reducing the vertical transmission risk debatable. However, the vaccination of female partners against hepatitis B may eliminate the risk of transmission to the mother as well as to the fetus [286].

\section{Microbial contamination of the IVF system}

In the embryology laboratory, microbial contamination of the IVF system deserves attention. Cross-contamination of samples is possible within liquid nitrogen storage tanks, since HBV can survive in liquid nitrogen [287]. It can be prevented using sterile techniques and supplementing culture media with screened sera or serum substitutes and antibiotics. Persons whose biological material is to be cryopreserved should be screened for HBV, HCV, and HIV, and separate containers should be used for infected and non-infected material. One study failed to detect viral sequencing from the spent culture media and liquid nitrogen samples of oocytes and embryos from hepatitis B infected females [288].

\section{Recommendations}

Assisted reproduction could be done following the same guidelines as in other pregnant females with chronic HBV infection (C2).

\section{Areas of future research}

Effect of maternal HBV DNA levels on rate of fertilization, rate of cleavage, quality of embryos, implantation, pregnancy, abortion, and rate of vertical transmission among infertile females with CHBV infection undergoing assisted reproduction requires further large-scale studies.

\section{Postpartum follow-up of children of chronic HBV-infected mothers}

\section{Review of literature}

Infants should be given appropriate immunoprophylaxis [see above]. Although a combination of active and passive immune prophylaxis is the optimum strategy to prevent HBV infection in babies of $\mathrm{HBsAg}$-positive mothers, its utility in $\mathrm{HBeAg}$-negative mothers is uncertain [see above].

Follow-up of infants born to HBsAg-positive mothers, including the post-vaccination serological testing, is important. Although routine post-vaccination testing is not necessary, it is important for babies born to HBsAg positive, and should be done at 9-18 months of age, 1-2 months after the last dose of HBV vaccine [289].

The post-vaccination serological testing should include HBsAg and anti-HBs titer tests. Passive immunization with 
HBIG may result in positive anti-HBs levels before 9 months of age [290]. Adequate protection is indicated by the antiHBs levels of more than $10 \mathrm{mIU} / \mathrm{mL}$. Revaccination with the entire 3 dose schedule should be done in babies with anti-HBs levels of less than $10 \mathrm{mIU} / \mathrm{mL}$. Babies who are HBsAg positive need appropriate follow-up and management. Anti HBc testing should not be done as it may remain positive up to 2 years of age in babies born to HBAg-positive mothers [290].

More than $95 \%$ of healthy newborns respond to a 3 dose vaccine series, and almost all respond to revaccination. However, there are no data regarding the utility of revaccination in babies showing undetectable anti-HBs levels even after $6 \mathrm{HBV}$ vaccine [291].

\section{Recommendations}

All children born to HBsAg-positive mothers should be tested at ages 9-18 months for seroconversion (with HBsAg and anti-HBs titers), at least 1 month after the last dose of vaccine (B1).

\section{Areas of future research}

Strategies for babies who do not develop protective antibodies even after revaccination need to be studied.

\section{Breastfeeding in hepatitis B virus-infected mothers}

\section{Review of literature}

Beneficial effects of breastfeeding for the children and the mothers are well known. Besides fostering the close emotional bond through mother-to-infant contact, breastfeeding has been shown to be associated with a significant reduction in hospitalization rates (from gastroenteritis, respiratory infections, and sepsis) in the initial few months after birth; better infant and childhood survival especially in lowresource countries [292, 293]. Prolonged breastfeeding has been associated with improved cognitive function in older children; lower cholesterol levels and body mass index; and lower incidence of obesity and type 2 diabetes among older children and adults [292, 293]. Mothers who breastfeed have shorter recovery time, less anemia (due to oxytocinstimulated uterus contraction), and reduced risk of obesity, breast cancer, ovarian cancer, and osteoporosis in the long term [294, 295].

Although some older studies had found HBsAg, HBeAg, and HBV DNA in breast milk (both colostral HBsAg and $\mathrm{HBeAg}$ titers correlated positively with the corresponding level in maternal blood) [296, 297], clinical studies have failed to demonstrate breastfeeding as a contributor to MTCT of HBV. In a meta-analysis of 10 prospective controlled trials (751 infants in the breastfeeding group and 873 infants in the non-breastfeeding group), there was no significant difference in MTCT of HBV (i.e., infant peripheral blood HBsAg or HBV DNA positivity at age 6-12 months), between the breastfeeding and the non-breastfeeding group [OR: 0.86 (95\% CI 0.51-1.45), $p=0.56$ ]. The rate of antiHBs development was also similar between the two groups [OR: 0.98 (95\% CI 0.69-1.40), $p=0.99$ ). Thus, breastfeeding (without cracked or bleeding nipples or lesions) does not contribute to MTCT of HBV after proper immunoprophylaxis in the infants [298]. The majority of studies were not randomized controlled; and did not study HBV markers in the breast milk or HBV DNA levels in newborns and the mothers. Also, correlation between the rate of MTCT and the duration of breastfeeding has not been studied.

Lactoferrin present in the human milk has antiviral activity against various viruses including HBV, HCV, and HIV [299, 300]. Milk stasis and breast engorgement (resulting from irregular or non-exclusive breastfeeding) have been shown to increase the epithelial permeability, more efficient para-cellular transfer of HIV, and increased HIV RNA in breast milk [301]. Whether the same applies to HBV is unknown. Thus, exclusive breastfeeding needs to be promoted especially in regions with low socio-economic standards, given the beneficial effects of exclusive breastfeeding on morbidity and mortality of the babies.

Another important consideration is the safety of antivirals taken by the breastfeeding mothers for the babies, Among HIV-positive mothers treated with lamivudine $300 \mathrm{mg} /$ day, although the mean concentration of lamivudine in the breast milk was slightly higher $(1.8 \mathrm{mg} / \mathrm{mL})$ as compared to that in maternal serum $(0.7 \mathrm{mg} / \mathrm{mL})$, the mean concentration of lamivudine was very low in the infant's serum $(0.03 \mathrm{mg} /$ $\mathrm{mL}$ ), indicating minimal absorption of lamivudine in the infants [302]. Although transient and asymptomatic hematological toxicity has been observed in HAART-exposed infants (15.9\% neutropenia at 1 month of age vs $3.7 \%$ in unexposed group), there were no differences in hematological and hepatic toxicity between breast-fed and formula-fed infants from 2 to 6 months postpartum [303].

Tenofovir disoproxil fumarate (TDF) is a prodrug of tenofovir. After being administered orally, TDF is quickly absorbed from the gut and is converted into tenofovir. As very low level of tenofovir is present in the breast milk and tenofovir also has poor absorption from the GIT, the concentration of tenofovir in infant's blood is very low. Among HIV-infected mothers on long-term treatment including $300 \mathrm{mg}$ oral TDF, very low median tenofovir blood concentrations in the infants have been found $(24 \mathrm{ng} / \mathrm{ml}$ and $0 \mathrm{ng} /$ $\mathrm{ml}$ at 6 and 12 months of age, respectively) [304]. In another study on HIV-positive mothers treated with $300 \mathrm{mg}$ TDF, 
none of the infants had a measurable tenofovir concentration in their blood [305].

Tenofovir concentrations in breast milk are also very low. In one study on HIV-infected mothers taking TDF $300 \mathrm{mg}$ daily, median concentration of tenofovir in the breast milk was $5.0 \mathrm{ng} / \mathrm{ml}$ at 1 month and $2.5 \mathrm{ng} / \mathrm{ml}$ at 12 months postpartum [304]. Another study reported median maximum concentration to be $6.0 \mathrm{ng} / \mathrm{ml}$ at 101 days (range 81-146) and 143 days (range 80-125) after delivery [305]. For comparison, the mothers taking TDF at a dose of $300 \mathrm{mg}$ per day, the maternal plasma maximum tenofovir concentration during pregnancy ranged from 245 to $280 \mathrm{ng} / \mathrm{ml}$ [306]. Therefore, breast-fed infants experience much lower drug exposure from breast milk [307]. The daily tenofovir dose ingested from breast milk is estimated at $0.4-2.1 \mu \mathrm{g} / \mathrm{kg} / \mathrm{day}$, which represented $0.01-0.04 \%$ of the proposed pediatric therapeutic daily dose of $6 \mathrm{mg} / \mathrm{kg} /$ day [307]. These data from the HIV-infected mothers can be extrapolated to the $\mathrm{HBV}$-infected mothers, as well. As there is negligible exposure to tenofovir of infants from breastfeeding (of mothers on TDF treatment), breastfeeding should be continued in females receiving TDF.

Tenofovir alafenamide fumarate (TAF), is a new oral prodrug of tenofovir. As compared to TDF, TAF delivers targeted increased intracellular levels of tenofovir, thus reducing the circulating tenofovir exposure. The enhanced safety profile of TAF makes it the ideal antiviral to use in pregnant and breastfeeding HBsAg-positive mothers.

\section{Recommendations}

Breastfeeding should be encouraged, as without cracked or bleeding nipples or lesions, breastfeeding does not contribute to MTCT of HBV after proper immunoprophylaxis in the infants (B1).

Breastfeeding should not be contraindicated in females receiving tenofovir for prophylaxis or treatment of $\mathrm{HBV}$, and mothers on TDF treatment should be encouraged to breastfeed (B1).

\section{Areas of future research}

If irregular or non-exclusive breastfeeding contributes to increased infectivity of human milk in HBV-infected mothers, needs evaluation.

Anti-HBV effects of components of breast milk, and the mechanisms of no additional risk of MTCT caused by breastfeeding need to be studied.

To properly evaluate the role of breastfeeding in HBV MTCT, more randomized controlled trials with detailed breast milk HBV marker testing and HBV DNA levels in mother/child blood and duration of breastfeeding are needed.
Data on whether a woman on entecavir safely breast feed are lacking.

Figure 1 shows the overall algorithm of maternal and infant management of pregnant females found to be $\mathrm{HBsAg}$ positive first time during $\mathrm{HBsAg}$ screening during pregnancy or previously known chronic $\mathrm{HBs} A g$-positive females who become pregnant (and are not on long-term antivirals). Figure 2 shows the overall algorithm of maternal and infant management of previously known chronic HBsAg-positive females who become pregnant and are already on long-term antivirals.

\section{Public health aspects of HBV infection in pregnancy}

\section{Review of literature}

Hepatitis B is still a major cause of morbidity and mortality due to liver diseases in the Asia-Pacific region. The burden of HBV infection remains disproportionately high in low- and middle-income countries, with most cases occurring from infection acquired soon after birth or during early childhood [308]. The World Health Assembly endorsed the Global Health Sector Strategy (GHSS) on viral hepatitis in May 2016, and proposed to eliminate viral hepatitis as a public health threat by 2030 [4]. Elimination is defined as a $90 \%$ reduction in incidence and a $65 \%$ reduction in mortality, compared with the 2015 baseline. The prevalence of HBsAg in children under 5 years of age is considered a surrogate indicator of the cumulative incidence of chronic HBV infections, and reduction in the prevalence of HBsAg in children under 5 years to $<0.1 \%$ by 2030 is one of the global targets [4]. Other global targets for 2030 include $90 \%$ coverage of timely HepB birth dose vaccination and $90 \%$ coverage of HepB3 [4].

WHO had recommended to include the hepatitis B vaccine in the Expanded Programme on Immunization (EPI) in 1992 [309]. In 2017, the latest update of the WHO position paper recommended for the universal immunization of infants (with three or four doses of hepatitis B vaccine), and giving the first dose of hepatitis B vaccine within $24 \mathrm{~h}$ after birth [310]. The birth dose of hepatitis B vaccine should be given as early as possible. If the immunization service is not located in the same health facility (like private clinics, home delivery), it could delay the first vaccine injection, as reported in Cambodia [311]. Injection of the first dose of vaccine just after birth in delivery room could be an effective public health measure by avoiding missed opportunities. Universal immunization of infants with hepatitis B vaccine, including a timely birth dose, is the most effective intervention to prevent MTCT. Other interventions to reduce MTCT 


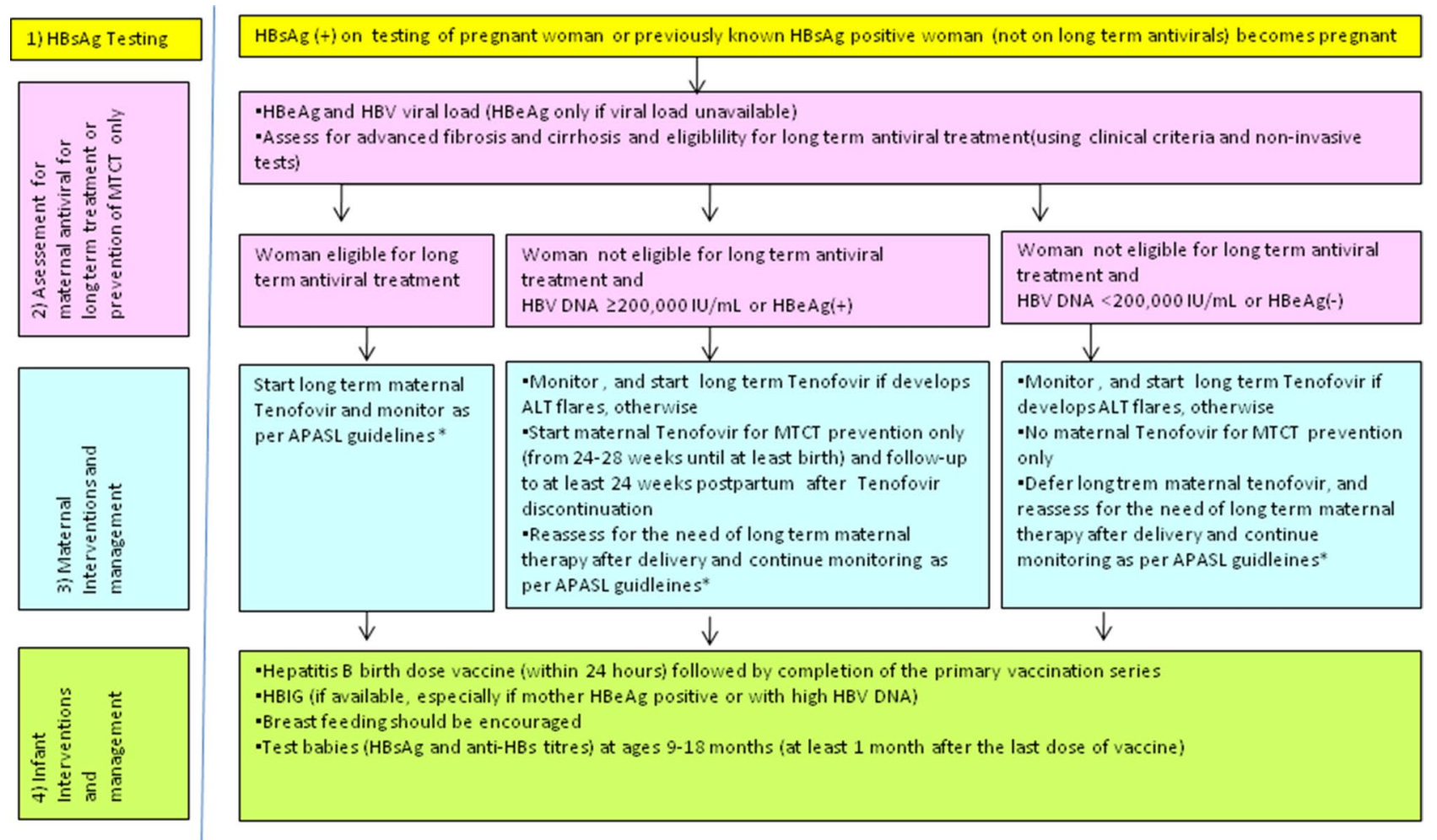

*Asian-Pacific clinical practice guidelines on the management of hepatitis B: a 2015 update [Reference 259]

Fig. 1 Algorithm of maternal and infant management of pregnant females found to be HBsAg-positive first time during HBsAg screening during pregnancy or previously known chronic HBsAg-positive females who become pregnant (and are not on long-term antivirals)

of hepatitis B virus can be implemented using this as the base (Fig. 3) [231].

\section{HBsAg screening of pregnant females}

Universal HBsAg screening of pregnant females is being conducted in many regions and countries of the world, but is not done in resource-limited regions and countries [312]. Many countries have adopted routine screening of all pregnant females, regardless of the HBsAg seroprevalence in the general population [313]. Testing should be done as early as possible during pregnancy, so that appropriate measures can be undertaken for the management of the mother, and to reduce the risk of MTCT. If not done during pregnancy, screening can also be performed during labor or after delivery. Laboratory-based immunoassays are the preferred assays. In settings with limited access to laboratory testing and/or where access to rapid testing would facilitate linkage to care and treatment, rapid diagnostic tests (RDTs) can be used to improve access. According to WHO, in regions with $\geq 0.4 \%$ of $\mathrm{HBsAg}$ prevalence, further virological evaluation and staging of liver disease can be started after a single positive serological assay $\mathrm{HBs} A g$ detection. In regions with $<0.4 \% \mathrm{HBsAg}$ prevalence, confirmation of HBsAg positivity on the same immunoassay with a neutralization step or a second different RDT assay should be considered [313].

The offering HBV testing alongside existing HIV services should be considered for scaling up HBV testing for pregnant females and their partners [231].

Pregnant females found to be HBsAg positive during screening should be tested HBV DNA or HBeAg or both, along with assessment of the severity of the liver disease. High levels of HBV DNA ( $\geq 200,000 \mathrm{IU} / \mathrm{mL})$ and/or HBeAg positivity are associated with high risk of MTCT of HBV, and these females are candidates for antiviral therapy for prevention of MTCT. In an important meta-analysis, Ott et al. examined the global prevalence of $\mathrm{HBeAg}$ status in female of child-bearing age in 2005, and found a global prevalence of $24-32 \%$ which had only marginally decreased since 1990 [314]. Consequently, we can surmise that almost $1 / 3$ of females of child-bearing age carry a higher risk of MTCT despite infant immunization and HBIG. In resourcelimited settings, the WHO recommends $\mathrm{HBeAg}$ status to be tested as a surrogate marker for those with high viral load [see above]. 


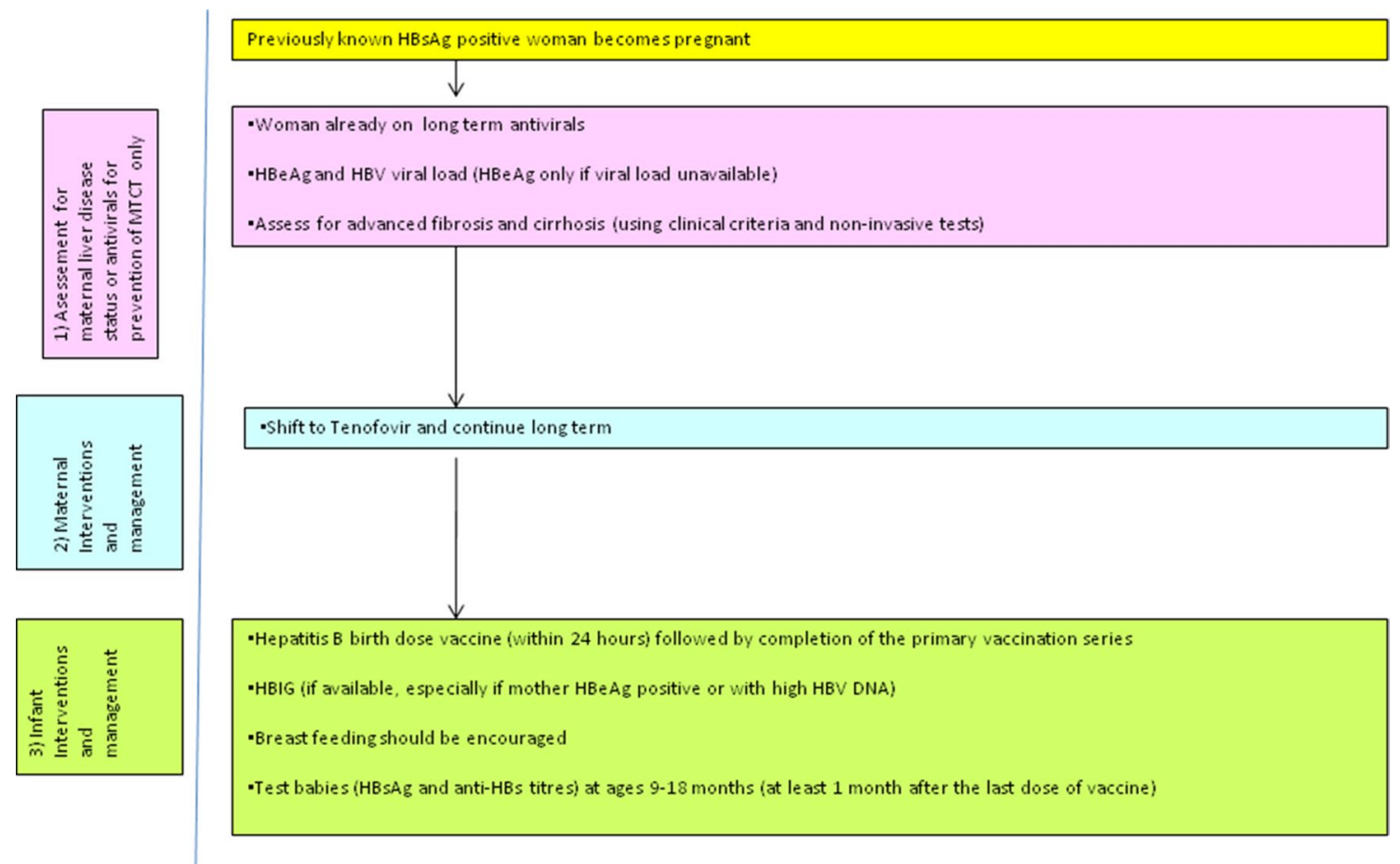

Fig. 2 Algorithm of maternal and infant management of previously known chronic HBsAg-positive females who become pregnant and are already on long-term antivirals

Fig. 3 Incremental epidemiological approaches to prevent mother-to-child transmission of hepatitis B virus infection

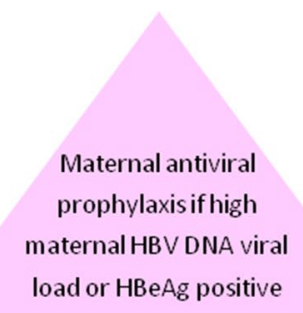

$\mathrm{HBsAg}$ testof pregnant women, linkage to care and follow up of infants; $\mathrm{HBIG}$ for infants born to $\mathrm{HBSAg}+$ and $\mathrm{HBeAg}+$ mothers

Complete hepatitis $\mathrm{B}$ vaccination series including a timely birth dose within 24 hours

HBsAg screening of pregnant females should be accompanied by pre- and post-test counseling. Pre-test information should include: the benefits of early diagnosis of HBV infection for their own health, as well as to reduce the risk of MTCT; and importance of testing for other infections. Posttest information for HBsAg-positive females should include: use of antivirals for the mother if needed; measures to reduce the risk of MTCT of HBV infection; encouraging family and partner screening; encouraging to deliver in a health facility to ensure access to MTCT services; encouraging breastfeeding; and importance of $\mathrm{HBsAg}$ testing for the infant [313].

Linkage to care of the HBsAg-positive mother is also important, to prevent loss to follow up and missing the opportunity to assess liver disease in the mother and the need for antiviral treatment as appropriate. Unvaccinated HBsAg-negative pregnant females can be offered HBV vaccination. Follow-up of HBsAg-positive pregnant females should continue through the postpartum period and beyond as per the clinical situation [313]. 
A higher prevalence of HBV infection in the general population is found among pregnant females from marginalized or stigmatized groups (e.g., people who inject drugs, sex workers) or minority groups (migrants, indigenous populations). They also have poor access to health care. Integrated antenatal services for HBV, HIV, and syphilis provide an opportunity to reach out to marginalized and minority groups. Appropriate measures should be taken to ensure that these groups have access to health services without stigma and discrimination [231, 313].

Appropriate measures should be taken to maintain confidentiality and prevent stigma and discrimination against those females who are found to be HBsAg positive. Healthcare worker training and rights-based frameworks are needed to achieve this [231].

\section{Prevention of mother-to-child transmission of hepatitis B virus}

All infants should receive appropriate immunoprophylaxis as early as possible after birth [see above] [231].

Antivirals as an additional measure to prevent MTCT in selected pregnant females should be used [see above]. Epidemiological and modeling studies have suggested that infant $\mathrm{HBV}$ vaccination alone would be insufficient to reach the $0.1 \%$ HBsAg prevalence goal in children by 2030 [231]. Worldwide, scaling up HBV vaccination to a $90 \%$ coverage of the three-dose hepatitis B vaccine, including timely birth dose, would prevent an additional 14 million new neonatal HBV infections over the next 10 years. Giving tenofovir prophylaxis to eligible pregnant females in addition to the HBV vaccination (including timely birth dose) would prevent an additional 2.9-3.0 million neonatal infections over the same period [231]. HBeAg can be used as an alternative test in settings where access to HBV DNA quantification is limited [See above] [231]. The challenges in providing tenofovir prophylaxis for MTCT prevention in eligible pregnant females include costs and availability of HBV DNA tests and tenofovir, lack of trained health-care workers, and lack of capacity and infrastructure [231].

Use of tenofovir prophylaxis to prevent MTCT in addition to HBV vaccination can reduce health inequities in lowincome regions where HBIG is not feasible. The drug is available within HIV national programs.

However, interventions based on testing of pregnant females followed by tenofovir prophylaxis are costlier than hepatitis B vaccination of infants alone. Therefore, tenofovir prophylaxis in addition to HBV vaccination may not be feasible in low-income regions currently [231].

Scaling up timely birth dose is the most cost-effective option. Countries that have not yet reached the 2020 goal of $1 \% \mathrm{HBsAg}$ prevalence among under 5 children through vaccination should focus on increasing their vaccination coverage, including timely birth dose. Improving HepBbirth dose coverage is a first step as it is still $<90 \%$ in many countries of the Asia-Pacific (Table 2). Birth dose continues to be a challenge for countries with low rates of health facilities deliveries and lack of skilled birth attendants [315]. Community-based interventions can be enhanced by training village health volunteers and expanding HepB-BD in the community by giving birth dose in home in case of home deliveries, as reported from Myanmar. Vaccine out-of-thecold chain is another option [316]. For countries with high rates of health facilities deliveries, providing the first dose of vaccine in delivery room should be considered.

In countries that have already scaled up the timely birth dose, adding antenatal HBsAg testing of pregnant females and tenofovir prophylaxis in eligible females is an additional measure to prevent MTCT which may be cost-effective in some regions [231]. All eligible pregnant and breastfeeding females living with HBV infection can safely use tenofovir [See above].

As reported in Table 2, the majority of countries in Asia-pacific have the capacity to provide HBsAg testing in ANC, but there are not yet effective national screening programs in routine for many of them. For positive $\mathrm{HBsAg}$ pregnant females, availability of HBV DNA and/or $\mathrm{HBeAg}$ testing is a concern for many countries. In these countries, ANC and deliveries are mainly conducted by midwives at the decentralized level (primary health centers, district hospitals) with no access to HBV DNA viral load measurement and immuno-enzymatic tests. The use of $\mathrm{HBeAg}$ rapid diagnosis tests as reported in Cambodia [255] or the use of HBV DNA point of care [317] could improve detection of pregnant females eligible for antivirals for MTCT prevention. Access to immunoglobulin is also limited in many countries of Asia-Pacific (Table 3).

\section{Programmatic considerations}

Strong government leadership, commitment, and multisectoral collaboration with a wide range of stakeholders are needed at all levels. Also, EMTCT of HBV activities must be integrated with the national/regional response to viral hepatitis. Normative guidance (including policies, guidelines, and implementation protocols) is needed for standardized implementation of services.

Civil society involvement in the planning, development, and implementation of the EMTCT programs should be encouraged.

Services delivery of HBV interventions for pregnant females should be guided by the principles of universal health coverage, so that a pregnant woman's ability to pay does not determine her access to available services. Efforts should be made to include HBV EMTCT services in national health insurance schemes to minimize out-of-pocket expenses. 
Table 3 Current status of interventions to eliminate mother-to-child transmission (MTCT) of hepatitis B virus as public health policy in the different countries of Asia-Pacific

\begin{tabular}{|c|c|c|c|c|c|c|}
\hline & $\begin{array}{l}\text { Antenatal testing } \\
\text { for } \mathrm{HBs} \mathrm{Ag}\end{array}$ & $\begin{array}{l}\text { Antenatal testing } \\
\text { for } \mathrm{HBeAg}\end{array}$ & $\begin{array}{l}\text { HBV DNA if } \\
\text { positive HBsAg }\end{array}$ & $\begin{array}{l}\text { Antiviral prophylaxis } \\
\text { for MTCT prevention } \\
\text { (if yes, eligibility) }\end{array}$ & $\begin{array}{l}\text { HBIG for exposed } \\
\text { infants }\end{array}$ & $\begin{array}{l}\text { Post-vaccination } \\
\text { anti-HBs testing }\end{array}$ \\
\hline \multicolumn{7}{|l|}{ North Asia } \\
\hline Russia & Yes & Yes, partially & $\begin{array}{l}\text { Limited. Out of } \\
\text { pocket }\end{array}$ & $\begin{array}{l}\text { Yes, if HBV } \\
\text { DNA }>10^{6} \mathrm{IU} / \mathrm{ml}\end{array}$ & Yes, partially & No \\
\hline \multicolumn{7}{|l|}{ Central Asia } \\
\hline Afghanistan & No & NA & NA & NA & NA & NA \\
\hline Kazakhstan & Yes & No & Yes & NA & NA & No \\
\hline Kyrgyzstan & Yes, partially & No & Yes, partially & $\begin{array}{l}\text { Yes, if HBV } \\
\text { DNA }>10^{7} \mathrm{IU} / \mathrm{ml}\end{array}$ & NA & No \\
\hline Tajikistan & Yes, partially & No & No & No & No & No \\
\hline Turkmenistan & Yes, partially & No & No & No & No & No \\
\hline Uzbekistan & Yes, partially & No & No & No & No & No \\
\hline \multicolumn{7}{|l|}{ Western Asia } \\
\hline Armenia & Yes & Yes, partially & Out of pocket & Out of pocket & $\begin{array}{l}\text { Limited, out of } \\
\text { pocket }\end{array}$ & No \\
\hline Azerbaijan & Yes & No & No & No & No & No \\
\hline Bahrain & Yes & No & No & Out of pocket & Out of pocket & No \\
\hline Cyprus & Yes & No & No & Out of pocket & Out of pocket & No \\
\hline Georgia & Yes & Yes, partially & Out of pocket & Out of pocket & Out of pocket & No \\
\hline Iran & $\begin{array}{l}\text { Yes, if high risk } \\
\text { behavior }\end{array}$ & Yes, partially & $\begin{array}{l}\text { Limited, out of } \\
\text { pocket }\end{array}$ & Out of pocket & Yes & No \\
\hline Iraq & NA & NA & NA & NA & NA & NA \\
\hline Israel & Yes & Yes & $\begin{array}{l}\text { Limited, out of } \\
\text { pocket }\end{array}$ & Out of pocket & Yes & No \\
\hline Jordan & Yes & No & Out of pocket & Out of pocket & Out of pocket & No \\
\hline Kuwait & Yes & Yes, partially & Out of pocket & Out of pocket & Yes & No \\
\hline Oman & Yes & Yes, partially & Out of pocket & Out of pocket & Yes & No \\
\hline Qatar & Yes & Yes, partially & Out of pocket & Out of pocket & Yes & No \\
\hline Saudi Arabia & Yes & Yes, partially & Out of pocket & Out of pocket & Out of pocket & No \\
\hline Syria & NA & NA & NA & NA & NA & NA \\
\hline Turkey & Yes & Yes & No & $\begin{array}{l}\mathrm{HBV} \\
\text { DNA }>200,000 \mathrm{IU} / \\
\text { mL or } \mathrm{HBeAg}+\end{array}$ & Yes & Yes \\
\hline $\begin{array}{l}\text { United Arab } \\
\text { Emirates }\end{array}$ & Yes & Yes & Out of pocket & Out of pocket & Yes & No \\
\hline Yemen & NA & NA & NA & NA & NA & NA \\
\hline \multicolumn{7}{|l|}{ East Asia } \\
\hline China Mainland & Yes & Yes, partially & No & $\begin{array}{l}\text { HBV } \\
\text { DNA > 200,000 IU/ } \\
\text { mL }\end{array}$ & Yes & $\begin{array}{l}\text { 7-9 months, pilot } \\
\text { only }\end{array}$ \\
\hline Mongolia & Yes & Yes & Yes & $\begin{array}{l}\mathrm{HBeAg}(+) \text { with HBV } \\
\text { DNA > 200,000 IU/ } \\
\text { mL }\end{array}$ & $\begin{array}{l}\text { Yes, infants of } \\
\operatorname{HBeAg}(+) \\
\text { mothers only }\end{array}$ & $\begin{array}{l}\text { Yes, } 2 \text { months after } \\
\text { completion of } \\
\text { vaccination }\end{array}$ \\
\hline $\begin{array}{l}\text { South Korea } \\
\text { (Republic of } \\
\text { Korea) }\end{array}$ & Yes & Yes & Yes & $\begin{array}{l}\mathrm{HBV} \\
\text { DNA > 200,000 IU/ } \\
\mathrm{mL}\end{array}$ & Yes & Yes \\
\hline $\begin{array}{l}\text { North Korea } \\
\text { (Democratic } \\
\text { People's } \\
\text { Republic of } \\
\text { Korea) }\end{array}$ & NA & NA & NA & NA & NA & NA \\
\hline Japan & Yes & Yes & Not official policy & Not official policy & Yes & Yes \\
\hline
\end{tabular}


Table 3 (continued)

\begin{tabular}{|c|c|c|c|c|c|c|}
\hline & $\begin{array}{l}\text { Antenatal testing } \\
\text { for } \mathrm{HBsAg}\end{array}$ & $\begin{array}{l}\text { Antenatal testing } \\
\text { for } \mathrm{HBeAg}\end{array}$ & $\begin{array}{l}\text { HBV DNA if } \\
\text { positive HBsAg }\end{array}$ & $\begin{array}{l}\text { Antiviral prophylaxis } \\
\text { for MTCT prevention } \\
\text { (if yes, eligibility) }\end{array}$ & $\begin{array}{l}\text { HBIG for exposed } \\
\text { infants }\end{array}$ & $\begin{array}{l}\text { Post-vaccination } \\
\text { anti-HBs testing }\end{array}$ \\
\hline Taiwan & Yes & Yes & Yes & $\begin{array}{l}\mathrm{HBV} \\
\text { DNA > 200,000 IU/ } \\
\text { mL }\end{array}$ & Yes & Yes \\
\hline \multicolumn{7}{|l|}{ South-East Asia } \\
\hline Brunei & Yes & Yes & Yes & $\begin{array}{l}\text { HBV DNA }>10^{6} \mathrm{IU} / \\
\text { ml hepatology } \\
\text { clinics }\end{array}$ & Yes & Yes, 9-12 months \\
\hline Cambodia & Not in routine & Yes (RDT) & No & $\begin{array}{l}\mathrm{HBe} A g \text { algorithm in a } \\
\text { research study }\end{array}$ & $\begin{array}{l}\text { Limited. Out of } \\
\text { pocket }\end{array}$ & No \\
\hline Indonesia & Not in routine & No & No & No & $\begin{array}{l}\text { Limited. Out of } \\
\text { pocket }\end{array}$ & No \\
\hline Lao PDR & Yes & No & No & No & $\begin{array}{l}\text { Limited. Out of } \\
\text { pocket }\end{array}$ & No \\
\hline Malaysia & Yes & Yes & Yes & $\begin{array}{l}\mathrm{HBV} \\
\text { DNA }>200,000 \mathrm{IU} / \\
\text { mL or } \mathrm{HBeAg}+\end{array}$ & Yes & Yes, 9 months \\
\hline Myanmar & Not in routine & No & No & No & $\begin{array}{l}\text { Limited. Out of } \\
\text { pocket }\end{array}$ & No \\
\hline Philippines & Yes & No & No & No & $\begin{array}{l}\text { Limited. Out of } \\
\text { pocket }\end{array}$ & No \\
\hline Singapore & Yes & Yes & Yes & $\begin{array}{l}\mathrm{HBV} \\
\text { DNA> 200,000 IU/ } \\
\mathrm{mL}\end{array}$ & Yes & $\begin{array}{l}\text { Yes, } 3 \text { months after } \\
\text { completion of } \\
\text { vaccination }\end{array}$ \\
\hline Thailand & Yes & Yes & Yes & $\begin{array}{l}\mathrm{HBeAg}+\text { or HBV } \\
\mathrm{DNA}>200,000 \mathrm{IU} / \\
\mathrm{mL}\end{array}$ & $\begin{array}{l}\text { Yes but out of } \\
\text { pocket }\end{array}$ & Yes \\
\hline \multicolumn{7}{|l|}{ Timor-Leste } \\
\hline Vietnam & Yes & Yes & Yes & $\begin{array}{l}\text { HBV } \\
\text { DNA > 200,000 IU/ } \\
\text { mL }\end{array}$ & Yes & No \\
\hline \multicolumn{7}{|l|}{ South Asia } \\
\hline Bangladesh & Yes & Yes & Yes & Yes & Yes & No \\
\hline Bhutan & NA & NA & NA & NA & NA & NA \\
\hline India & $\begin{array}{l}\text { Not as public } \\
\text { health policy }\end{array}$ & $\begin{array}{l}\text { Not as public } \\
\text { health policy }\end{array}$ & $\begin{array}{l}\text { Not as public } \\
\text { health policy }\end{array}$ & $\begin{array}{l}\text { Not as public health } \\
\text { policy }\end{array}$ & $\begin{array}{l}\text { Yes, but out of } \\
\text { pocket }\end{array}$ & No \\
\hline Maldives & NA & NA & NA & NA & NA & NA \\
\hline Nepal & Yes & Yes & Yes & Yes & Yes & No \\
\hline Pakistan & Yes & No & No & No & Yes & No \\
\hline Sri Lanka & $\begin{array}{l}\text { Not as public } \\
\text { health policy }\end{array}$ & $\begin{array}{l}\text { Not as public } \\
\text { health policy }\end{array}$ & $\begin{array}{l}\text { Not as public } \\
\text { health policy }\end{array}$ & $\begin{array}{l}\text { Not as public health } \\
\text { policy }\end{array}$ & $\begin{array}{l}\text { Not as public } \\
\text { health policy }\end{array}$ & No \\
\hline \multicolumn{7}{|l|}{ Pacific Countries } \\
\hline Australia & Yes & Yes & Yes & $\begin{array}{l}\mathrm{HBV} \\
\text { DNA > 200,000 IU/ } \\
\mathrm{mL}\end{array}$ & Yes & $\begin{array}{l}\text { Yes, } 3-12 \text { months } \\
\text { after completing } \\
\text { primary series }\end{array}$ \\
\hline New Zealand & Yes & Yes & Yes & $\begin{array}{l}\mathrm{HBV} \\
\text { DNA > 200,000 IU/ } \\
\text { mL }\end{array}$ & Yes & $\begin{array}{l}\text { Yes, } 3-12 \text { months } \\
\text { after completing } \\
\text { primary series }\end{array}$ \\
\hline $\begin{array}{l}\text { American } \\
\text { Samao }\end{array}$ & Yes & No & No & No & Yes & No \\
\hline Cook Islands & Yes & No & No & No & Yes & No \\
\hline $\begin{array}{l}\text { Federated States } \\
\text { of Micronesia }\end{array}$ & Yes & No & No & No & Yes & No \\
\hline Fiji & Yes & No & No & No & Yes & No \\
\hline
\end{tabular}


Table 3 (continued)

\begin{tabular}{|c|c|c|c|c|c|c|}
\hline & $\begin{array}{l}\text { Antenatal testing } \\
\text { for } \mathrm{HBsAg}\end{array}$ & $\begin{array}{l}\text { Antenatal testing } \\
\text { for } \mathrm{HBeAg}\end{array}$ & $\begin{array}{l}\text { HBV DNA if } \\
\text { positive HBsAg }\end{array}$ & $\begin{array}{l}\text { Antiviral prophylaxis } \\
\text { for MTCT prevention } \\
\text { (if yes, eligibility) }\end{array}$ & $\begin{array}{l}\text { HBIG for exposed } \\
\text { infants }\end{array}$ & $\begin{array}{l}\text { Post-vaccination } \\
\text { anti-HBs testing }\end{array}$ \\
\hline French Polynesia & Yes & No & No & No & Yes & No \\
\hline Guam & Yes & No & No & No & Yes & No \\
\hline Kiribati & Yes & Yes & Yes & NA & No & No \\
\hline Marshall Islands & Yes & Yes & Yes & NA & No & No \\
\hline Nauru & Yes & NA & NA & NA & No & No \\
\hline New Caledonia & Yes & No & No & No & Yes & No \\
\hline Niue & Yes & NA & NA & NA & NA & NA \\
\hline $\begin{array}{l}\text { Papua New } \\
\text { Guinea }\end{array}$ & No & No & No & NA & No & No \\
\hline Pitcairn & NA & NA & NA & NA & NA & NA \\
\hline Samoa & Yes & NA & NA & NA & NA & NA \\
\hline Solomon Islands & Yes & No & No & NA & No & No \\
\hline Tokelau Islands & NA & NA & NA & NA & NA & NA \\
\hline Tonga & Yes & NA & NA & NA & NA & NA \\
\hline Tuvalu & NA & NA & NA & NA & NA & NA \\
\hline Vanuatu & NA & NA & NA & NA & NA & NA \\
\hline $\begin{array}{l}\text { Wallis and Futuna } \\
\text { Islands }\end{array}$ & NA & NA & NA & NA & NA & NA \\
\hline
\end{tabular}

$H B V$ Hepatitis B virus, $H B s A g$ Hepatitis B surface antigen, $H B e A g$ Hepatitis B envelop antigen, $H B I G$ Hepatitis B immunoglobulin

Stigma and discrimination may be experienced by peoples and families affected by hepatitis B. Confidentiality of test results must be ensured. Steps should be taken to prevent stigma and discrimination against HBsAg-positive pregnant females and other family members, in health-care settings and in the communities [231].

Training and capacity building of health workforce are needed to ensure availability of trained staff in providing EMTCT interventions. Training and capacity-building strategies related to EMTCT of HBV may include the development of algorithms for HBsAg screening of all pregnant females and appropriate measures to prevent MTCT (including timely administration of the HepB birth dose to all infants); training on assessment of liver diseases in the pregnant females and antivirals use for treatment of pregnant female or prevention of MTCT; training on follow-up of exposed infants, including post-vaccination serological testing; and follow-up of females with HBV infection after delivery.

\section{Recommendations}

All pregnant females should be screened for HBsAg as early as possible in the pregnancy. Screening should be performed in each pregnancy, regardless of previous HBV vaccination or previous negative $\mathrm{HBsAg}$ test results (C1).
HBsAg screening of pregnant females should include pre- and post-test counseling and linkage to further care as appropriate (C1).

Scaling up timely birth dose is the most cost-effective option for preventing MTCT. Countries that have not yet reached the 2020 goal of $1 \% \mathrm{HBsAg}$ prevalence among under 5 children through vaccination should focus on increasing their vaccination coverage, including timely birth dose (A1).

Countries that have already scaled up the timely birth dose, adding antenatal HBsAg testing of pregnant females and tenofovir prophylaxis in eligible females as an additional opportunity to prevent MTCT may be cost-effective in some regions $(\mathrm{B} 1)$.

\section{Areas of future research}

Studies to evaluate the efficacy of TDF in preventing MTCT of HBV among females whose infants did not receive HBIG or a timely birth dose are needed.

Different service delivery models for providing integrated HBV, HIV, and syphilis services to pregnant females need to be studied.

Evaluation of service delivery models and measures to provide equitable health services access without stigma and discrimination (especially to vulnerable, marginalized or minority groups) are required. 


\section{Conclusions}

The purpose of these guidelines is to provide scientific and specific guidance for the management of chronic HBVinfected pregnant females and newborn from pregnancy planning to postpartum period. There are unavoidable limitations to the process of development of guidelines that mainly reflect the low quality of the existing clinical studies and the small number of good quality randomized controlled trials in pregnant females with chronic HBV infection.

There is a need for higher quality data and many potential areas of future research as highlighted after each section in these guidelines. Further scientific research in future will address many of the areas of uncertainty that currently exist. It is hoped that these guidelines will be used as guidance only and clinical judgment will be used by the practitioners in making clinical decisions for the benefit of their patients.

Author contributions All the authors wrote their respective parts of the manuscript and then reviewed the final manuscript and recommendations.

Funding No funding was taken from any pharmaceutical company.

\section{Declarations}

Conflict of interest Manoj Kumar, Zaigham Abbas, Milad Azami, Maria Belopolskaya, A. K. Dokmeci, Hasmik Ghazinyan, Jidong Jia, Ankur Jindal, Han Chu Lee, Wei Lei, Seng Gee Lim, Chun-Jen Liu, Qiang Li, Mamun Al Mahtab, David H. Muljono, Madunil Anuk Niriella, Masao Omata, Diana A. Payawal, Shiv K. Sarin, Olivier Ségéral, Tawesak Tanwandee, Nirupma Trehanpati, Kumar Visvanathan, Jin Mo Yang, Man-Fung Yuen, Yingjie Zheng, Y. H. Zhou declare that they have no conflict of interest.

Ethical approval Not applicable.

Informed consent Not applicable.

Data availability All data, materials, and software applications support the published claims and comply with field standards.

\section{References}

1. Atkins D, Best D, Briss PA, Eccles M, Falck-Ytter Y, et al. Grading quality of evidence and strength of recommendations. BMJ. 2004;328:1490

2. Sarin SK, Kumar M, Eslam M, George J, Al Mahtab M, Akbar SMF, et al. Liver diseases in the Asia-Pacific region: a Lancet Gastroenterology and Hepatology Commission. Lancet Gastroenterol Hepatol. 2020;5(2):167-228

3. World Health Organization. Operationalizing elimination of mother-to-child transmission of Hepatitis B virus in the Western Pacific Region. World Health Organization Regional Office for the Western Pacific, Manila, Licence: CC BY-NC-SA 3.0 IGO. 2021
4. World Health Organization. Global health sector strategy on viral hepatitis 2016-2021. World Health Organization, Geneva. 2016. (http://www.who.int/hepatitis/strategy2016-2021/ghss-hep/en/)

5. https://www.globalhep.org/country-data-dashboards

6. https://apps.who.int/immunization_monitoring/globalsummary/ timeseries/tswucoveragehepb3.html

7. Esaulenko V, Lyalina LV, Trifonov GF, Pokrovsky VI, Totolyan AA. Viral hepatitis in the Russian Federation. Analytical review. Issue 10/E. SPb: FBUN NIIEM named after Pasteur, 2016. 152 (In Russian)

8. Ganina AA, Kyuregyan KK, Mikhaylov MI. Detection rate of hepatitis among pregnant female screened for TORCH-infections medical alphabet No. 19/2016. Volume No. 3 Modern Laboratory. 41. https://www.elibrary.ru/item.asp?id=29992553 (In Russian)

9. Belopolskaya MA, Avrutin VY, Ostankova YV, Dmitrieva MI, Rukoiatkina EA, Dmitriev AV, Kalinina OV. Modern trends and problems of hepatitis B in pregnant womenin St-Petersburg: prevalence and genetic variants of virus. HIV Infect Immunosuppr 2017; 9(4). https://hiv.bmoc-spb.ru/jour/article/view/305/ 281. (In Russian)

10. Kovaleva TA. Chronic viral hepatitis B and C during pregnancy: clinical and epidemiological, psychosocial, pathogenetic aspects. 2017; 327. https://www.dissercat.com/content/khronicheskievirusnye-gepatity-v-i-s-v-period-beremennosti-kliniko-epide miologicheskie-psik. (In Russian)

11. Köse Ş, Gül S, Tatar B, Temur M, Göl B. HBV, HCV and HAV seroprevalence in pregnant women admitted to İzmir Aegean Obstetrics and Gynecology Training and Research Hospital: 2010-2011 İzmir Ege Doğumevi ve Kadın Hastalıkları Eğitim ve Araştırma Hastanesi'ne başvuran gebe kadınlarda HBV, HCV ve HAV seroprevalanslar1: 2010-2011. Turk Hij Den Biyol Derg 2017; 74(1): 21-28. Doi: https://doi.org/10.5505/TurkHijyen. 2016.39259

12. Nersesov AV, Berkinbayev SF, Junusbekova GA, Jumabayeva AE, Novitskaya MS, Kyanysh N. Prevalence of viral hepatitis among residents of South Kazakhstan region. Medicine (Almaty). 2016;171(9):30-33 (In Russian)

13. Azimova SM, Odinaev RI Chronic hepatitis " $B$ " in pregnant women. Bull Acad Sci Repub Tajikistan. Department of Biological and Medical Sciences. 2015; 2:89-93 (In Russian)

14. https://aua.am/chsr/PDF/2000/HepatitB_FINAL.pdf

15. Agayev S, Geleishvili M, Rush T, Maes E. Evaluation of surveillance system for hepatitis B in pregnant women in Baku, Azerbaijan. 2009. https://www.tephinet.org/evaluation-of-surve illance-system-for-hepatitis-b-in-pregnant-women-in-baku-azerb aijan-may-2009-\%E2\%80\%93

16. Khachatryan S, Vanyan A, Sahakyan G. Hepatitis B immunoprophylaxis in Armenia. Blood. 2015;2(20):53

17. Aminzadeh Z, Gachkar L, Sayyadi Anari AR. Frequency of HBsAg positive in pregnant womenRafsanjan in the year 2003. J Rafsanjan Univ Med Sci. 2004;3(2):126-133 (Persian)

18. Mohebbi SR, Sanati A, Cheraghipour K, Rostami Nejad M, Shalmani HM, Zali MR. Hepatitis C and hepatitis B virus infection: epidemiology and risk factors in a large cohort of pregnant women in Lorestan, West of Iran. Hepat Mon. 2011;11(9):736-739

19. Motamedifar M, Amini E, Talezadeh Shirazi P, Sarvari J. The prevalence of HBsAgandHBsAbamongpregnantwomenreferring to Zeinabiyeh Hospital, Shiraz Iran. Shiraz E Med J. 2012;13(4):187-196

20. Motazakker M, Shokat Nagadeh M, Khalili F, Shayeri B. Hepatitis $B$ virus infection among pregnant women attending health care centers of Urmia. J Uilan Univ Med Sci. 2014;23(89):45-50 (Persian) 
21. Shoghli A, Nabavi SM, Alavian SM, Kolifarhood G, Goya MM, Namazi R, et al. Hepatitis B surface antigen prevalence in pregnant women: a cross-sectional survey in Iran. Int J Prev Med. 2014;5(Suppl 3):S213-S218

22. Mobin AR, Mohammadian F, Mazloomzadeh S, Esmaeilzadeh A, Sorouri Zanjani R, Savabi S, et al. Seroprevalence of Hepatitis $B$ virus among pregnant women referred to healthcare centers of Zanjan. Zanjan Univ Mes Sci J. 2014;22(93):96-104 (Persian)

23. Kavosi A, Vizvari P, Mohammadi G, Jouybari L, Sanagu A. Seroprevalence of positive $\mathrm{HbsAg}$ and its associated factors in pregnantwomen referred to health centers of Agh-Ghala city in 2010-2012. Iran J Obstet Gynecol Infertil. 2015;18(149):8-16 (Persian)

24. Kheiri L, Makvandi S. The prevalence of hepatitis B surface antigen (HBsAg) and its influencing factors in pregnant women referring to Healthcare Centers of Dehloran, Iran in 2011-2012. J Midwifery Reprod Health. 2015;3(3):424-429

25. Afzali H, Momen Heravi M, Moravveji SA, Poorrahnama M. Prevalence of hepatitis B surface antigen in pregnant women in Beheshti Hospital of Kashan, Isfahan. Iran Red Crescent Med J. 2015;17(7):e20598

26. Bayani M, Biazar T, Bayani F, Siadati S. The effect of hepatitis $B$ vaccination at birth on reducing the prevalence of hepatitis $B$ surface antigen among rural pregnant women in Babol, Iran. J Babol Univ Med Sci. 2016;18(1):7-10

27. Malekifar P, Babanejad M, Izadi N, Alavian SM. The frequency of HBsAg in pregnant women from eastern mediterranean and Middle Eastern countries: a systematic review and meta-analysis. Hepat Mon. 2018;18(9):e58830

28. Mahdi BM, Saour M, Abdulrazzaq HI. Evaluation of hepatitis B virus infection in pregnant women. Int J Biomed Res. 2015;6(06):379-381

29. Ali SS, Salman BR. Seroprevalence of Hepatitis B surface antigen among pregnant women visiting primary health centers in Baghdad Al-jadeda sector in Baghdad. J Fac Med Baghdad. 2018;60(1):43-46

30. Zamir C, Dagan R, Zamir D, et al. Evaluation of screening for hepatitis B surface antigen during pregnancy in a population with a high prevalence of hepatitis B surface antigen-positive/ hepatitis B e antigen-negative carriers. Pediatr Infect Dis J. 1999;18(Suppl. 3):262-266

31. Safir A, Levy A, Sikuler E, Sheiner E. Maternal hepatitis B virus or hepatitis $\mathrm{C}$ virus carrier status as independent risk factor for adverse perinatal outcome. Liver Int. 2010;30:765-770

32. Abu Freha N, Wainstock T, Menachem TN, Sheiner E. Maternal hepatitis B virus or hepatitis $\mathrm{C}$ virus carrier status and long-term endocrine morbidity of the offspring-a population-based cohort study. J Clin Med. 2020;9(3):796

33. Batayneh N, Bdour S. Risk of perinatal transmission of hepatitis B virus in Jordan. Infect Dis Obstet Gynecol. 2002;10(3):127-132

34. Othman B, Al-Najjar MAA, Othman D, Al-Qudah R, Basheti I. Prevalence, knowledge of and attitude towards hepatitis B virus among pregnant females in Jordan. J Viral Hepat. 2020;27(11):1108-1118

35. Madi N, Al-Tawalah H, Abdul Khalik D, Al-Nakib W. A relatively high number of pregnant women in kuwait remain susceptible to rubella: a need for an alternative vaccination policy. Med Princ Pract. 2014;23:145-148

36. Al Awaidy S, Abu-Elyazeed R, Al Hosani H, Al Mulla A, Al Busaiedy S, Al Amiry A, et al. Sero-epidemiology of hepatitis B infection in pregnant women in Oman, Qatar and the United Arab Emirates. J Infect. 2006;52:202-206

37. Khalil MK, Al-Mazrou YY, Al-Jeffri M, Al-Ghamdi YS, Mishkhas A, Bakhsh M, et al. Serosurvey of hepatitis B surface antigen in pregnant Saudi women. East Mediterr Health J. 2005;11(4):640-647

38. Alrowaily MA, Abolfotouh MA, Ferwanah MS. Hepatitis B virus seroprevalence among pregnant females in Saudi Arabia. Saudi J Gastroenterol. 2008;14(2):70-72

39. Bani I, Mahfouz MS, Gaffar EMA, Elhassan I, Yassin AO, Ageely HM. Prevalence and risk factors of hepatitis B virus among pregnant women in Jazan Region-Kingdom of Saudi Arabia. J Biol Agric Healthc. 2012;2(8):45-48

40. Yalçın Bahat P, Turan G, Yüksel Özgör B, Bağcı ÇK. Comparison of hepatitis B, hepatitis C, and HIV seropositivity of Syrian and Turkish pregnant women. Turk J Obstet Gynecol. 2019;16(2):95-99

41. Evirgen Ö, Aksakal M, Melek I, Önlem Y, Sabahattin O. Seropositivity of hepatitis $\mathrm{B}$ and hepatitis $\mathrm{C}$ in women who were admitted to Hatay Maternityand Children's Hospital. Viral Hepat Derg. 2010;16(2):111-116

42. Yavuzcan A, Altınbas A, Altınbas S. An unexpected low Hepatitis B seroprevalence in pregnant women from the rural Southeastern Turkey. Afr J Microbiol Res. 2011;5(23):3942-3945

43. Gönen I. The frequency of HBV and HCV in pregnant women in rural areas. Viral Hepat Derg. 2011;17(2):66-68

44. Deveci O. Investigation of intrauterine transmission of hepatitis B Virus to children from $\mathrm{HBsAg-positive} \mathrm{pregnant} \mathrm{women.} \mathrm{J}$ Microbiol Infect Dis. 2011;1(1):14-16

45. Balık G, Üstüner I, Kagıtcı M, Ural UM, Tekin YB, Sentürk $\mathrm{S}$. HBsAg, antiHBs and anti-HCV seroprevalance in pregnant women living in Rize region. Dicle Med J. 2013;40(2):254-257

46. Aynioglu A, Aynioglu Ö, Tarik A, Aydin M, Altunok ES. $\mathrm{HBsAg}$, anti-HBs and anti-HCV seropositivity rates among pregnant women attending a University Hospital in Zonguldak. Viral Hepat J. 2015;21(1):31-34

47. Dogan K, Guraslan H, Ozel G, Aydan Z, Yasar L. Seroprevalence rates of Toxoplasma gondii, rubella, cytomegalovirus, syphilis, and hepatitis B, seroprevalences rate in the pregnant population in Istanbul. Turk Parazitol Derg. 2014;38(4):228-233 (Turkish)

48. Guckan R, Kilinc C, Gozdemir E. HBSAG, anti Hbs, anti -HCV and anti -HIV seroplevalence in pregnant women living. Asian Pac J Nurs. 2016;3(1):9-12

49. Furuncuoglu Y, Bolukbas FF, Bolukbas C, Torun P, Ozturk R. Changes in the prevalence of HBV infection in pregnant women in Turkey between 1995 and 2015: a 20-year evaluation. Postgrad Med J. 2016;92(1091):510-513

50. Murad EA, Babiker SM, Gasim GI, Rayis DA, Adam I. Epidemiology of hepatitis B and hepatitis C virus infections in pregnant women in Sana'a, Yemen. BMC Pregnancy Childbirth. 2013;13:127

51. Chen CT. Global prevalence of hepatitis B virus infection and prevention of mother-to-child transmission. Lancet Gastroenterol Hepatol. 2018;3(9):598-599

52. Zheng H, Cui FQ, Wang FZ, et al. The epidemiology of hepatitis B virus infection in women of reproductive age in highly endemic areas in China. J Viral Hepat. 2018;25(1):88-96

53. Wang Y, Zhou H, Zhang L, et al. Prevalence of chronic hepatitis $\mathrm{B}$ and status of HBV care among rural women who planned to conceive in China. Sci Rep. 2017;7(1):12090

54. Liu J, Zhang S, Liu M, Wang Q, Shen H, Zhang Y. Distribution of $\mathrm{ABO} / \mathrm{Rh}$ blood groups and their association with hepatitis $\mathrm{B}$ virus infection in 3.8 million Chinese adults: a population-based cross-sectional study. J Viral Hepat. 2018;25(4):401-411

55. Zhang L, Wang YY, Huang YJ, et al. Status of HBsAg seroprevalence in 15 million rural couples in China: a cross-sectional study. Sci Rep. 2017;7:42822

56. Xin X, Wang Y, Cheng J, et al. Seroepidemiological survey of hepatitis B virus infection among 764,460 women of 
childbearing age in rural China: a cross-sectional study. J Clin Virol. 2016;81:47-52

57. Evans AA, Cohen C, Huang P, et al. Prevention of perinatal hepatitis B transmission in Haimen City, China: results of a community public health initiative. Vaccine. 2015;33(26):3010-3015

58. Ding Y, Sheng Q, Ma L, Dou X. Chronic HBV infection among pregnant women and their infants in Shenyang, China. Virol J. 2013;10:17

59. Zhang L, Gui X, Wang B, et al. A study of immunoprophylaxis failure and risk factors of hepatitis B virus mother-to-infant transmission. Eur J Pediatr. 2014;173(9):1161-1168

60. Wang F, Zhang G, Zheng H, et al. Post-vaccination serologic testing of infants born to hepatitis B surface antigen positive mothers in 4 provinces of China. Vaccine. 2017;35(33):4229-4235

61. Chen T, Wang J, Qiu H, et al. Different interventional criteria for chronic hepatitis B pregnant women with $\mathrm{HBeAg}(+)$ or $\mathrm{HBeAg}(-)$ : epidemiological data from Shaanxi, China. Medicine (Baltimore). 2018;97(27):e11406

62. Sheng QJ, Wang SJ, Wu YY, Dou XG, Ding Y. Hepatitis B virus serosurvey and awareness of mother-to-child transmission among pregnant women in Shenyang, China: an observational study. Medicine (Baltimore). 2018;97(22):e10931

63. Dashtseren B, Bungert A, Bat-Ulzii P, Enkhbat M, LkhagvaOchir O, Jargalsaikhan G, et al. Endemic prevalence of hepatitis $\mathrm{B}$ and $\mathrm{C}$ in Mongolia: a nationwide survey amongst Mongolian adults. J Viral Hepat. 2017;24(9):759-767

64. Woodring J, Pastore R, Brink A, Ishikawa N, Takashima Y, Tohme RA. Progress toward hepatitis B control and elimination of mother-to-child transmission of hepatitis B virus-Western Pacific Region, 2005-2017. MMWR Morb Mortal Wkly Rep. 2019;68:195-200

65. Cho EJ, Kim SE, Suk KT, et al. Current status and strategies for hepatitis B control in Korea. Clin Mol Hepatol. 2017;23(3):205-211

66. Hur YJ, Choe SA, Choe YJ, Paek J. Hepatitis B surface antigen and antibody positivity among women of childbearing age after three decades of universal vaccination in South Korea. Int J Infect Dis. 2020;104:551-555

67. Kim JH, Kim JS, Lee JJ, et al. Survey of perinatal hepatitis B virus transmission after Korean National Prevention Program in a tertiary hospital. Korean J Intern Med. 2014;29(3):307-314

68. Sugiyama A, Ohisa M, Nagashima S, Yamamoto C, Chuon C, Fujii T, et al. Reduced prevalence of hepatitis B surface antigen positivity among pregnant women born after the national implementation of immunoprophylaxis for babies born to hepatitis B virus-carrier mothers in Japan. Hepatol Res. 2017;47(12):1329-1334

69. Chen DS. Fighting against viral hepatitis: lessons from Taiwan. Hepatology. 2011;54:381-392

70. CDC. Center for disease control, Taiwan 2015 national various immunization completion rate. 2017. http://www.cdc.gov.tw/ professional/page .aspx ?treeid $=5$ b0231 beb94edffc $\&$ nowtreeid $=$ 3D1CDC342B28E123

71. Su WJ, Chen SF, Yang CH, Chuang PH, Chang HF, Chang MH. The impact of universal infant hepatitis B immunization on reducing the hepatitis B carrier rate in pregnant women. J Infect Dis. 2019;220:1118-1126

72. Ork V, Woodring J, Shafiqul Hossain M, et al. Hepatitis B surface antigen seroprevalence among pre- and post-vaccine cohorts in Cambodia, 2017. Vaccine. 2019;37:5059-5066

73. Minta AA, Silva MWT, Shrestha A, et al. Hepatitis B surface antigen seroprevalence among children in the Philippines, 2018. Vaccine. 2021;39:1982-1989

74. Sebastian VJ, Bhattacharya S, Ray S, Daud JH. Prevalence of hepatitis-B surface antigen in the pregnant women of
Brunei Darussalam. Southeast Asian J Trop Med Public Health. 1990;21:123-127

75. Htwe O, Coates PD, Krasu M, Tju H, Soe NN, Tan C, et al. Prevalence of hepatitis B and other infections among pregnant women seen in a referral centre in Brunei Darussalam. Brunei Int Med J. 2013;9(4):220-226

76. Gunardi H, Zaimi LF, Soedjatmiko AR, Muljono DH. Current prevalence of hepatitis B infection among parturient women in Jakarta, Indonesia. Acta Med Indones. 2014;46:3-9

77. Muljono HD. Epidemiology of Hepatitis B and C in Republic of Indonesia. Euroasian J Hepatogastroenterol. 2017;7(1):55-59

78. Girawan D, Judistiani RTD, Risan NA, Bestari MB, Nugraha ES, Ermaya YS, et al. The high prevalence of negative hepatitis B surface antibody (Anti-HBs) among pregnant women in bandung, indonesia: a community-based study. Int J Hepatol. 2020;19(2020):3414869

79. Norizuki M, Kitamura T, Komada K, et al. Serologic testing of randomly selected children after hepatitis B vaccination: a cross-sectional population-based study in Lao People's Democratic Republic. BMC Infect Dis. 2019;19:1-9

80. Xeuatvongsa A, Komada K, Kitamura T, et al. Chronic hepatitis B prevalence among children and mothers: results from a nationwide, population-based survey in Lao People's Democratic Republic. PLoS ONE. 2014;9:e88829

81. Black AP, Nouanthong P, Nanthavong N, Souvannaso C, Vilivong K, Jutavijittum P, et al. Hepatitis B virus in the Lao People's Democratic Republic: a cross sectional serosurvey in different cohorts. BMC Infect Dis. 2014;14:457

82. Choisy M, Keomalaphet S, Xaydalasouk K, Quet F, Latthaphasavang V, Buisson Y. Prevalence of hepatitis B virus infection among pregnant women attending antenatal clinics in Vientiane, Laos, 2008-2014. Hepat Res Treat. 2017;2017:1-5

83. Shamsuddin K, Marmuji LZ. Weighted analysis of prevalence and risk factors of hepatitis B infection among antenatal mothers in Ipoh. Singap Med J. 2010;51:800-805

84. Bierhoff M, Angkurawaranon C, Myat Min A, Gilder ME, Win Tun N, Keereevijitt A, et al. Maternal hepatitis B infection burden, comorbidity and pregnancy outcome in a low-income population on the myanmar-thailand border: a retrospective cohort study. J Pregnancy. 2019;25(2019):8435019

85. Carpio GCA, Taguba AQ, Tan LCQ, Ong JP, Daez MLO. Prevalence and risk factors of hepatitis $B$ infection in pregnant women at the prenatal clinic of the university of the Philippines-Philippine General Hospital. Int Dig Dis Forum Hong Kong Electron Only Abstr. 2015;13(7):E83

86. Mendoza IT, Jose SM. The association of chronic hepatitis B infectivity with fetomaternal outcome: a retrospective cohort study in a tertiary hospital. PJOG. 2020;44(2):16-24

87. Thamkhantho M, Chayachinda C. Characteristics, prevalence, and $\mathrm{HBeAg}$ correlation of hepatitis B in pregnancy: a siriraj hospital experience. J Med Assoc Thailand. 2020;103:276-280

88. Hall C, Gibbons M, Murphy D, Nourse C. Prevalence of hepatitis $\mathrm{B}$ infection in women delivering at a community health centre in Dili, Timor-Leste and discussion of programmatic challenges. Trans R Soc Trop Med Hyg. 2015;109(4):280-282

89. Miyakawa M, Yoshida L-M, Nguyen H-AT, et al. Hepatitis B virus infection among pregnant mothers and children after the introduction of the universal vaccination program in Central Vietnam. Sci Rep. 2021;11:8676

90. Dunford L, Carr MJ, Dean J, Nguyen LT, Ta Thi TH, Nguyen BT, et al. A multicentre molecular analysis of hepatitis B and blood-borne virus coinfections in Viet Nam. PLoS ONE. 2012;7(6): e39027

91. Nguyen VTT, Trang HTQ, Ishikawa N, Anh Nguyen L, Anh LAK, Minh TB, et al. Feasibility, benefits, and cost-effectiveness of adding universal hepatitis $\mathrm{B}$ and syphilis testing to routine 
antenatal care services in Thai Nguyen province, Vietnam. Int J Std Aids. 2021;32(2):135-143

92. Akhter S, Talukder MQ, Bhuiyan N, Chowdhury TA, Islam MN, Begum S. Hepatitis B virus infection in pregnant mothers and its transmission to infants. Indian J Pediatr. 1992;59(4):411-415

93. Karim Rumi MA, Begum K, Sawkat Hassan M, Munir Hasan SM, Golam Azam M, Nadim Hasan K, et al. Detection of hepatitis B surface antigen in pregnant women attending a public hospital for delivery: Implication for vaccination strategy in Bangladesh. Am J Trop Med Hyg. 1998;59(2):318-322

94. Shamsuzzaman M, Singhasivanon P, Kaewkungwal J, Lawpoolsri S, Tangkijvanich P, Gibbons RV, et al. Hepatitis B among pregnant women attending health care facilities in rural Bangladesh. Southeast Asian J Trop Med Public Health. 2011;42(6):1410-1413

95. Nayak NC, Panda SK, Bhan MK, Guha DK, Zuckerman AJ. Dynamics and impact of perinatal transmission of hepatitis B virus in North India. J Med Virol [Internet]. 1987;21(2):137-145

96. Abass F, Thomas RD, Rajkumar A, Gupta N, Puliyel JM. Controlling perinatally acquired hepatitis B [Internet]. Indian J Pediatr. 2001;9:365

97. Sandesh K, Varghese T, Harikumar R, Beena P, Sasidharan VP, Bindu CS, et al. Prevalence of hepatitis B and C in the normal population and high risk groups in north Kerala. Trop Gastroenterol. 2006;27(2):80-83

98. Pande C, Sarin SK, Patra S, Bhutia K, Mishra SK, Pahuja S, et al. Prevalence, risk factors and virological profile of chronic hepatitis B virus infection in pregnant women in India. J Med Virol. 2011;83(6):962-967

99. Naveira MCM, Badal K, Dhakal J, Mayer NA, Pokharel B, Del Prado RF. Seroprevalence of hepatitis B and C in Nepal: a systematic review (1973-2017). Hepatol Med Policy. 2018;3(1):1-17

100. Shedain PR, Baral G, Sharma KR, Dhital S, Devkota MD. Prevalence and mother-to-newborn transmission of hepatitis B Virus in Tertiary Care Hospital in Nepal. J Nepal Health Res Counc. 2019;17(3):278-284

101. Qureshi H, Bile KM, Jooma R, Alam SE, Afridi HUR. Prevalence of hepatitis B and C viral infections in Pakistan: findings of a national survey appealing for effective prevention and control measures. East Mediterr Health J. 2010;16(Suppl):S15-23

102. Ali M, Idrees M, Ali L, Hussain A, Ur Rehman I, Saleem S, et al. Hepatitis B virus in Pakistan: a systematic review of prevalence, risk factors, awareness status and genotypes. Virol J. 2011;6(8):102

103. Ahmad A, Khichi GQ, Rehman A. Hepatitis B markers Professional. Med J. 2007;1:307-311

104. Yousfani S, Mumtaz F, Memon A, Memon MA, Sikandar R. Antenatal screening for hepatitis $\mathrm{B}$ and $\mathrm{C}$ virus carrier state at a university hospital. JLUMHS. 2006;5:24-27

105. Hakeem A, Khan MS, Abdullah M, Rehman A, Hashmi MI. Prevalence of HbsAg AND anti HCV in pregnant ladies attending antenatal clinic at Sheikh Zayed Medical Complex, Rahim Yar Khan. Esculapio. 2006;2:6-8

106. Sheikh SM. Hepatitis B and C: value of universal antenatal screening. J Coll Phys Surg Pak. 2009;19(3):179-182

107. Khattak ST, Ali Marwat M, Khattak IU, Khan TM, Naheed T. Comparison of frequency of hepatitis B and hepatitis C in pregnant women in urban and rural area of district Swat. J Ayud Med Coll Abbottabad. 2009;21(2):12-15

108. Ahmad I. Prevalence of Hepatitis B and C Viral Infection Among Pregnant Women in Peshawar, Pakistan. Hepat Mon. 2016;16(6): 36383

109. Jamil A, Hamid S, Aziz Q, Asim M. Prevalence of hepatitis B among pregnant women. JIMDC. 2018;7(2):128-131
110. Howell J, Pedrana A, Cowie BC, Doyle J, Getahun A, Ward J, et al. Aiming for the elimination of viral hepatitis in Australia, New Zealand, and the Pacific Islands and Territories: where are we now and barriers to meeting World Health Organization targets by 2030. J Gastroenterol Hepatol. 2019;34(1):40-48

111. Howell J, Balderson G, Hellard M, et al. The increasing burden of potentially preventable liver disease among adult liver transplant recipients: a comparative analysis of liver transplant indication by era in Australia and New Zealand. J Gastroenterol Hepatol. 2016;31:434-441

112. Graham S, Guy RJ, Cowie B, et al. Chronic hepatitis B prevalence among Aboriginal and Torres Strait Islander Australians since universal vaccination: a systematic review and meta-analysis. BMC Infect Dis. 2013;13:403

113. Bergin H, Wood G, Walker SP, Hui L. Perinatal management of hepatitis B virus: clinical implementation of updated Australasian management guidelines. Obstet Med. 2018;11(1):23-27

114. O'Sullivan BG, Gidding H, Law MG, Kaldor JM, Gilbert GL, Dore GJ. Estimates of chronic hepatitis b virus infection in Australia in 2000. Aust N Z J Public Health. 2004;28:212-216

115. Guirgis M, Zekry A, Yan K, Bu YM, Lee A. Chronic hepatitis B infection in an Australian antenatal population: seroprevalence and opportunities for better outcomes. J Gastroenterol Hepatol. 2009;24(6):998-1001

116. Giles ML, Davey MA, Wallace EM. Chronic hepatitis B infection and the risk of gestational diabetes: a cross-sectional study. BJOG. 2020;127(9):1147-1152

117. Robinson T, Bullen C, Humphries W, Hornell J, Moyes C. The New Zealand hepatitis B screening programme: screening coverage and prevalence of chronic hepatitisB infection. N Z Med J. 2005;118:U1345

118. Addidle M. Impact of universal hepatitis B vaccination on antenatal hepatitis B prevalence in the Midlands region of the North Island New Zealand. N Z Med J. 2011;124(1332):40-44

119. WHO: Country cooperation strategy at a glance: Pacific Island countries. 2011. http://wpro.who.int/en

120. Lee AU, Mair L, Kevin B, Gandi L, Tarumuri O, Lee C, et al. Prevalence of chronic hepatitis B in Oro Province, Papua New Guinea. West Pac Surveill Response J. 2020;11(4):6-9

121. Bauduceau O, Berlioz A, Buisson Y. Hepatites B, C et E en Nouvelle-Calédonie. Etude séro-épidémiologique chez les appelés du contingent. Hepatitis B, C, and E in New Caledonia Seroepidemiologic study in military recruits. Med Trop (Mars). 2000;60(2):167-170 (French)

122. Berlioz-Arthaud A, Perolat P, Buisson Y. 10 year assessment of infant hepatitis B vaccination program, in the Loyalty Islands (New Caledonia). Vaccine. 2003;21(21-22):2737-2742

123. Wilson N, Ruff TA, Rana BJ, Leydon J, Locarnini S. The effectiveness of the infant hepatitis B immunisation program in Fiji, Kiribati, Tonga and Vanuatu. Vaccine. 2000;18:3059-3066

124. Tuinakelo LR, Tayler-Smith K, Khogali M, Marks GB. Prevalence of anaemia, syphilis and hepatitis B in pregnant women in Nausori, Fiji. Public Health Action. 2013;3(1):72-75

125. Abara WE, Cha S, Malik T, DeSimone MS, Schillie S, Collier M, et al. Prenatal screening for and prevalence of hepatitis B surface antigen in pregnant women and prevention of transmission to infants born to infected mothers-guam, 2014. J Pediatr Infect Dis Soc. 2018;7(4):290-295

126. World Health Organization. Regional Office for the Western Pacific. Prevalence surveys of sexually transmitted infections among seafarers and women attending antenatal clinics in Kiribati: 2002-2003. WHO Regional Office for the Western Pacific, Manila. 2004. https://apps.who.int/iris/handle/10665/206930

127. Fischer G, Wang S, Ahring S, Fowler K, Hainline S, Chinglong $\mathrm{M}$, et al. An investigation of perinatal hepatitis B virus infections 
among a high risk population: the delivery hospital as a safety net. Pediatr Infect Dis J. 2009;28(7):593-597

128. Ménard D. Toxoplasmose, rubéole, tréponématoses, hépatite virale B et infection par le VIH chez les femmes suivies pour grossesse de la population de la côte Est de Nouvelle-Calédonie [Toxoplasmosis, rubella, syphilis, hepatitis B and HIV infection in women being followed for pregnancy in a population on the east coast of New Caledonia]. Bull Soc Pathol Exot. 2001;94(5):403-405

129. https://www.aidsdatahub.org/sites/default/files/resource/sgsantenatal-women-youth-solomon-islands-2008.pdf

130. Getahun A, Baekalia M, Panda N, Lee A, Puiahi E, Khan S, et al. Seroprevalence of hepatitis B surface antigen in pregnant women attending antenatal clinic in Honiara Solomon Islands, 2015. World J Hepatol. 2016;8(34):1521-1528

131. Han YT, Sun C, Liu CX, Xie SS, Xiao D, Liu L, et al. Clinical features and outcome of acute hepatitis B in pregnancy. BMC Infect Dis. 2014;14:368

132. Ratnam D, Visvanathan K. New concepts in the immunopathogenesis of Chronic hepatitis B: the importance of the innate immune response. Hepatol Int. 2008;2(1):12-18

133. Jonas MM. Hepatitis B and pregnancy: an underestimated issue. Liver Int. 2009;29(Suppl 1):133-139

134. Mohite BJ, Rath S, Bal V, Kamat SA, Marathe SN, Zuckerman AJ, et al. Mechanisms of liver cell damage in acute hepatitis B. J Med Virol. 1987;22(3):199-210

135. Chang CY, Aziz N, Poongkunran M, Javaid A, Trinh HN, Lau DT, et al. Serum aminotransferase flares in pregnant and postpartum women with current or prior treatment for chronic hepatitis B. J Clin Gastroenterol. 2018;52:255-261.106-110

136. Bzowej NH, Tran TT, Li R, Belle SH, Smith CI, Khalili M, et al. Total alanine aminotransferase (ALT) flares in pregnant North American women with chronic hepatitis B infection: results from a prospective observational study. Am J Gastroenterol. 2019;114:1283-1291

137. Lin $\mathrm{HH}, \mathrm{Wu}$ WY, Kao JH, Chen DS. Hepatitis B post-partum e antigen clearance in hepatitis B carrier mothers: correlation with viral characteristics. J Gastroenterol Hepatol. 2006;21:605-609

138. La Rocca C, Carbone F, Longobardi S, Matarese G. The immunology of pregnancy: regulatory $\mathrm{T}$ cells control maternal immune tolerance toward the fetus. Immunol Lett. 2014;162:41-48

139. Li L, Wang L, Huang C, Diao L, Zhang Y, Zhang X, et al. Chronic hepatitis B infection alters peripheral immune response in women with reproductive failure. Am J Reprod Immunol. 2019;81:e13083

140. Singhal A, Kanagala R, Jalil S, Wright HI, Kohli V. Chronic HBV with pregnancy: reactivation flare causing fulminant hepatic failure. Ann Hepatol. 2011;10:233-236

141. Liaw YF. Hepatitis flares and hepatitis B e antigen seroconversion: implication in anti-hepatitis B virus therapy. J Gastroenterol Hepatol. 2003; 18:246-252

142. Wong F, Pai R, Van Schalkwyk J, Yoshida EM. Hepatitis B in pregnancy: a concise review of neonatal vertical transmission and antiviral prophylaxis. Ann Hepatol. 2014;13:187-195

143. Milich DR, Jones JE, Hughes JL, Price J, Raney AK, McLachlan A. Is a function of the secreted hepatitis $B$ e antigen to induce immunologic tolerance in utero? Proc Natl Acad Sci USA. 1990;87:6599-6603

144. Tian Y, Kuo CF, Akbari O, Ou JH. Maternal-derived hepatitis $B$ virus e antigen alters macrophage function in offspring to drive viral persistence after vertical transmission. Immunity. 2016;44:1204-1214

145. Bai G, Wang Y, Zhang L, Tang Y, Fu F. The study on the role of hepatitis B virus $\mathrm{X}$ protein and apoptosis in $\mathrm{HBV}$ intrauterine infection. Arch Gynecol Obstet. 2012;285:943-949
146. Xu DZ, Yan YP, Choi BC, Xu JQ, Men K, Zhang JX, et al. Risk factors and mechanism of transplacental transmission of hepatitis B virus: a case-control study. J Med Virol. 2002;67:20-26

147. Foaud H, Maklad S, Mahmoud F, El-Karaksy H. Occult hepatitis $\mathrm{B}$ virus infection in children born to HBsAg-positive mothers after neonatal passive-active immunoprophylaxis. Infection. 2015;43(3):307-314

148. Inui A, Komatsu H, Sogo T, Nagai T, Abe K, Fujisawa T. Hepatitis B virus genotypes in children and adolescents in Japan: before and after immunization for the prevention of mother to infant transmission of hepatitis B virus. J Med Virol. 2007;79:670-675

149. Liu SL, Dong Y, Zhang L, Li MW, Wo J, Lu LW, et al. Influence of HBV gene heterogeneity on the failure of immunization with HBV vaccines in eastern China. Arch Virol. 2009;154:437-443

150. Papadakis MA, Elefsiniotis IS, Vlahos G, Daskalakis G, Barbatis $\mathrm{C}$, Antsaklis A. Intrauterine-transplacental transmission of hepatitis B virus (HBV) from hepatitis B e antigen negative (precore mutant, G1896A) chronic HBV infected mothers to their infants Preliminary results of a prospective study. J Clin Virol. 2007;38:181-183

151. Cheng H, Su H, Wang S, Shao Z, Men K, Li M, et al. Association between genomic heterogeneity of hepatitis B virus and intrauterine infection. Virology. 2009;387:168-175

152. Vyas AK, Sharma BC, Sarin SK, Trehanpati N. Immune correlates of hepatitis B surface antigen spontaneous seroconversion in hepatitis B e antigen negative chronic hepatitis B patients. Liver Int. 2018;38(1):38-49

153. Vyas AK, Negi P, Patra S, Maras JS, Ramakrishna G, Sarin SK, et al. Maternal immunity influences vertical transmission of hepatitis B to newborns. Hepatol Commun. 2019;3:795-811

154. Wu TW, Lin HH, Wang LY. Chronic hepatitis B infection in adolescents who received primary infantile vaccination. Hepatology. 2013;57:37-45

155. Wang J, He Y, Jin D, Liu J, Zheng J, Yuan N, et al. No response to hepatitis B vaccine in infants born to $\mathrm{HBsAg}(+)$ mothers is associated to the transplacental transfer of HBsAg. Infect Dis (Lond). 2017;49:576-583

156. Cao M, Wu Y, Wen S, Pan Y, Wang C, Zhang X, et al. $20 \mu \mathrm{g}$ hepatitis $\mathrm{B}$ vaccination reduced the risk of low responsiveness in [infants with HLA-II risk genotype of $\mathrm{HBsAg}$ positive mothers. Infect Genet Evol. 2018;63:243-248

157. Machaira M, Papaevangelou V, Vouloumanou EK, Tansarli GS, Falagas ME. Hepatitis B vaccine alone or with hepatitis B immunoglobulin in neonates of $\mathrm{HBsAg}+/ \mathrm{HBeAg}-$ mothers: a systematic review and meta-analysis. J Antimicrob Chemother. 2015;70:396-404

158. Yue Y, Meng J, Zhang S. Mechanism of peripheral blood mononuclear cell invasion by HBV on artificial immunization in newborns. Chin Med J (Engl). 2002;115:1380-1382

159. Koumbi L, Bertoletti A, Anastasiadou V, Machaira M, Goh W, Papadopoulos NG, et al. Hepatitis B-specific T helper cell responses in uninfected infants born to $\mathrm{HBsAg}+/ \mathrm{HBeAg}-$ mothers. Cell Mol Immunol. 2010;7:454-458

160. Carollo M, Palazzo R, Bianco M, Pandolfi E, Chionne P, Fedele $\mathrm{G}$, et al. Hepatitis B specific T cell immunity induced by primary vaccination persists independently of the protective serum antibody level. Vaccine. 2013;31:506-513

161. Shrivastava S, TrehanPati N, Patra S, Kottilil S, Pande C, Trivedi $\mathrm{SS}$, et al. Increased regulatory $\mathrm{T}$ cells and impaired functions of circulating CD8 T lymphocytes is associated with viral persistence in hepatitis B virus-positive newborns. J Viral Hepat. 2013;20:582-591

162. Shrivastava S, TrehanPati N, Kottilil S, Sarin SK. Decline in immature transitional B cells after hepatitis B vaccination in hepatitis B positive newborns. Pediatr Infect Dis J. 2013;32:792-794 
163. Hong M, Sandalova E, Low D, Gehring AJ, Fieni S, Amadei $\mathrm{B}$, et al. Trained immunity in newborn infants of HBV-infected mothers. Nat Commun. 2015;6:6588

164. Unal C, Tanacan A, Ziyadova G, Fadiloglu E, Beksac MS. Effect of viral load on pregnancy outcomes in chronic hepatitis B infection. J Obstet Gynaecol Res. 2019;45(9):1837-1842

165. Cui AM, Cheng XY, Shao JG, Li HB, Wang XL, Shen Y, et al. Maternal hepatitis B virus carrier status and pregnancy outcomes: a prospective cohort study. BMC Pregnancy Childbirth. 2016; $16: 87$

166. Safir A, Levy A, Sikuler E, Sheiner E. Maternal hepatitis B virus or hepatitis $\mathrm{C}$ virus carrier status as an independent risk factor for adverse perinatal outcome. Liver Int. 2010;30(5):765-770

167. Salemi JL, Whiteman VE, August EM, Chandler K, Mbah AK, Salihu HM. Maternal hepatitis B and hepatitis C infection and neonatal neurological outcomes. J Viral Hepat. 2014;21(11):e144-e153

168. Connell LE, Salihu HM, Salemi JL, August EM, Weldeselasse $\mathrm{H}, \mathrm{Mbah} \mathrm{AK}$. Maternal hepatitis B and hepatitis $\mathrm{C}$ carrier status and perinatal outcomes. Liver Int. 2011;31(8):1163-1170

169. Bajema KL, Stankiewicz Karita HC, Tenforde MW, Hawes SE, Heffron R. Maternal hepatitis B infection and pregnancy outcomes in the united states: a population-based cohort study. Open Forum Infect Dis. 2018;5(6):ofy 134

170. Tan J, Mao X, Zhang G, Wang W, Pan T, Liu X, et al. Hepatitis $B$ surface antigen positivity during pregnancy and risk of gestational diabetes mellitus: a systematic review and meta-analysis. J Viral Hepat. 2018;25(11):1372-1383

171. Leng J, Zhang C, Wang P, Li N, Li W, Liu H, et al. Plasma levels of alanine aminotransferase in the first trimester identify high risk chinese women for gestational diabetes. Sci Rep. 2016;6:27291

172. Huang X, Tan H, Li X, Zhou S, Wen SW, Luo M. Maternal chronic HBV infection would not increase the risk of pregnancyinduced hypertension - results from pregnancy cohort in Liuyang rural China. PLoS ONE. 2014;9(12):e114248

173. Tse KY, Ho LF, Lao T. The impact of maternal HBsAg carrier status on pregnancy outcomes: a case-control study. J Hepatol. 2005;43(5):771-775

174. Huang QT, Chen JH, Zhong M, Hang LI, Wei SS, Yu YH. Chronic hepatitis B infection is associated with decreased risk of preeclampsia: a meta-analysis of observational studies. Cell Physiol Biochem. 2016;38(5):1860-1868

175. Huang QT, Wei SS, Zhong M, Hang LL, Xu YY, Cai GX, et al. Chronic hepatitis B infection and risk of preterm labor: a metaanalysis of observational studies. J Clin Virol. 2014;61(1):3-8

176. Luo LL, Wu JL, Qu Y, Li J, Pan LL, Li DY, et al. Association between maternal HBsAg carrier status and neonatal adverse outcomes: meta-analysis. J Matern Fetal Neonatal Med. 2015;28(11):1308-1317

177. Zhuang X, Cui AM, Wang Q, Cheng XY, Shen Y, Cai WH, et al. Liver dysfunction during pregnancy and its association of with preterm birth in china: a prospective cohort study. EBioMedicine. 2017;26:152-156

178. Tan J, Liu X, Mao X, Yu J, Chen M, Li Y, et al. HBsAg positivity during pregnancy and adverse maternal outcomes: a retrospective cohort analysis. J Viral Hepat. 2016;23(10):812-819

179. Cai Q, Liu H, Han W, Liu L, Xu Y, He Y, et al. Maternal HBsAg carriers and adverse pregnancy outcomes: a hospital-based prospective cohort analysis. J Viral Hepat. 2019;26(8):1011-1018

180. Lao TT. Hepatitis B-chronic carrier status and pregnancy outcomes: an obstetric perspective. Best Pract Res Clin Obstet Gynaecol. 2020;68:66-77

181. Xiong Y, Liu C, Huang S, Wang J, Qi Y, Yao G, et al. Impact of maternal infection with hepatitis B virus on pregnancy complications and neonatal outcomes for women undergoing assisted reproductive technology treatment: a population-based study. J Viral Hepat. 2021;28(4):613-620

182. Kushner T, Shaw PA, Kalra A, Magaldi L, Monpara P, Bedi $\mathrm{G}$, et al. Incidence, determinants and outcomes of pregnancyassociated hepatitis B flares: a regional hospital-based cohort study. Liver Int. 2018;38:813-820

183. Li L, Zou H, Xu M, Li S, Zhu Y, Zheng S, et al. Risk factors related to postpartum hepatic inflammation in pregnant women with chronic hepatitis B. J Int Med Res. 2020;48:300060520966439

184. Giles M, Visvanathan K, Lewin S, Bowden S, Locarnini S, Spelman T, et al. Clinical and virological predictors of hepatic flares in pregnant women with chronic hepatitis B. Gut. 2015;64:1810-1815

185. Wang S, Xiong H, Luo C, Zhao H, Fan Y, Zhang T, et al. Acuteon-chronic liver failure in pregnant patients with chronic hepatitis B: a retrospective observational case series study. Gastroenterol Res Pract. 2020;2020:9831687

186. Lee JC, Li PH, Mok TY, You SH, Hung HC, Lee CF, et al. Acute exacerbation of hepatitis $\mathrm{B}$ with hepatic failure during the first trimester of pregnancy: delivery of a healthy term baby after liver transplantation. Hepatol Res. 2020;50:1386-1390

187. The antiretroviral pregnancy registry. Available from: URL:http:// www.apregistry.com

188. Pan CQ, Chan S, Trinh H, Yao A, Bae H, Lou L. Similar efficacy and safety of tenofovir in Asians and non-Asians with chronic hepatitis B. World J Gastroenterol. 2015;21(18):5524-5531

189. Pan CQ, Duan Z, Dai E, et al. Tenofovir to prevent hepatitis B transmission in mothers with high viral load. N Engl J Med. 2016;374(24):2324-2334

190. Tacke F, Kroy DC. Treatment for hepatitis B in patients with drug resistance. Ann Transl Med. 2016;4(18):334

191. Wong GL, Seto WK, Wong VW, Yuen MF, Chan HL. Review article: long-term safety of oral anti-viral treatment for chronic hepatitis B. Aliment Pharmacol Ther. 2018;47(6):730-737

192. Zhou Y, Hu Y, Liu X, Yang H. CSOG MFM committee guideline: management of hepatitis $\mathrm{B}$ during pregnancy and prevention of mother-to-child transmission of hepatitis B virus. Matern Fetal Med. 2021;3(1):7-17

193. Charlton MR, Alam A, Shukla A, et al. An expert review on the use of tenofovir alafenamide for the treatment of chronic hepatitis B virus infection in Asia. J Gastroenterol. 2020;55(9):811-823

194. Seto WK, Hui AJ, Wong VW, Wong GL, Liu KS, Lai CL, et al. Treatment cessation of entecavir in Asian patients with hepatitis $\mathrm{B}$ e antigen negative chronic hepatitis B: a multicentre prospective study. Gut. 2015;64:667-672

195. Kim HY, Choi JY, Park CH, Jang JW, Kim CW, Bae SH, et al. Outcome after discontinuing antiviral agents during pregnancy in women infected with hepatitis B virus. J Clin Virol. 2013;56:299-305

196. Chang CY, Aziz N, Poongkunran M, Javaid A, Trinh HN, Lau DT, et al. Serum aminotransferase flares in pregnant and postpartum women with current or prior treatment for chronic hepatitis B. J Clin Gastroenterol. 2018;52:255-261

197. ter Borg MJ, Leemans WF, de Man RA, Janssen HL. Exacerbation of chronic hepatitis B infection after delivery. J Viral Hepat. 2008; 15:37-41

198. Nguyen G, Garcia RT, Nguyen N, Trinh H, Keeffe EB, Nguyen $\mathrm{MH}$. Clinical course of hepatitis B virus infection during pregnancy. Aliment Pharmacol Ther. 2009;29:755-764

199. Joshi SS, Wong D, Castillo E, Swain MG, Coffin CS. Peripartum cytokine flares in a multiethnic cohort of chronic hepatitis B carriers does not correlate with hepatitis B virus suppression or increased risk of liver disease. Am J Reprod Immunol. 2017;78:e12707 
200. Shaheen AA, Myers RP. The outcomes of pregnancy in patients with cirrhosis: a population-based study. Liver Int. 2010;30:275-283

201. Chang CY, Aziz N, Poongkunran M, Javaid A, Trinh HN, Lau $\mathrm{D}$, et al. Serum alanine aminotransferase and hepatitis B DNA flares in pregnant and postpartum women with chronic hepatitis B. Am J Gastroenterol. 2016;111:1410-1415

202. Samadi Kochaksaraei G, Castillo E, Osman M, Simmonds K, Scott AN, Oshiomogho JI, et al. Clinical course of 161 untreated and tenofovir-treated chronic hepatitis B pregnant patients in a low hepatitis B virus endemic region. J Viral Hepat. 2016;23:15-22

203. Burra P, De Martin E, Gitto S, Villa E. Influence of age and gender before and after liver transplantation. Liver Transpl. 2013;19:122-134

204. Aggarwal N, Sawnhey H, Suril V, Vasishta K, Jha M, Dhiman RK. Pregnancy and cirrhosis of the liver. Aust N Z J Obstet Gynaecol. 1999;39:503-506

205. Westbrook RH, Yeoman AD, O'Grady JG, Harrison PM, Devlin J, Heneghan MA. Model for end-stage liver disease score predicts outcome in cirrhotic patients during pregnancy. Clin Gastroenterol Hepatol. 2011;9:694-699

206. Tan J, Surti B, Saab S. Pregnancy and cirrhosis. Liver Transpl. 2008; 14:1081-1091

207. Cheng YS. Pregnancy in liver cirrhosis and/or portal hypertension. Am J Obstet Gynecol. 1977;128:812-822

208. Rasheed SM, Abdel Monem AM, Abd Ellah AH, Abdel Fattah MS. Prognosis and determinants of pregnancy outcome among patients with post-hepatitis liver cirrhosis. Int J Gynaecol Obstet. 2013;121:247-251

209. Hay JE. Liver disease in pregnancy. Hepatology. 2008;47:1067-1076

210. Allen AM, Hay JE. Review article: the management of cirrhosis in women. Aliment Pharmacol Ther. 2014;40:1146-1154

211. Pillai AK, Joseph AM, Reddick M, Toomay S, Kalva S. Intravascular US-guided transjugular intrahepatic portosystemic shunt creation in a second-trimester pregnancy to prophylactically decompress abdominal wall varices before cesarean section. J Vasc Interv Radiol. 2014;25:481-483

212. Lelei-Mailu FJ, Mariara CM. Pregnancy in a patient with portal hypertension secondary to liver cirrhosis. BMJ Case Rep. 2018;2018:bcr2017223076

213. Chen HL, Lin LH, Hu FC, Lee JT, Lin WT, Yang YJ, et al. Effects of maternal screening and universal immunization to prevent mother-to-infant transmission of HBV. Gastroenterology. 2012;142(4):773-781

214. Cheung KW, Seto MTY, Kan ASY, Wong D, Kou KO, So PL, et al. Immunoprophylaxis failure of infants born to hepatitis B carrier mothers following routine vaccination. Clin Gastroenterol Hepatol. 2018;16(1):144-145

215. Cheung KW, Lao TT. Hepatitis B-vertical transmission and the prevention of mother-to-child transmission. Best Pract Res Clin Obstet Gynaecol. 2020;68:78-88

216. Zeng QL, Yu ZJ, Ji F, Li GM, Zhang GF, Xu JH, et al. Tenofovir alafenamide to prevent perinatal hepatitis B transmission: a multicenter, prospective, observational study. Clin Infect Dis. 2021. https://doi.org/10.1093/cid/ciaa1939

217. Jourdain G, Ngo-Giang-Huong N, Harrison L, Decker L, Khamduang W, Tierney C, et al. Tenofovir versus placebo to prevent perinatal transmission of hepatitis B. N Engl J Med. 2018;378(10):911-923

218. Ghendon Y. Perinatal transmission of hepatitis B virus in highincidence countries. J Virol Methods. 1987;17(1-2):69-79

219. Pan CQ, Duan ZP, Bhamidimarri KR, Zou HB, Liang XF, Li $\mathrm{J}$, et al. An algorithm for risk assessment and intervention of mother to child transmission of hepatitis B virus. Clin Gastroenterol Hepatol. 2012;10(5):452-459

220. Beasley RP, Hwang LY, Lee GC, Lan CC, Roan CH, Huang FY, et al. Prevention of perinatally transmitted hepatitis B virus infections with hepatitis B immune globulin and hepatitis B vaccine. Lancet. 1983;2(8359):1099-1102

221. Zhang L, Gui XE, Wang B, Fan JY, Cao Q, Mullane K, et al. Serological positive markers of hepatitis B virus in femoral venous blood or umbilical cord blood should not be evidence of in-utero infection among neonates. BMC Infect Dis. 2016;16(1):408

222. Liu J, Xu B, Chen T, Chen J, Feng J, Xu C, et al. Presence of hepatitis B virus markers in umbilical cord blood: exposure to or infection with the virus? Dig Liver Dis. 2019;51(6):864-869

223. Schweitzer IL. Vertical transmission of the hepatitis B surface antigen. Am J Med Sci. 1975;270(2):287-291

224. Goudeau A, Yvonnet B, Lesage G, Barin F, Denis F, Coursaget $\mathrm{P}$, et al. Lack of anti-HBc IgM in neonates with HBsAg carrier mothers argues against transplacental transmission of hepatitis B virus infection. Lancet. 1983;2(8359):1103-1104

225. Lin HH, Lee TY, Chen DS, Sung JL, Ohto H, Etoh T, et al. Transplacental leakage of HBeAg-positive maternal blood as the most likely route in causing intrauterine infection with hepatitis B virus. J Pediatr. 1987;111(6 Pt 1):877-881

226. Tse K, Siu SL, Yip KT, Chan SM, Que TL, Lui WY, et al. Immuno-prophylaxis of babies borne to hepatitis B carrier mothers. Hong Kong Med J. 2006;12(5):368-374

227. Shikata T, Karasawa T, Abe K. Two distinct types of hepatitis in experimental hepatitis B virus infection. Am J Pathol. 1980;99(2):353-368

228. Masuzaki H, Miura K, Miura S, Yoshiura K, Mapendano CK, Nakayama D, et al. Labor increases maternal DNA contamination in cord blood. Clin Chem. 2004;50(9):1709-1711

229. Merrill DA, Dubois RS, Kohler PF. Neonatal onset of the hepatitis-associated-antigen carrier state. N Engl J Med. 1972;287(25):1280-1282

230. Lu Y, Zhu FC, Liu JX, Zhai XJ, Chang ZJ, Yan L, et al. The maternal viral threshold for antiviral prophylaxis of perinatal hepatitis B virus transmission in settings with limited resources: a large prospective cohort study in China. Vaccine. 2017;35(48 Pt B):6627-6633

231. Prevention of mother-to-child transmission of hepatitis B virus: guidelines on antiviral prophylaxis in pregnancy. World Health Organization, Geneva. 2020. Licence: CC BY-NC-SA 3.0 IGO

232. Terrault NA, Lok ASF, McMahon BJ, Chang KM, Hwang JP, Jonas MM, et al. Update on prevention, diagnosis, and treatment of chronic hepatitis B: AASLD 2018 hepatitis B guidance. Hepatology. 2018;67(4):1560-1599

233. Zhou YH. Issues meriting further study in preventing motherto-infant transmission of hepatitis B by antiviral therapy during pregnancy. Matern Fetal Med. 2019;1(1):42-47

234. Hu Y, Zhang S, Luo C, Liu Q, Zhou YH. Gaps in the prevention of perinatal transmission of hepatitis B virus between recommendations and routine practices in a highly endemic region: a provincial population-based study in China. BMC Infect Dis. 2012;12:221

235. Wang F, Zheng H, Zhang G, Ding Z, Li F, Zhong G, et al. Effectiveness of prevention of mother-to-child transmission practice in three provinces of Southern China. Hum Vaccin Immunother. 2015;11(8):2061-2067

236. Huang H, Xu C, Liu L, Chen L, Zhu X, Chen J, et al. Increased protection of earlier use of immunoprophylaxis in preventing perinatal transmission of hepatitis B virus. Clin Infect Dis. 2020. https://doi.org/10.1093/cid/ciaa898

237. Sun KX, Li J, Zhu FC, Liu JX, Li RC, Zhai XJ, et al. A predictive value of quantitative HBsAg for serum HBV DNA 
level among HBeAg-positive pregnant women. Vaccine. 2012;30(36):5335-5340

238. Wen WH, Huang CW, Chie WC, Yeung CY, Zhao LL, Lin WT, et al. Quantitative maternal hepatitis B surface antigen predicts maternally transmitted hepatitis B virus infection. Hepatology. 2016;64(5):1451-1461

239. Thilakanathan C, Wark G, Maley M, Davison S, Lawler J, Lee A, et al. Mother-to-child transmission of hepatitis B: examining viral cut-offs, maternal HBsAg serology and infant testing. Liver Int. 2018;38(7):1212-1219

240. Xiao Y, Sun K, Duan Z, Liu Z, Li Y, Yan L, et al. Quasispecies characteristic in "a" determinant region is a potential predictor for the risk of immunoprophylaxis failure of mother-to-childtransmission of sub-genotype $\mathrm{C} 2$ hepatitis $\mathrm{B}$ virus: a prospective nested case-control study. Gut. 2020;69(5):933-941

241. Epidemiology of vaccine preventable diseases. The pink book course textbook, 13th edition. Atlanta (GA): Centers for Disease Control and Prevention. 2015. (https://www.cdc.gov/vaccines/ pubs/pinkbook/ hepb.html)

242. Hepatitis B vaccines: WHO position paper-July 2017. Weekly epidemiological record. 2017; 92(27):369-92. http://www.who. int/immunization/policy/position_papers/hepatitis_b/en/

243. Beasley RP, Trepo C, Stevens CE, Szmuness W. The e antigen and vertical transmission of hepatitis B surface antigen. Am J Epidemiol. 1977;105(2):94-98

244. Linder N, Vishne TH, Levin E, Handsher R, Fink-Kremer I, Waldman D, et al. Hepatitis B vaccination: long term follow-up of the immune response of preterm infants and comparison of two vaccination protocols. Infection. 2002;30:136-139

245. Saari TN, American Academy of Pediatrics-Committee on Infectious Diseases. Immunization of preterm and low birth weight infants. Pediatrics. 2003;112:193-198

246. Lee C, Gong Y, Brok J, Boxall EH, Gluud C. Effect of hepatitis B immunisation in newborn infants of mothers positive for hepatitis B surface antigen: systematic review and meta-analysis. BMJ. 2006;332:328-336

247. Isaacs D, Kilham HA, Alexander S, Wood N, Buckmaster A, Royle J. Ethical issues in preventing mother-to-child transmission of hepatitis B by immunisation. Vaccine. 2011;29(37):6159-6162

248. Fu S, Yao NJ, Feng YL, Li J, Wu YC, Tian Z, et al. The efficacy of two different dosages hepatitis B immunoglobulin in interrupting mother-to-infant transmission of hepatitis B virus: a systematic review and meta-analysis. J Hepatol. 2019;70:E124

249. Machaira M, Papaevangelou V, Vouloumanou EK, Tansarli GS, Falagas ME. Hepatitis B vaccine alone or with hepatitis B immunoglobulin inneonates of $\mathrm{HBsAg}+/ \mathrm{HBeAg}$ - mothers: a systematic review and meta-analysis. J Antimicrob Chemother. 2015;70:396-404

250. Milne A, West DJ, Chinh DV, Moyes CD, Poerschke G. Field evaluation ofthe efficacy and immunogenicity of recombinant hepatitis B vaccine without HBIG in newborn Vietnamese infants. J Med Virol. 2002;67:327-333

251. Segeral O, Dim B, Durier C et al. Immunoglobulin-free alternative strategy to prevent $\mathrm{HBV}$ mother to child transmission in Cambodia: preliminary results of the ANRS 12345 TA PROHM study. EASL International Liver Congress, June 23-26, 2021. Abstract OS-865

252. Funk AL, Lu Y, Yoshida K, Zhao T, Boucheron P, van Holten $\mathrm{J}$, et al. Efficacy and safety of antiviral prophylaxis during pregnancy to prevent mother-to-child transmission of hepatitis B virus: a systematic review and meta-analysis. Lancet Infect Dis. 2021;21(1):70-84

253. Ségéral O, N'Diaye DS, Prak S, Nouhin J, Chhun S, Khamduang W, et al. Usefulness of a serial algorithm of $\mathrm{HBsAg}$ and $\mathrm{HBeAg}$ rapid diagnosis tests to detect pregnant women at risk of $\mathrm{HBV}$ mother-to-child transmission in Cambodia, the ANRS 12328 pilot study. J Clin Virol. 2018;109:29-34

254. Seck A, Ndiaye F, Maylin S, Ndiaye B, Simon F, Funk AL, et al. Poor sensitivity of commercial rapid diagnostic tests for hepatitis B e antigen in Senegal, West Africa. Am J Trop Med Hyg. 2018;99(2):428-434

255. Segeral O, Dim B, Durier C, Prak S, Chhim K, Vong C, et al. Hepatitis $\mathrm{B}$ e antigen $(\mathrm{HBeAg})$ rapid test and alanine aminotransferase level-based algorithm to identify pregnant women at risk of HBV mother-to-child transmission: the ANRS 12345 TA PROHM study. Clin Infect Dis. 2020;71(10):e587-e593

256. Wu Y, Liu J, Feng Y, Fu S, Ji F, Ge L, et al. Efficacy and safety of antiviral therapy for HBV in different trimesters of pregnancy: systematic review and network meta-analysis. Hepatol Int. 2020;14:180-189

257. Yi W, Pan CQ, Li MH, et al. The characteristics and predictors of postpartum hepatitis flares in women with chronic hepatitis B. Am J Gastroenterol. 2018;113(5):686-693

258. Zhao Y, Feng Y, Wu Y, Ji F, Chen T. Hepatic flare after antiviral treatment withdraw in post-partum for pregnancy of chronic hepatitis B viral infection: a pairwise and Bayesian network meta-analysis. J Hepatol. 2019;70:E127

259. Sarin SK, Kumar M, Lau GK, Abbas Z, Chan HL, Chen CJ, et al. Asian-Pacific clinical practice guidelines on the management of hepatitis B: a 2015 update. Hepatol Int. 2016;10(1):1-98

260. Wang XX, Lu JF, Wu YL, Ma LN, Jin Y, Cao ZH, et al. Clinical study on liver function, virology, serological changes and the safety of drug withdrawal in pregnant women who are chronic HBV carriers during pregnancy and postpartum. Zhonghua Gan Zang Bing Za Zhi. 2019;27(4):261-266 (Chinese)

261. Liu J, Wang J, Jin D, Qi C, Yan T, Cao F, et al. Hepatic flare after telbivudine withdrawal and efficacy of postpartum antiviral therapy for pregnancies with chronic hepatitis B virus. J Gastroenterol Hepatol. 2017;32(1):177-183

262. Wen WH, Chen HL, Shih TT, Wu JF, Ni YH, Lee CN, et al. Long-term growth and bone development in children of HBVinfected mothers with and without fetal exposure to tenofovir disoproxil fumarate. J Hepatol. 2020;72(6):1082-1087

263. Yi W, et al. Risk of vertical transmission of hepatitis B after amniocentesis in HBs antigen-positive mothers. J Hepatol. 2014;60:523-529

264. Zou H, Chen Y, Duan Z, Zhang H, Pan C. Virologic factors associated with failure to passive-active immunoprophylaxis in infants born to HBsAg-positive mothers. J Viral Hepat. 2012;19:e18-e25

265. Han Z, Zhang Y, Bai X, Yin Y, Xu C, Hou H. Mother-to-child transmission of hepatitis $\mathrm{B}$ virus after amniocentesis: a retrospective matched cohort study. Prenat Diagn. 2019;39:431-440

266. Dionne-Odom J, et al. \#38: hepatitis B in pregnancy screening, treatment, and prevention of vertical transmission. Am J Obstet Gynecol. 2016;214:6-14

267. Visvanathan K, Dusheiko G, Giles M, Wong ML, Phung N, Walker S, et al. Managing HBV in pregnancy. Prevention, prophylaxis, treatment and follow-up: position paper produced by Australian, UK and New Zealand key opinion leaders. Gut. 2016;65(2):340-350

268. He R, Wen P, Xiong M, Fan Z, Li F, Luo D, et al. Cesarean section in reducing mother-to-child HBV transmission: a metaanalysis. J Matern Fetal Neonatal Med. 2020;20:1-9

269. Steyaert SR, Leroux-Roels GG, Dhont M. Infections in IVF: review and guidelines. Hum Reprod Update. 2000;6:432-441

270. Mak JSM, Lao TT. Assisted reproduction in hepatitis carrier couples. Best Pract Res Clin Obstet Gynaecol. 2020;68:103-108

271. Nie R, Jin L, Zhang H, Xu B, Chen W, Zhu G. Presence of hepatitis $\mathrm{B}$ virus in oocytes and embryos: a risk of hepatitis 
B virus transmission during in vitro fertilization. Fertil Steril. 2011;95:1667-1671

272. Hu XL, Zhou XP, Qian YL, Wu GY, Ye YH, Zhu YM. The presence and expression of the hepatitis B virus in human oocytes and embryos. Hum Reprod. 2011;26:1860-1867

273. Lin J, Sha Y, Qiu P. Effects of hepatitis B virus infection in women with different ovarian reserve on outcomes of in vitro fertilization and embryo transfer. Reprod Contracept. 2017;37:106-111

274. Shi L, Liu S, Zhao W, Zhou H, Ren W, Shi J. Hepatitis B virus infection reduces fertilization ability during in vitro fertilization and embryo transfer. J Med Virol. 2014;86:1099-1104

275. Liu L, Liu Q, Wen Y. Ovarian reserve function in infertile women with HBV infection. J Reprod Med. 2016;25:27-31

276. Yao N, Ma Y, Wang J, Zhang X, Zhao Y, Chen Y, et al. Role of infertile female chronic hepatitis B virus infection in assisted reproduction and infantile outcomes: a systematic review and meta-analysis. Hepatology. 2019;70:599A

277. Chen H, Ge H-S, Lv J-Q, Wu X-M, Xi H-T, Huang J-Y, et al. Chronic hepatitis B virus infection in women is not associated with IVF/ICSI outcomes. Arch Gynecol Obstet. 2014;289:213-217

278. Lee VCY, Ng EHY, Yeung WSB, Ho PC. Impact of positive hepatitis B surface antigen on the outcome of IVF treatment. Reprod Biomed Online. 2010;21:712-717

279. Jin L, Nie R, Li Y, Xiao N, Zhu L, Zhu G. Hepatitis B surface antigen in oocytes and embryos may not result in vertical transmission to offspring of hepatitis B virus carriers. Fertil Steril. 2016;105:1010-1013

280. Nie R, Wang M, Liao T, Qian K, Zhu G, Jin L. Assisted conception does not increase the risk for mother-to-child transmission of hepatitis B virus, compared with natural conception: a prospective cohort study. Fertil Steril. 2019;111:348-356

281. Kang X, Xie Q, Zhou X, Li F, Huang J, Liu D, et al. Effects of hepatitis B virus $\mathrm{S}$ protein exposure on sperm membrane integrity and functions. PLoS ONE. 2012;7:e33471

282. Zhou X-P, Hu X-L, Zhu Y-M, Qu F, Sun S-J, Qian Y-L. Comparison of semen quality and outcome of assisted reproductive techniques in Chinese men with and without hepatitis B. Asian J Androl. 2011;13:465-469

283. Bu Z, Kong H, Li J, Wang F, Guo Y, Su Y, et al. Effect of male hepatitis $\mathrm{B}$ virus infection on outcomes of in vitro fertilization and embryo transfer treatment: insights from couples undergoing oocyte donation. Int J Clin Exp Med. 2014;7:1860-1866

284. Huang J-M, Huang T-H, Qiu H-Y, Fang X-W, Zhuang T-G, Liu $\mathrm{H}-\mathrm{X}$, et al. Effects of hepatitis B virus infection on human sperm chromosomes. World J Gastroenterol. 2003;9:736-740

285. Ali BA, Huang T-H, Salem H-H, Xie Q-D. Expression of hepatitis B virus genes in early embryonic cells originated from hamster ova and human spermatozoa transfected with the complete viral genome. Asian J Androl. 2006;8:273-279

286. Qx C, Yy Z. Is hepatitis B virus transmitted via the male germ line? A seroepidemiological study in fetuses [Internet]. International journal of infectious diseases: IJID: official publication of the International Society for Infectious Diseases. Int J Infect Dis. 2013. Available from: https://pubmed.ncbi.nlm.nih.gov/23154 $176 /$

287. Practice Committee of the American Society for Reproductive Medicine. Recommendations for reducing the risk of viral transmission during fertility treatment with the use of autologous gametes: a committee opinion. Fertil Steril. 2020;114:1158-1164

288. Cobo A, Bellver J, de los Santos MJ, Remohí J. Viral screening of spent culture media and liquid nitrogen samples of oocytes and embryos from hepatitis $\mathrm{B}$, hepatitis $\mathrm{C}$, and human immunodeficiency virus chronically infected women undergoing in vitro fertilization cycles. Fertil Steril. 2012;97:74-8.

289. World Health Organization. Hepatitis B vaccines WHO position paper. Weekly Epidemiol Rec. 2009;84:405-420

290. Mast EE, Margolis HS, Fiore AE, Brink EW, Goldstein ST, Wang SA, et al. A comprehensive immunization strategy to eliminate transmission of hepatitis B virus infection in the United States: recommendations of the Advisory Committee on Immunization Practices (ACIP) part 1: immunization of infants, children, and adolescents. MMWR Recomm Rep. 2005;54:1-31

291. Tan KL, Goh KT, Oon CJ, Chan SH. Immunogenicity of recombinant yeast-derived hepatitis $\mathrm{B}$ vaccine in nonresponders to perinatal immunization. JAMA. 1994;271:859-861

292. Kramer MS, Aboud F, Mironova E, Vanilovich I, Platt RW, Matush L, et al. Breastfeeding and child cognitive development: new evidence from a large randomized trial. Arch Gen Psychiatry. 2008;65:578-584

293. Koletzko B, von Kries R, Closa R, Escribano J, Scaglioni S, Giovannini M, et al. Can infant feeding choices modulate later obesity risk? Am J Clin Nutr. 2009;89:1502S-1508S

294. Shantakumar S, Terry MB, Teitelbaum SL, Britton JA, Millikan RC, Moorman PG, et al. Reproductive factors and breast cancer risk among older women. Breast Cancer Res Treat. 2007;102:365-374

295. Petrova M, Kamburov V. Breastfeeding and chronic HBV infection: clinical and social implications. World J Gastroenterol. 2010;16(40):5042-5046

296. Lin HH, Hsu HY, Chang MH, Chen PJ, Chen DS. Hepatitis B virus in the colostra of HBeAg-positive carrier mothers. J Pediatr Gastroenterol Nutr. 1993;17:207-210

297. Yang D, Li Y, Song J. Significance of detection of HBV-DNA and CMV-DNA by polymerase chain reaction in screening mothers' milk. Hunan Yikedaxue Xuebao. 1999;24:44-46

298. Shi Z, Yang Y, Wang H, Ma L, Schreiber A, Li X, et al. Breastfeeding of newborns by mothers carrying hepatitis B virus: a meta-analysis and systematic review. Arch Pediatr Adolesc Med. 2011;165(9):837-846

299. Egashira M, Takayanagi T, Moriuchi M, Moriuchi H. Does daily intake of bovine lactoferrin-containing products ameliorate rotaviral gastroenteritis? Acta Paediatr. 2007;96:1242-1244

300. Li S, Zhou H, Huang G, Liu N. Inhibition of HBV infection by bovine lactoferrin and iron-, zinc-saturated lactoferrin. Med Microbiol Immunol. 2009;198:19-25

301. Thea DM, Aldrovandi G, Kankasa C, Kasonde P, Decker WD, Semrau K, et al. Post-weaning breast milk HIV-1 viral load, blood prolactin levels and breast milk volume. AIDS. 2006;20:1539-1547

302. Shapiro RL, Holland DT, Capparelli E, et al. Antiretroviral concentrations in breast-feeding infants of women in Botswana receiving antiretroviral treatment. J Infect Dis. 2005;192:720-727

303. Bae WH, Wester C, Smeaton LM, Shapiro RL, Lockman S, Onyait K, et al. Hematologic and hepatic toxicities associated with antenatal and postnatal exposure to maternal highly active antiretroviral therapy among infants. AIDS. 2008;22:1633-1640

304. Palombi L, Pirillo MF, Marchei E, Jere H, Sagno JB, Luhanga $\mathrm{R}$, et al. Concentrations of tenofovir, lamivudine and efavirenz in mothers and children enrolled under the option B-plus approach in Malawi. J Antimicrob Chemother. 2016;71:1027-1030

305. Waitt C, Olagunju A, Nakalema S, Kyohaire I, Owen A, Lamorde $\mathrm{M}$, et al. Plasma and breast milk pharmacokinetics of emtricitabine, tenofovir and lamivudine using dried blood and breast milk spots in nursing African mother-infant pairs. J Antimicrob Chemother. 2018;73:1013-1019 
306. Best BM, Burchett S, Li H, Stek A, Hu C, Wang J, et al. Pharmacokinetics of tenofovir during pregnancy and postpartum. HIV Med. 2015;16:502-511

307. Hu X, Wang L, Xu F. Guides concerning tenofovir exposure via breastfeeding: a comparison of drug dosages by developmental stage. Int J Infect Dis. 2019;87:8-12

308. Ghazinyan HL. Hepatitis B and Pregnanacy. Blood. 2015;2(20):46-47

309. Hepatitis B. Vaccines. Wkly Epidemiol Rec. 2009;84(40):405-419

310. Hepatitis B. vaccines: WHO position paper, July 2017. Wkly Epidemiol Rec. 2017;92(27):369-392

311. Ork V, Woodring J, Shafiqul Hossain M, Wasley A, Nagashima S, Yamamoto C, et al. Hepatitis B surface antigen seroprevalence among pre- and post-vaccine cohorts in Cambodia, 2017. Vaccine. 2019;37(35):5059-5066

312. Thio CL, Guo N, Xie C, Nelson KE, Ehrhardt S. Global elimination of mother-to-child transmission of hepatitis B: revisiting the current strategy. Lancet Infect Dis. 2015;15(8):981-985
313. WHO guidelines on hepatitis B and C testing. World Health Organization, Geneva. 2017. Licence: CC BY-NC-SA 3.0 IGO

314. Ott JJ, Stevens GA, Wiersma ST. The risk of perinatal hepatitis $B$ virus transmission: hepatitis $B$ e antigen $(\mathrm{HBe} A g)$ prevalence estimates for all world regions. BMC Infect Dis. 2012;9(12):131

315. Allison RD, Patel MK, Tohme RA. Hepatitis B vaccine birth dose coverage correlates worldwide with rates of institutional deliveries and skilled attendance at birth. Vaccine. 2017;35:4094-4098

316. Petit D, Tevi-Benissan C, Woodring J, Hennessey K, Kahn A-L. Countries' interest in a hepatitis B vaccine licensed for the controlled temperature chain; survey results from African and Western Pacific regions. Vaccine. 2017;35:6866-6871

317. Abravanel F, Lhomme S, Trémeaux P, et al. Performance of the Xpert HBV viral load assay versus the aptima quant assay for quantifying hepatitis B virus DNA. Diagn Microbiol Infect Dis. 2020;96:114946

Publisher's Note Springer Nature remains neutral with regard to jurisdictional claims in published maps and institutional affiliations.

\title{
Authors and Affiliations
}

\author{
Manoj Kumar ${ }^{1}$ (D) Zaigham Abbas ${ }^{2} \cdot$ Milad Azami $^{3} \cdot$ Maria Belopolskaya $^{4} \cdot$ A. K. Dokmeci ${ }^{5} \cdot$ Hasmik Ghazinyan $^{6}$. \\ Jidong Jia ${ }^{7}$. Ankur Jindal ${ }^{1} \cdot$ Han Chu Lee ${ }^{8}$. Wei Lei ${ }^{9}$. Seng Gee Lim ${ }^{10}$. Chun-Jen Liu ${ }^{11}$. Qiang Li $^{12}$. \\ Mamun Al Mahtab ${ }^{13}$. David H. Muljono ${ }^{14}$. Madunil Anuk Niriella ${ }^{15} \cdot$ Masao Omata $^{16,17}$. Diana A. Payawal ${ }^{18}$. \\ Shiv K. Sarin ${ }^{1}$. Olivier Ségéral ${ }^{19}$. Tawesak Tanwandee ${ }^{20}$. Nirupma Trehanpati ${ }^{21} \cdot$ Kumar Visvanathan $^{22}$. \\ Jin Mo Yang ${ }^{23} \cdot$ Man-Fung Yuen ${ }^{24} \cdot$ Yingjie Zheng ${ }^{25} \cdot$ Y. H. Zhou ${ }^{26}$
}

Zaigham Abbas

drzabbas@gmail.com

Milad Azami

milad98azami@gmail.com

Maria Belopolskaya

belopolskaya.maria@yahoo.com

A. K. Dokmeci

akdokmeci@hotmail.com

Hasmik Ghazinyan

ghazinian@gmail.com

Jidong Jia

jiamd@263.net

Ankur Jindal

ankur.jindal3@gmail.com

Han Chu Lee

hch@amc.seoul.kr

Wei Lei

weelai@163.com

Seng Gee Lim

mdclimsg@nus.edu.sg

Chun-Jen Liu

cjliu@ntu.edu.tw

Qiang Li

doctorliqiang@gmail.com; doctorliqiang@ aliyun.com

Mamun Al Mahtab

shwapnil@agni.com
David H. Muljono

davidhm@eijkman.go.id

Madunil Anuk Niriella

maduniln@yahoo.co.uk

Masao Omata

aug8808@yahoo.co.jp

Diana A. Payawal

dianapayawal@yahoo.com

Olivier Ségéral

olivier_segeral@uhs.edu.kh

Tawesak Tanwandee

tawesak@gmail.com

Nirupma Trehanpati

trehanpati@gmail.com

Kumar Visvanathan

kv@unimelb.edu.au

Jin Mo Yang

jmyangdr@catholic.ac.kr

Man-Fung Yuen

mfyuen@hku.hk

Yingjie Zheng

yjzheng@shmu.edu.cn

Y. H. Zhou

zgr03summer@126.com 
1 Department of Hepatology and Liver Transplantation, Institute of Liver and Biliary Sciences, D1 Vasant Kunj, New Delhi 110070, India

2 Department of Medicine, Ziauddin University Hospital, Karachi, Pakistan

3 Faculty of Medicine, Ilam University of Medical Sciences, Ilam, Iran

4 Botkin Infectious Diseases Hospital, Saint Petersburg, Russia

5 Department of Gastroenterology, Ankara University School of Medicine, Ankara, Turkey

6 Department of Hepatology, Nork Clinical Hospital of Infectious Disease, Yerevan, Armenia

7 Liver Research Center, Beijing Friendship Hospital, Capital Medial University, Beijing, China

8 Department of Gastroenterology, Liver Center, Asan Medical Center, University of Ulsan College of Medicine, Seoul, Republic of Korea

9 Hepatopancreatobiliary Center, School of Clinical Medicine, Beijing Tsinghua Changgung Hospital, Tsinghua University, Beijing, China

10 Department of Medicine, Yong Loo Lin School of Medicine, National University of Singapore, Singapore, Singapore

11 Department of Internal Medicine and Hepatitis Research Center, National Taiwan University Hospital, National Taiwan University College of Medicine, Taipei City, Taiwan

12 Division of Liver Diseases Jinan Infectious Disease Hospital, Shandong University, Jinan, China

13 Department of Hepatology, Bangabandhu Sheikh Mujib Medical University, Dhaka, Bangladesh
14 Eijkman Institute for Molecular Biology, Jakarta, Indonesia

15 Department of Medicine, Faculty of Medicine, University of Kelaniya, Ragama, Colombo, Sri Lanka

16 Department of Gastroenterology, Yamanashi Central Hospital, Yamanashi, Japan

17 University of Tokyo, Tokyo, Japan

18 Fatima University Medical Center Manila, Manila, Philippines

19 French Agency for Research on AIDS and Viral Hepatitis, University of Health Science, Phnom Penh, Cambodia

20 Division of Gastroenterology, Department of Medicine, Faculty of Medicine Siriraj Hospital, Mahidol University, Bangkok, Thailand

21 Department of Molecular and Cellular Medicine, Institute of Liver and Biliary Sciences, New Delhi, India

22 Department of Medicine, University of Melbourne, Melbourne, VIC, Australia

23 Department of Internal Medicine, College of Medicine, The Catholic University of Korea, Seoul, South Korea

24 Li Shu Fan Medical Foundation Professor in Medicine, The University of Hong Kong, Pok Fu Lam, Hong Kong

25 Department of Epidemiology, School of Public Health, Fudan University, Shanghai, China

26 Department of Laboratory Medicine, Department of Infectious Diseases, Nanjing Drum Tower Hospital, Nanjing University Medical School, Nanjing, China 